Florida International University

FIU Digital Commons

FIU Electronic Theses and Dissertations

University Graduate School

$7-27-2015$

\title{
A Cultural Analysis of Employees' Work Values and Their Consequences for Work-Related Outcomes: The Case of China
}

Jun Yang

jyang007@fiu.edu

DOI: $10.25148 /$ etd.FIDC000216

Follow this and additional works at: https://digitalcommons.fiu.edu/etd

Part of the Business Administration, Management, and Operations Commons, Human

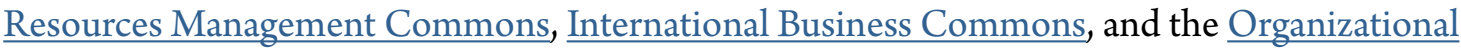

Behavior and Theory Commons

\section{Recommended Citation}

Yang, Jun, "A Cultural Analysis of Employees' Work Values and Their Consequences for Work-Related Outcomes: The Case of China" (2015). FIU Electronic Theses and Dissertations. 2327.

https://digitalcommons.fiu.edu/etd/2327

This work is brought to you for free and open access by the University Graduate School at FIU Digital Commons. It has been accepted for inclusion in FIU Electronic Theses and Dissertations by an authorized administrator of FIU Digital Commons. For more information, please contact dcc@fiu.edu. 


\section{FLORIDA INTERNATIONAL UNIVERSITY}

Miami, Florida

\section{A CULTRAL ANALYSIS OF EMPLOYEES’ WORK VALUES AND THEIR CONSEQUENCES FOR WORK-RELATED OUTCOMES: THE CASE OF CHINA}

A dissertation submitted in partial fulfillment of the requirements for the degree of DOCTOR OF PHILOSOPHY

in

BUSINESS ADMINISTRATION

by

Jun Yang

2015 
To: Acting Dean Jose M. Aldrich

College of Business

This dissertation, written by Jun Yang, and entitled A Cultural Analysis of Employees' Work Values and Their Consequences for Work-related Outcomes: The Case of China, having been approved in respect to style and intellectual content, is referred to you for judgment.

We have read this dissertation and recommend that it be approved.

Karl G. Krock

Angela L. Heavey

Isadore Newman

Wayne F. Cascio

Mary Ann Von Glinow, Major Professor

Date of Defense: July 27, 2015

The dissertation of Jun Yang is approved.

\begin{tabular}{r}
$\begin{array}{r}\text { Acting Dean Jose M. Aldrich } \\
\text { College of Business }\end{array}$ \\
\hline Dean Lakshmi N. Reddi \\
University Graduate School
\end{tabular}

Florida International University, 2015 
(C) Copyright 2015 by Jun Yang

All rights reserved. 


\section{DEDICATION}

I dedicate this dissertation to my loving family—my parents, Jian-Xiong Yang and GuiYing Tang, my brother Chun Yang, and especially my spouse Ziqing Jiang—for their untiring support, encouragement, and love at all times throughout the long journey of intellectual pursuit. 


\section{ABSTRACT OF THE DISSERTATION \\ A CULTRAL ANALYSIS OF EMPLOYEES’ WORK VALUES AND THEIR CONSEQUENCES FOR WORK-RELATED OUTCOMES: THE CASE OF CHINA

\author{
by
} \\ Jun Yang}

Florida International University, 2015

Miami, Florida

\section{Professor Mary Ann Von Glinow, Major Professor}

To create and maintain a fully engaged workforce, establishing personorganization (P-O) fit among employees has continued to be a central focus of organizational research. In addition, with growing numbers of older workers approaching retirement age, younger workers will soon become the dominant segment of the future workforce. Given this unfolding population trend, it has become increasingly necessary for organizations to gain a clearer understanding of the work values of the growing young population of workers and how P-O fit based on those work values may be linked to desirable work-related attitudes and behaviors.

The overarching aim of this dissertation is two-fold: (1) investigate the generational differences and similarities in work values among younger Chinese workers; (2) uncover the underlying mechanisms by which the linkages between the work-value-based person-organization fit and employee work outcomes may be influenced by the impact of leader-member exchange (LMX) and perceived organizational support (POS). 
In this study, I used a research design that blended interviews and two surveybased studies to address four main research questions. More specifically, I conducted a pilot test to refine the work-value scale in China, and to pretest the established and validated measures for the key variables. In the second study, I gathered survey data from a sample of 179 employees from three Chinese small- and medium-sized enterprises (SMEs).

The research findings showed no significant differences in employee work values between the two younger generations (i.e., the Social-Reform Generation and the Millennial Generation). Regarding the hypothesized conceptual scheme that links P-O fit and work outcomes, the results supported most of my hypotheses. Specifically, P-O fit is a significant predictor of three important work outcomes; it is positively related to job satisfaction and organizational commitment, while negatively related to turnover intention after controlling for demographic characteristics. The three hypothesized mediating mechanisms involving POS also received empirical support. That is, as predicted, POS mediates the effect of P-O fit on job satisfaction, organizational support, and turnover intention. Finally, when LMX was incorporated into the conceptual model and statistical analyses, the findings revealed that there was overall moderated mediation for the connections between P-O fit, job satisfaction, and organizational commitment, but no moderated mediation for the connection between P-O fit and turnover intention. 


\section{TABLE OF CONTENTS}

CHAPTER

PAGE

I. INTRODUCTION 1

Research Motivation 1

$\begin{array}{ll}\text { Purpose of the Study } & 6\end{array}$

Research Questions $\quad 8$

Definitions of Key Terms $\quad 8$

$\begin{array}{ll}\text { Structure of the Dissertation } & 10\end{array}$

II. REVIEW OF LITERATURE 15

Work Values $\quad 15$

Work Values and Generations $\quad 17$

$\begin{array}{ll}\text { Generational Cohort Theory } & 18\end{array}$

Person-Organization Fit 20

Content of Person-organizational Fit $\quad 21$

Justification for Methodological Operationalization of Fit 22

Social Exchange Relationships in Organizations 23

$\begin{array}{ll}\text { Summary } & 25\end{array}$

III. THEORY AND HYPOTHESES $\quad 27$

$\begin{array}{ll}\text { Overview } & 27\end{array}$

Generational Differences in Work Values $\quad 27$

P-O Fit and Work Outcomes 32

Mediating Role of POS in P-O Fit-Work Outcome Relationships 33

Moderating Role of LMX in POS-Work Outcome Relationships 34

Relational Chain: A Moderated Mediation Model 36

IV. RESEARCH METHOD 38

V. STUDY 1: WORK-VALUE SCALE REFINEMENT AND PILOT TESTING 42

Overview $\quad 42$

Development and Validation of the Work-value Scale 42

Phase 1: Item Generation and Screening 42

Phase 2: Pilot Testing for Evaluation of the Work-value Scale 50

Data Analysis $\quad 52$

Phase 3: Work-value Scale Refinement and Finalization 55

Pilot Testing of Instrumentation $\quad 58$

Job Satisfaction $\quad 58$

Turnover Intention $\quad 61$

$\begin{array}{ll}\text { Perceived Organizational Support } & 61\end{array}$

$\begin{array}{ll}\text { Leader-member Exchange } & 62\end{array}$

Summary

62 
VI. STUDY 2: HYPOTHESES TESTING $\quad 64$

Participants and the Sampling Setting $\quad 64$

Data Collection Procedures $\quad 65$

$\begin{array}{ll}\text { Measures } & 68\end{array}$

Person-Organization Fit $\quad 68$

$\begin{array}{ll}\text { Job Satisfaction } & 69\end{array}$

Organizational Commitment $\quad 70$

Control Variables $\quad 71$

$\begin{array}{ll}\text { Sample } & 71\end{array}$

Analyses $\quad 72$

Comparison of Work Values Between Generations 73

Exploration of the P-O Fit Processes

$\begin{array}{ll}\text { Summary } & 79\end{array}$

VII. RESEARCH FINDINGS $\quad 80$

Descriptive Statistics and Correlation Matrix $\quad 80$

Factor Analysis of Work-value Scale $\quad 81$

Results Organized Around Research Questions 83

Research Question1 and $2 \quad 83$

Research Question 3 and $4 \quad 89$

$\begin{array}{ll}\text { Summary } & 97\end{array}$

VIII. DISCUSSIONAND CONCLUSION 98

Work-value Profile of the Two Young Generation Cohorts 99

Mechanisms Linking P-O Fit to Employee Work Outcomes 102

Significance of the Study 104

Theoretical Contributions 104

Managerial Implications 106

Limitations of the Study and Implications for Future Research 109

$\begin{array}{ll}\text { Conclusion } & 111\end{array}$

LIST OF REFERENCES $\quad 113$

$\begin{array}{ll}\text { APPENDICES } & 136\end{array}$

VITA 141 


\section{LIST OF TABLES}

TABLE

PAGE

1-1. Summary of Theoretical Gaps, Associated Research Questions, and Proposed Research Designs of the Dissertation

1-2 Definitions and Operationalizations of the Constructs in the Dissertation

3-2 Summary of the Three Generations in China and Their Characteristics

5-1 Original Items, Additional Items, New Items, Final Items for the Work-value Scale

5-2 Demographic Profile of Employee Participants in the Pilot Test

5-3 Pilot Test (Study 1): Factor Loadings from Principal Component Analysis with Oblimin Rotation

5-4 International Consistency Coefficients for All Translated Scales in Published Study Conducted in China

6-1 Demographic Profile of Employee Participants in Study 2

7-1 Descriptive Statistics: Mean, Standard Deviation, Reliability, and Correlations for All Studied Variables

7-2 Factor Loadings from Principal Component Analysis with Oblimin Rotation (Study 2)

7-3 Mean Scores and Significant Differences on Work Value

7-4 Results of Hierarchical Regression Analysis with Job Satisfaction, Organizational Commitment, and Turnover Intention as Outcome Measures

7-6-1 Regression Results for Conditional Indirect Effect (Job Satisfaction as the Dependent Variable)

7-6-2 Regression Results for Conditional Indirect Effect (Organizational Commitment as the Dependent Variable)

7-6-3 Regression Results for Conditional Indirect Effect (Turnover Intention as the Dependent Variable) 


\section{LIST OF FIGURES}

FIGURES

PAGE

3-1 Proposed Full Research Model (Moderated Mediation Model)

4-1 A Flow Char for Research Design of the Study

39

6-2 The Total Effect Model and Simple Mediation Model

78

6-3 The Conceptual Model for the Second Stage Moderation Model

79

7-5 The Indirect Effect of P-O Fit on Work Outcomes through POS

93 


\section{CHAPTER I}

\section{INTRODUCTION}

\section{Research Motivation}

Recent years have witnessed significant demographic changes in the workplace. With growing numbers of older workers approaching retirement age, younger workers will soon become the dominant segment of the future workforce (Winter \& Jackson, 2014). Because of their profound and far-reaching implications for societies, demographic changes have attracted considerable attention from both management scholars and practitioners in recent years. For example, on August $11^{\text {th }}$ of 2014, Nightly Business Report (NBR) started to air a four-part series on aging in America, which focuses on some of the challenges that a society has to face in the midst of the unfolding demographic changes (PBS, 2014). Echoing the great fanfare in the popular media, a timely Editorial appeared, at the same time, in a recent issue of Academy of Management Journal, centering around the increased age diversity in the work environment and what it may mean for organizational researchers—“to open new areas of inquires for management research” (Kulik, Ryan, Harper \& George, 2014, p. 929). Here, I would extend this line of thought by suggesting that the emerging generation phenomena may offer us a golden opportunity and fertile ground to delve into human resource challenges across an employee’s work-life stages—with younger and older employees standing on the two ends of the age spectrum —as they are unfolding and evolving right in front our eyes. In addition, given such a high-level common interest shared by both scholars and practitioners alike, age and generations study 
may bring us to the crucial "tipping point” (Rynes, 2007, p. 1046) in stimulating collaborative efforts between researchers and practitioners in the hope to bridge the academic-practice gap (Bartunek, 2007; Cascio, 2015). It is with this spirit in mind that I am proposing this dissertation study multidisciplinary in nature, which cuts across four main streams of literature—-work values, generations, person-organization fit, and social exchange relationships in organizations.

As young workers are gradually joining the workforce, managers are increasingly taking notice of the demographic changes in the contemporary workplace that is increasingly characterized by the employment of multiple generations. Interactions among the different generations may lead to intergenerational conflicts and tensions (Burke, 2004; Glass, 2007; Joshi, Dencker, \& Franz, 2011) and, thus, has profound implications for HR practice and research in organizations (Kulik, et al., 2014). Such situations might prove to be especially challenging for organizations that are struggling to find better ways of attracting young talent, while at the same time embracing multiple generations in the work environment (Chen \& Hoskin, 2007; Sujansky \& Ferri-Reed, 2009; Zemke, Raines \& Filipczak, 2000). Thus, it has become progressively crucial for organizations to confront the rising workforce-age diversity. One area of focus that has recently drawn increased attention from management scholars is in studying the generational differences manifested by values and mindsets that members from different age groups tend to bring with them to the workplace (e.g., Gursoy, Maier \& Chi, 2008; Kupperschmidt, 2000; Twenge \& Campbell, 2008; Johson, Sage \& Mortimer, 2012). Despite such heightened managerial attention to generational differences and similarities in the work environment, there is a dearth of empirical studies to focus on young workers 
in the management literature, leaving us with scarce knowledge about their work needs, and work attitudes and behaviors (Loughlin \& Barling, 2001). Thus, this study seeks to fill in the gaps by paying greater attention to this otherwise neglected new breed of workers. More fundamentally, such a particular focus on young workers is further warranted for the profound effects of the unfolding population trend in the workplace as young workers are growing into leadership roles and emerging as the future of organizations of every size and shape.

Whereas research investigating generational differences or similarities in work values has rapidly ascended to the forefront in HR management research, to date most knowledge on generational differences in work values seems to be popularized by the mass media without rigorous investigation. The excessive reliance on anecdotal evidence without a strong theoretical basis in this growing stream of research, at least, has partly contributed to the research findings lack of consistency (e.g., Lyons \& Kuron, 2013; Twenge, Campbell, Hoffman \& Lance, 2010). For instance, Po-Ju and Choi (2008) found U. S. hospitality-industry employees from Baby Boomers Generation valued intrinsic aspects of work such as personal growth much more highly than those from more recent Generations $\mathrm{X}$ and Millennials. Others found no empirical support to significant generational differences in intrinsic work values such as accomplishment (see Parry \& Urwin, 2011, for a more comprehensive review). As such, organizations guided by such information may run the risk of making poor choices with respect to attracting, cultivating, and retaining younger workers. Hence, given the paucity of empirical research regarding generational differences in the management field (Joshi, 
Dencker, Franz \& Martocchio, 2010), there is the need for additional research to fill in this theoretical lacuna.

Another major limitation to this body of literature, including the aforementioned research, is that few of the related theories have devoted enough attention to the cultural context, and most are conceptualized and tested within the United States (e.g., Smola \& Sutton, 2002; Twenge, et al., 2010). Work values, as constructs, are not culture-free because the ways that employees view the attractiveness of work aspects differ across cultures. This lack of sensitivity to the differences across societies—unique economic, cultural, and institutional environments—can be especially problematic because social science models are hardly transferable across cultures (Farh, Hackett \& Liang, 2007; Tsui, 2004; Whetten, 2009). Furthermore, even studies incorporating China as a non-Western research context tend to heavily focus on comparing attitudes or values of Chinese employees with their counterparts from Western societies (e.g., Hofstede, 2001; House, Hanges, Javidan, Dorfman \& Gupta, 2004; Schwartz, 1994). The implicit assumption commonly shared by most cross-cultural research is that intra-country values are homogeneous (Au, 1999; Morris, 2014). Such an overly simplistic approach may lead researchers to overlook crucial subcultural differences (McSweeney, 2009; Sasaki \& Yoshikawa, 2014; Taras, Steel \& Kirkman, 2012; Tung \& Verbeke, 2010), such as those among generations within organizational settings (Cox, Hannif \& Rowley, 2014). Thus, a cultural perspective is essential to gaining a more holistic understanding toward work values and generational phenomena in the workplace, given the changing demographics worldwide and increasingly globalized world economy. Therefore, to overcome the limitations mentioned above the primary purpose of my dissertation is to focus on the 
focal construct of work values by taking an intra-country generational subculture approach. More specifically, I intended to empirically examine the intergenerational differences or similarities in work values among the younger Chinese employees.

In addition, there is an ever-growing need for organizations to continuously foster as well as harness human capital to its full potential (Pfeffer, 1995; Barney, 1991). Therefore, one central thrust for many organizations is to engage in building a fully-engaged and highly-motivated workforce in ways that facilitate the establishment of person-organization (P-O) fit. P-O fit at the outset can be defined as the compatibility between individual employees and their organizations with regard to value congruence (Chatman, 1989; Edwards, 2008; Kristof, 1996). Indeed, abundant research has demonstrated that P-O fit/alignment has important implications for work-related outcomes, such as job satisfaction (Edwards \& Cable, 2009; Johnson, Mortimer, Lee \& Stern, 2007), intent to leave (Cable \& Judge, 1996), organizational commitment (Kristof-Brown, Zimmerman \& Johnson, 2005), and workplace attitudes (Edwards \& Cable, 2009). Despite the tremendous strides made by organizational scholars to advance our understanding of the positive linkages between employees' perceived P-O fit and its correlates, out collective knowledge is still limited as to the processes whereby an employee's perceived P-O fit is linked to work outcomes. Specifically, a number of scholars have called for more empirical efforts to be focused on exploring the boundary conditions that can impact the relationship between P-O fit and outcome variables (Kim, Aryee, Loi \& Kim, 2013; Cable \& DeRue, 2002; Edwards, 2008; 
Erdogan, Kraimer \& Liden, 2004; Lee \& Antonakis, 2014). Thus, the second major goal of my dissertation is to examine the possible mechanisms through which organizational interventions may impact the relationships between P-O fit and work outcomes. Particularly, I focused on the two key exchange relationships-leader-member exchange (LMX) and perceived organizational support (POS)—-that employees tend to develop within organizations. Particularly, I examined the combined moderated mediation influence of LMX and POS by integrating both perspectives (Settoon, Bennett \& Liden, 1996; Wayne, Shore \& Liden, 1997).

\section{Purpose of the Study}

Against this backdrop, this dissertation aims to enrich our understanding of Chinese employees' work values with an emphasis on the young workers in the workplace by including cultural and generation-based analyses of work values. Anchoring the study in the China context offers us the following advantages toward both theoretical and managerial implications. First, since the launch of economic reforms in the late 1970s, China, the largest emerging-market country in the world (Kumar, Mudambi \& Gray, 2013), has experienced dramatic and complex social and economic changes. Consequently, the dissimilarity among Chinese managers from different generation cohorts has shown to be at least as great as that among the US managers (Egri \& Ralston, 2004).

Furthermore, compared to their Western counterparts, Chinese employees may exhibit important variations in work values because the subtle cultural differences between China and Western countries may influence the way how work is perceived and 
valued (Wong \& Yuen, 2012). Therefore, studying in the China context would allow us to gain a more fine-grained and nuanced understanding toward theorizing work values and generations. Second, in reference to the China context, due to serious talent shortages in China (Gupta \& Wang, 2009; Cooke, 2012), recruiting and retaining talented local employees through effective HR practices has become one of the most pressing issues (Cooke, 2009; Ma \& Trigo, 2008). In particular, these HR concerns may become increasingly challenging to Western multinational enterprises that are trying to enter as well as expand their presence in the Chinese market, because they have to compete head to head in the same talent pool (Chu, 2013). Thus, in order to achieve business success it is crucial that Western MNCs gain a better understanding of how demographic changes in the workforce impact the effectiveness of HR practices. Indeed, scholars have voiced their concern about the effectiveness of using blanket-type HR policies that were developed around workers of older generations while ignoring generational differences (Li \& Nimon, 2008; Sujansky \& Ferri-Reed, 2009).

In sum, the overarching aims of this dissertation were two-fold. First, I aimed to examine the inter-generational differences in work values among the young workers in Chinese organizations. Second, a further aim of this dissertation was to investigate how objective employee person-organization fit—based on the work values identified—may impact important work-related outcomes. In particular, I proposed to explore the mechanisms through which an employee's P-O fit is linked to work outcomes. The two situational variables that were considered to play important but different roles in influencing the relationship between employee P-O fit and outcome variables of interest 
to organizations were: (1) leader-member exchange (LMX); and (2) perceived organizational support (POS).

\section{Research Questions}

Overall, following the discussion above, this dissertation was designed to address the following research questions:

1) What are the work values that are important to Chinese employees of the two younger generations?

2) Do those identified work values differ significantly between the two younger generation cohorts in China?

3) What is the relationship between P-O fit and work-related outcomes (i.e., job satisfaction, organizational commitment, and turnover intention) that are of interest to organizations?

4) What are the roles played by POS and LMX in influencing the linkages between P-O fit and important work-related outcomes?

Table 1-1 summarizes the key theoretical gaps identified in the literature, followed by research questions, and study designs used to explore those four research questions.

\section{Definitions of Key Terms}

Before moving on to outline the structure of the dissertation, I will briefly describe the definitions (Table 1-2) of the ten key terms used in this dissertation study. 
Work values can be defined as "hierarchical organization of relatively

stable needs, desires, and goals as applied to the world of work." (Super, 1995, p.

54)

Extrinsic work values reflect employees' preferences towards rewards

external to work (Johnson, Sage \& Mortimer, 2012).

Table 1-1.

Summary of Theoretical Gaps, Associated Research Questions, and Proposed Research Designs of the Dissertation

\begin{tabular}{|c|c|c|}
\hline Theoretical Gaps & Research Questions & Research Designs \\
\hline $\begin{array}{l}\text { Few empirical efforts have been } \\
\text { devoted to studying generational } \\
\text { differences in the workplace, } \\
\text { despite its criticality for } \\
\text { organizations; less attention in } \\
\text { prior research on work values has } \\
\text { been given to the cultural context. } \\
\text { Our knowledge of generational } \\
\text { differences in work values } \\
\text { remains limited. In particular, } \\
\text { systematic empirical research on } \\
\text { the work needs and expectations } \\
\text { of young workers is still scarce } \\
\text { despite their practical and } \\
\text { theoretical significance. }\end{array}$ & $\begin{array}{l}\text { 1) What work values are most } \\
\text { attractive and important to } \\
\text { Chinese employees from the two } \\
\text { younger generations? } \\
\text { 2) Do those identified work } \\
\text { values differ significantly } \\
\text { between the two generation } \\
\text { cohorts in China? }\end{array}$ & $\begin{array}{l}\text { Literature review and } \\
\text { use a research design } \\
\text { blending interviews } \\
\text { with two survey- } \\
\text { based studies (i.e., } \\
\text { study } 1 \text { and study 2) }\end{array}$ \\
\hline $\begin{array}{l}\text { Less attention in prior research on } \\
\text { work values has been given to the } \\
\text { cultural context }\end{array}$ & $\begin{array}{l}\text { 3) What is the relationship } \\
\text { between P-O fit and work-related } \\
\text { outcomes (job satisfaction, } \\
\text { organizational commitment, and } \\
\text { turnover intention) that are of } \\
\text { interest to organizations? }\end{array}$ & $\begin{array}{l}\text { Literature review and } \\
\text { empirical study } 2 \\
\text { (hypothesis testing) }\end{array}$ \\
\hline $\begin{array}{l}\text { There is a need for additional } \\
\text { research in identifying the } \\
\text { boundary conditions that can } \\
\text { affect the relationships between } \\
\text { work-value-based P-O fit and } \\
\text { work outcomes. }\end{array}$ & $\begin{array}{l}\text { 4) What are the roles played by } \\
\text { POS and LMX in influencing the } \\
\text { linkages between P-O fit and } \\
\text { important work-related } \\
\text { outcomes? }\end{array}$ & $\begin{array}{l}\text { Literature review and } \\
\text { empirical study } 2 \\
\text { (hypothesis testing) }\end{array}$ \\
\hline
\end{tabular}


Intrinsic work values refer to employees' desires to derive satisfaction and interest from the work itself (Johnson, et al., 2012)

Person-organization fit ( $\mathrm{P}-\mathrm{O}$ fit) refers to the extent of congruence between a worker's work values and perceived fulfillment of those work needs by his/her employer (Cable \& DeRue, 2002; Kristof-Brown, et al., 2005).

Generation can be defined as a group of individuals that share the same year of birth, a common location, and experiences of significant historical and life events during their crucial formative years (Gursoy, Chi \& Karadag, 2013; Kupperschmidt, 2000; Lancaster \& Stillman, 2002).

Job satisfaction is defined as an employee’s expressed pleasure derived from working in the job and organization (Cammann, Fichman Jenkins \& Klesh, 1983; Muchinsky, 2003).

Organizational commitment (OC) refers to an employee’s psychological connection to his/her employer (Meyer, Allen, \& Smith, 1993; Francesco \& Chen, 2004) Turnover intention (TI) can be defined as "a conscious and deliberate willfulness to leave the organization” (Tett \& Meyer, 1993, p. 262; see also Wong, 2012 ).

Perceive organizational support (POS) refers to an employee’s beliefs "concerning the extent to which the organization values their contributions and cares about his/her well-being (Eisenberger, Huntington, Hutchison \& Sowa, 1986, p. 501) Leader-member exchange (LMX) can be defined as a relationship, wherein "each party must offer something the other party sees as valuable and each party must see the exchange as reasonably equitable or fair” (Graen \& Scandura,1987, p.182; see also Wayne, et al, 1997). 


\section{Structure of the Dissertation}

The two overarching purposes of this study were: (1) to examine the work values among the young Chinese employees from the two generational cohortsthe Social- Reform Generation born between 1967 and 1981, and the Millennials Generation born after 1982; (2) to explore work-value-based person-organization fit (P-O fit) and its 
Table 1-2.

Definitions and Operationalizations of the Constructs in the Dissertation

\begin{tabular}{|l|l|l|}
\hline Constructs & \multicolumn{1}{|c|}{ Definitions } & \multicolumn{1}{|c|}{ Measurement } \\
\hline Work Values & $\begin{array}{l}\text { Work values can be defined as "hierarchical } \\
\text { organization of relatively stable needs, desires, } \\
\text { and goals as applied to the world of work." } \\
\text { (Super, 1995, p. 54) }\end{array}$ & $\begin{array}{l}\text { 18 Work Values items, evenly distributed into } \\
\text { extrinsic work values (9 questions) and intrinsic } \\
\text { work values (9 questions). (Instrument refined } \\
\text { from Bu \& McKeen (2001) and Manhardt (1972) } \\
\text { through a qualitative study and pilot testing) }\end{array}$ \\
\hline $\begin{array}{l}\text { Extrinsic Work } \\
\text { Values }\end{array}$ & $\begin{array}{l}\text { They reflect employees' preferences towards } \\
\text { rewards external to work (Johson, Sage \& } \\
\text { Mortimer, 2012; Porter \& Lawler, 1968). }\end{array}$ & $\begin{array}{l}\text { Questions 1--9 (see the table below; 5-Likert } \\
\text { scale) }\end{array}$ \\
\hline Intrinsic Work Values & $\begin{array}{l}\text { They refer to employees' desires to derive } \\
\text { satisfaction and interest from the work itself } \\
\text { (Johnson, Sage, \& Mortimer, 2012; Porter \& } \\
\text { Lawler, 1968) }\end{array}$ & $\begin{array}{l}\text { Questions 10--18 (see the table below; 5-Likert } \\
\text { scale) }\end{array}$ \\
\hline
\end{tabular}


Table 1-2. (continued)

\begin{tabular}{|c|c|c|}
\hline $\begin{array}{l}\text { Person-Organization } \\
\text { Fit (P-O fit) }\end{array}$ & $\begin{array}{l}\text { The extent of congruence between a worker's } \\
\text { work values and perceived fulfillment of those } \\
\text { work needs by his/her employer (Cable \& } \\
\text { DeRue, 2002; Kristof-Brown, Zimmerman, \& } \\
\text { Johnson, 2005). }\end{array}$ & $\begin{array}{l}\text { 1) P-O misfit score (as Euclidean Distance) = } \\
\text { SQRT ((extrinsic work values (ideal)-extrinsic } \\
\text { work values (experienced)) })^{2}+((\text { intrinsic work } \\
\text { values (ideal)-intrinsic work values } \\
\text { (experienced) })^{2} \text { ) } \\
\text { 2) P-O fit = (maximum P-O misfit from the } \\
\text { sample -P-O misfit of one given employee)+0.01 } \\
\text { (Joshi, Kathuria \& Porth, 2003; Venkatraman, } \\
\text { 1989) }\end{array}$ \\
\hline Generation & $\begin{array}{l}\text { Generation can be defined as a group of } \\
\text { individuals that share the same year of birth, a } \\
\text { common location, and experiences of } \\
\text { significant historical and life events during their } \\
\text { crucial formative years (Gursoy, Chi, \& } \\
\text { Karadag, 2013; Kupperschmidt, 2000; } \\
\text { Lancaster \& Stillman, 2002). }\end{array}$ & $\begin{array}{l}\text { Age-based classification scheme (see Table 2-1) } \\
\text { (Yi, Ribbens \& Morgan, 2010) }\end{array}$ \\
\hline Job Satisfaction (JS) & $\begin{array}{l}\text { It is defined as an employee's expressed } \\
\text { pleasure derived from working in the job and } \\
\text { organization (Cammann, Fichman Jenkins, \& } \\
\text { Klesh, 1983; Muchinsky, 2003) }\end{array}$ & $\begin{array}{l}\text { 3-item measure of Overall Job Satisfaction } \\
\text { (Cammann, Fichman, Jenkins \& Klesh, 1983) (7- } \\
\text { Likert scale) }\end{array}$ \\
\hline
\end{tabular}


Table 1-2. (continued)

\begin{tabular}{|l|l|l|}
\hline $\begin{array}{l}\text { Organizational } \\
\text { Commitment (OC) }\end{array}$ & $\begin{array}{l}\text { It can be defined as an employee’s } \\
\text { psychological connection to his/her employer } \\
\text { (Meyer, Allen, \& Smith, 1993; Francesco \& } \\
\text { Chen, 2004) }\end{array}$ & $\begin{array}{l}\text { 6-item measure of Organizational Commitment } \\
\text { (Meyer, Allen, \& Smith, 1993; Allen \& Meyer, } \\
\text { 1996) (7-Likert Scale) }\end{array}$ \\
\hline $\begin{array}{l}\text { Turnover Intention } \\
\text { (TI) }\end{array}$ & $\begin{array}{l}\text { It can be defined as “a conscious and deliberate } \\
\text { willfulness to leave the organization” (Tett \& } \\
\text { Meyer, 1993, p. 262; see also Wong, 2012 ). }\end{array}$ & $\begin{array}{l}\text { 3-item measure of intention to change jobs } \\
\text { (Cammann, Fichman, Jenkins, \& Klesh, 1979) (7- } \\
\text { Likert Scale) }\end{array}$ \\
\hline $\begin{array}{l}\text { Perceived } \\
\text { Organizational } \\
\text { Support (POS) }\end{array}$ & $\begin{array}{l}\text { It can be defined as an employee’s beliefs } \\
\text { “concerning the extent to which the } \\
\text { organization values their contributions and } \\
\text { cares about his/her well-being (Eisenberger, } \\
\text { Huntington, Hutchison, \& Sowa, 1986, p. 501) }\end{array}$ & $\begin{array}{l}\text { 8-item measure of perceived organizational } \\
\text { support (Settoon, Bennett, \& Liden (1996) (7- }\end{array}$ \\
\hline $\begin{array}{l}\text { Leader-Memberte) } \\
\text { Exchange (LMX; The } \\
\text { Subordinate } \\
\text { Questionnaire) }\end{array}$ & $\begin{array}{l}\text { The leader-member exchange can be defined as } \\
\text { a relationship, wherein “each party must offer } \\
\text { something the other party sees as valuable and } \\
\text { each party must see the exchange as reasonably } \\
\text { equitable or fair” (Graen \& Scandura,1987, } \\
\text { p.182; see also Wayne, et al, 1997) }\end{array}$ & $\begin{array}{l}\text { 7-item measure of LMX quality (Liden, Wayne \& } \\
\text { Stilwell, 1993) (7-Likert Scale) }\end{array}$ \\
\hline
\end{tabular}


relationship with employee work-related outcomes.

In order to achieve these two research goals, the remainder of the dissertation is organized as follows. In Chapter 2, a thorough literature review is conducted to provide initial insights gleaned from the three streams of literaturework values, generation sub-culture research, and person-organization fit. Because the dissertation represents an attempt to integrate various fields of research, each will be discussed separately. Nonetheless, it is noteworthy that the common thread running through the three disparate research domains is the focal construct of work values. Chapter 3 presents the integrative conceptual model and develops a series of hypotheses. Following that, Chapter 4 describes in detail the research methods used in this study. Chapter 5 focuses on refining the work-value scale so as to ensure its suitability for the China context as well as pretesting the measures of the key constructs in the theoretical model by using a pilot sample. Next, Chapter 6 describes the main hypothesis-testing study to test the proposed theoretical model. In this part, I mainly present the measures, sample and procedures, and analyses employed before presenting the key findings in Chapter 7. In Chapter 8, I will focus on the theoretical and practical implications of the research findings, and then discuss the limitations of the study and conclude with proposing avenues for future research. 


\section{CHAPTER II}

\section{REVIEW OF LITERATURE}

The multidisciplinary nature of the proposed study involves bringing together four previously disparate study streams (i.e., work values, generations, person-organization fit, and exchange relationships in organizations). Thus, this chapter provides definitions of the key variables of interest in the study and a systematic review of existing theory and research pertaining to those four research domains. This literature review sets a sound conceptual foundation for formulating the five research hypotheses in Chapter 3 that reflect the specific research questions raised in Chapter 1 . Furthermore, concerted effort will be made to both identify and rationalize the selected techniques to operationalize the key constructs in this study.

\section{Work Values}

With a growing number of older workers approaching retirement age, young workers are starting to enter the workplace and will soon become the dominant segment of the future workforce (Winter \& Jackson, 2014). To manage that workforce effectively, organizations must confront the growing workforce age diversity, manifested in the unique values and mindsets that members from different age groups tend to bring along with them to the workplace (Gursoy, et al., 2008: Lancaster \& Stillman, 2002; Lyons \& Kuron, 2013).

There is a wealth of literature dedicated to values. Values are "conscious, as well as subconscious goals, ideals and preferences of worth, expressing intentionality and shaping directions of action” (Aadland, 2010, p. 471). A main purpose of research on 
values has been to investigate how values relate to attitudes, behavior, and social experiences and roles (Ros, Schwartz \& Surkiss, 1999). Among the studies of values, one major branch of value research has focused primarily on work values (e.g., Cennamo \& Gardner, 2008; Elizur, Borg, Hunt \& Becker, 1991; Harpaz, 1990; Hofstede, 2001). Researchers have long recognized the central role played by work values in influencing the attractiveness of work outcomes and their unique effects on subsequently motivating individual actions or behaviors (Dose, 1997; Eccles \& Wigfield, 2002). There seems to be a general agreement among researchers that a better understanding of work values can greatly facilitate the development of HR practices to address growing workplace challenges spawned by age diversity.

While work values have received considerable research attention, there is much less agreement, among management scholars, on what work values are as constructs $(\mathrm{Bu}$ \& McKeen, 2001; Dose, 1997; Gursoy et al., 2013; Pryor, 1982). There are a variety of ways to conceptualize work values. Super (1995, p. 54) defines work values as a "hierarchical organization of relatively stable needs, desires, and goals as applied to the world of work." This definition highlights the hierarchical structure of work values—-that is, individuals may value and prioritize various needs and goals linked to work differently. Most research on work values shares this assumption and attempts to build a multidimensional representation of work values by assessing the relative importance employees attach to each work-value measure. As such, a majority of studies have investigated work values from a structural perspective (Sagie, Elizur \& Koslowsky, 1996), and classified various attributes of work into dimensions and factors. 
There are a wide variety of approaches to classifying work values. The most widely used approach classifies work values as intrinsic or extrinsic (e.g., Elizur, 1984; Johnson et al., 2007; Schwartz, 1999; Vansteenkiste, Neyrinck, Niemiec, Soenens, De Witte \& Van den Broeck, 2007). On the one hand, extrinsic work values reflect employees' preferences toward rewards external to work, such as pay and job security (Johnson et al., 2012). On the other hand, intrinsic work values concern employees' desires to derive satisfaction and interest from the work itself; sources of such satisfaction, for example, can include autonomy, intellectual challenges, and personal growth (Johnson et al., 2012). Apart from the extrinsic-intrinsic work-value distinction, other research has suggested the following additional dimensions of work values: status-related values (e.g. influence, recognition, advancement) (Ros et al., 1999); freedom-related values (e.g. work-life balance, working hours); social values (e.g. good relationships with supervisors or peers) (Lyons, Higgins \& Duxbury, 2010); and altruistic values (e.g. making a contribution to society) (Borg, Groenen, Jehn, Bilsky \& Schwartz, 2011). At present, however, there is far less consensus among researchers on their appropriateness.

\section{Work values and Generations}

When it comes to generational differences in work values, previous studies have been criticized for a lack of theoretical focus and methodological rigor, as most were built primarily on anecdotal evidence and observation (Cogin, 2012; Joshi et al., 2010; Twenge et al., 2010). More importantly, the mechanisms underlying any differences or similarities across generations in work values remain unknown. Several scholars (e.g., Dencker, Joshi \& Martocchio, 2008; Lyons \& Kuron, 2013; Parry \& Urwin, 2011) have 
suggested that research that explores the links between work values and generations could provide theoretical insights into some of the reasons behind the work-value differences and similarities across generations. In this paper, I seek to identify such linkages by synthesizing knowledge from both literatures.

Super's (1995) definition of work values implies that a more complete conceptualization of work values will require a deeper understanding of the extrinsicintrinsic work-value structure. Consistent with generation theories (Inglehart, 1977, 1990; described below), recent research exploring various aspects of generations has provided preliminary evidence that generational differences in the hierarchy of work-needs is, at least partly, driven by changes in social conditions (Chaudhuri \& Ghosh, 2012; Johnson et al., 2012; Kanchier \& Unruh, 1989; Twenge, 2001). This suggests that an intergenerational shift in priorities attached to work-related needs may occur. Thus, the fundamental question guiding my exploration is: To what degree can workers from the two generational cohorts be distinguished from each other, with respect to their preferences for different work values, as a function of different social conditions that generational cohorts have been exposed to during their formative years? The following section will consider the theory of generations and draw its implications with regard to the differences and similarities between the two younger generations in the Chinese workplace.

\section{Generational Cohort Theory}

The concept of generations can trace its sociological root back to at least the 1920s, first appearing in the seminal treatment of The Problem of Generations, where 
Mannheim (1952/1928) postulated that the distinct socioeconomic events experienced by members from a given birth cohort can profoundly shape their value orientation as well as the way how they view and interact with the world. In line with this notion, more recent work in the management field has defined a generation as a group of individuals that share the same year of birth, a common location, and experiences of significant historical and life events during their crucial formative years (Gursoy et al., 2013). It is worth noting that those values and beliefs formed during a person's youth years (i.e., childhood and adolescence) will remain fairly stable into adulthood (Egri \& Ralston, 2004; Macky, Gardner \& Forsyth, 2008; Twenge et al., 2010).

Consistent with Mannheim’s (1952/1928) seminal conceptualization of generations, Inglehart $(1977 ; 1990)$, in the field of political science, developed the generational cohort theory that offers two insightful hypotheses - the socialization hypothesis and the scarcity hypothesis—-while explaining the underlying reason for the observed inter-generational value change. The socialization hypothesis contends that those salient societal circumstances of one's childhood and adolescence change across generational cohorts, and are reflected consistently in values tagged to a certain generation cohort. The scarcity hypothesis holds that those things that are in short supply in one's socioeconomic environment over young age are highly valued and can leave a lasting imprint on his/her value preferences in later adult life. Thus, generations growing up in an environment characterized by socioeconomic insecurity (e.g., social turmoil, war, material scarcity) will be most likely to embrace materialist values (e.g., materialism, respect to authority, high saving rate) (Inglehart \& Welzel, 2005). In comparison, generations growing up in times of relative socioeconomic prosperity and stability (e.g., 
material affluence, social stability) tend to take on more post-modernist values (e.g., the rising self-expression, independence) (Brooks \& Manza, 1994; Egri \& Ralston, 2004).

In a nutshell, Inglehart's (1990) theory attributes social and cultural changes to a process called “cohort replacement” (Ryder, 1965). It implies that intergenerational changes in values may well be rooted in differences in early impressionable experiences of members of a cohort as they are inducted or socialized into normative attitudes and practices. More importantly, the extent to which basic material needs, such as physical survival and safety, are met during one's formative years can affect the emergence of higher-order, non-material needs, mostly centering on lofty aspirations and selffulfillment (Diener, 2000; Inglehart, 2008).

\section{Person-Organization Fit}

Person-organization fit, as a research domain has long occupied a prominent position in organization and management studies, and has continued to attract widespread research attention in recent years (e.g., Cable and Judge, 1996; Edwards \& Cable, 2009; Kristof-Brown et al., 2005; Lee \& Antonakis, 2014). Chatman $(1989,1991)$ is generally credited with first developing the prevailing view of person-organization fit that substantially hinges on the congruence between individual values and organizational values. Despite the intuitive appeal of the concept of P-O fit, this body of literature is fraught with fragmentation and inconsistencies that further lead to theoretical confusions and ambiguities (Cable \& DeRue, 2002; Edwards, 2008; O’Reilly, Chatman \& Caldwell, 1991). These difficulties emanate from at least two interrelated reasons: (1) a lack of conceptual 
clarity of the concept of P-O fit; (2) a difficulty in opertionalizing the construct of fit.

\section{Content of Person-Organizational Fit}

In a thorough review of the recent development in P-O fit theories, Edwards (2008, p. 220) concluded that the elusiveness surrounding the concept of P-O fit largely stems from our lack of clear understanding of "the content of person and environment [including organization] dimensions”. In regard to content dimensions, there are two dominant and distinct frameworks for conceptualizing P-O fit (Cable \& DeRue, 2002; Edwards, 2008; Kristof, 1996; Edwards, 1996): (1) The demands-abilities fit; this aspect of P-O fit is also labeled as Person-Job (P-J) fit , which rests on match between abilities and work skills possessed by individual employees and those needed by their organizations (Edwards, 2008; Kristof-Brown et al., 2005); (2) The perspective of needssupplies fulfillment (French, Caplan \& Harrison, 1982), another way to conceptualize PO fit as the extent to which an employee's work preferences or needs get fulfilled by his/her employer (Cable \& Edwards, 2004; Locke, 1976; Manhardt, 1972; Meglino, Ravlin \& Adkins, 1989; Super, 1970,1995;Wanous \& Lawler, 1972). In this study, I will focus on the needs-supplies fulfillment approach of P-O fit for the following reasons: (1) Compared to needs-supplies fulfillment approach, the demands-abilities approach is limited in scope and application in regard to impact on associated outcomes as it is most relevant to the area of recruitment and selection (Turban, Lau, Ngo, Chow \& Si, 2001; Edwards \& Cooper, 1990; Werbel \& Gilliland, 1999); (2) The integration of needssupplies fulfillment approach with Chatman's $(1989 ; 1991)$ value congruence concept described above may afford us with "a more comprehensive picture of fit” (Cable \& Edwards, 2004; Kristof, 1996, p. 30). More specifically, drawing the insights from the 
work-value theory discussed previously, comprehensive comparisons at the individual level can be made across content dimensions associated with work values. Such an approach may permit us to decipher the purportedly multifaceted P-O fit processes (Edwards, 2008) and may further lead us to greater conceptual clarity of P-O fit as well as improve its mathematical operationalization.

Collectively, work-value-based P-O fit can be conceptualized as the outcome from the comparison of a person's desired amount and importance of work needs relative to the amount that is supplied by the organization. Further, to remedy shortcomings of existing approaches used in P-O fit research, this unifying view of P-O fit developed above will serve as the conceptual ground to furnish the content dimensions of P-O fit that will be incorporated into its mathematical formulation.

\section{Justification for Methodological Operationalization of Fit}

As mentioned above, theoretical ambiguities of P-O fit arise not only from conceptual issues associated with the content of P-O fit but also from methodological difficulties in aligning the fit concept with its mathematical formulation (Drazin \& Van de Ven, 1985; Van de Ven \& Drazin, 1985; both cited in Venkatraman, 1989).

Fit, as a concept, has long been considered a cornerstone for theory building in a wide spectrum of management research—from strategic management (see Venkatraman \& Camillus, 1984 for a review) to organizational behavior (see Edwards, 2008; Kristof-Brown \& Guay, 2010 for more recent, circumstantial reviews). In his seminal work on fit, Venkatraman (1989) carefully 
reviewed various conceptualizations of fit in the past and developed a consolidated fit model comprised of six perspectives. Among these distinct conceptualizations, the profile-deviation perspective treats fit as "the degree of adherence to... an environmentspecific ideal profile... [in] dimensions of strategy” (Venkatraman, 1989, pp. 433-434). Although this perspective was developed for understanding a focal business unit's performance implications of environment-strategy fit within the context of strategic management, it seems to be logically most akin to my previously conceived conceptual framework of P-O fit; as discussed above, the needs-supplies fulfillment paradigm of P-O fit rests upon the comparison between an individual's ideal work value profile and his/her perceived true experience with respect to the supplies from the organization. Outcome from such comparison can be numerically or algebraically depicted using Euclidean distance method suggested by Venkatraman (1989). It is important to note that such mathematical formulation of fit based on profile-deviation perspective has been successfully used by Joshi and her colleagues (2003) to compute alignment/fit scores for their theory testing.

Taken together, this section of the chapter concentrates much effort to the development of a clear and sound theoretical base for conceptualizing P-O fit and for guiding its empirical assessment. To that purpose, I specifically delve into the content of P-O fit —a set of work-value dimensions that will also be detailed in Chapter 5-and take stock from the profile-deviation perspective of the fit concept. A more detailed operationalization of P-O fit will be presented in Chapter 6.

\section{Social Exchange Relationships in Organizations}


Substantial research studies have pointed to the importance of the alignment between the values of employees and organizations, noting that value congruence is capable of engendering desirable employee attitudes and behaviors (e.g., Chatman, 1989; Edwards \& Cable, 2009; Kristof-Brown et al., 2005; Meglino \& Ravlin, 1998). However, the most fundamental question still remains underexplored: whether and, to a much greater extent, how value-oriented P-O fit influences employees' attitudes and behaviors?

The dominant principle of needs-supplies fulfillment has been incorporated into the conceptualization of $\mathrm{P}-\mathrm{O}$ fit, and has allowed us to explain the positive connections between P-O fit and work attitudes and behaviors (e.g., Cable \& Edwards, 2004; Yu, 2014). Recently, however, scholars have increasingly emphasized the need for research to move beyond merely establishing the simplistic associations between P-O fit and its work correlates (e.g., Edwards \& Cable, 2009; Lee \& Antonakis, 2014; Liu, Liu \& Hu, 2010; Resick, Baltes \& Shantz, 2007). Indeed, there are both theoretical reasons and empirical evidences to believe that the relationships between P-O fit and work outcomes may be more complex than previously thought; for example, a few studies have begun to argue that the influence of P-O fit on employees' workrelated outcomes may not be uniform for all situations, and may be contingent upon the quality of personal relationships that a focal employee develops with exchange parties through social interactions within organizations (Erdogan et al., 2004; Kim et al., 2013). 
These initial empirical leads appear to suggest that social exchange relationships at work could provide invaluable opportunities for facilitating a fuller understanding of the processes underpinning the relations between P-O fit and employee outcomes.

Social exchange theory has been widely acclaimed as "one of the most influential conceptual paradigms in organizational behavior (Cropanzano \& Mitchell, 2005, p. 874; also cited in Song, Tsui \& Law, 2009). The central tenet of social exchange theory (Blau, 1964 ) is that an employee develops a sense of obligation and indebtedness to repay support and favors (Gouldner, 1960) as he/she interacts repeatedly with exchange parties. Such expectation for reciprocity is firmly hinged upon the focal employee's perceived relational quality derived from the assistance and support received by him/her.

To employees, exchange relationships may vary in nature depending on the exchange party involved in the social exchange process; two main types have recently received most research attention (Aryee, Budhwar \& Chen, 2002; Erdogan \& Enders, 2007; Settoon et al., 1996; Wayne et al., 1997): exchanges between employees and their leaders/supervisors, labeled as leader-member exchange (LMX) (Graen \& Scandura, 1987) and exchanges between employees and their employers, labeled as perceived organizational support (POS) (Eisenberger, Huntington, Hutchison \& Sowa, 1986). Highquality exchange relationships of both LMX and POS have been found to exert strong influence on employees’ positive feelings about job, high organizational commitment, and low turnover intention (e.g., Eisenberger, Armeli, Rexwinkel, Lynch \& Rhoades, 2001; Farh et al., 2007; Hom, Tsui, Wu, Lee, Zhang, Fu \& Li, 2009; Mossholder, Settoon \& Henagan, 2005)— the three key work outcome variables of primary focus in this study. 
In summary, two major implications can be drawn from Chapter 2. First, regarding the perceived importance of various work aspects, generation theories work-values theories seem to suggest that Chinese employees may exhibit distinct generation-based value patterns that appear to be founded on substantial differences in societal conditions that define each generational cohort. More specifically, rising socioeconomic stability and prosperity will promote a generational shift towards greater emphasis on seeking the gratification of highorder intrinsic needs in work itself.

Second, another theme emerging from the literature review is the lack of research attention to specify boundary conditions that may govern the influences of P-O fit (Edwards, 2008). Only recently, some researchers have begun to integrate social exchange perspective into the research on P-O fit with some promising results (e.g., Erdogan et al., 2004; Kim et al., 2013). However, more research effort should be invested in this emerging area, as knowledge thus created may enable us to gain a more complete view of the process underlying the effects of P-O fit on work outcomes. 


\section{CHAPTER III}

\section{THEORY AND HYPOTHESES}

\section{Overview}

As noted in Chapter 1, the primary objectives of the current study are: (1) to explore the generational differences and similarities in work values; (2) to examine the relationships between P-O fit and work outcomes, and to specify the boundary conditions that may affect those relationships.

For the first research objective, building on generation theory discussed in the preceding literature review, I developed two exploratory hypotheses to specifically examine how the perceived importance of work values differs between the two younger generations_-Social-Reform Generation and Millennials Generation. To achieve the second research objective, I constructed an integrative conceptual model, summarized in Figure 3-1, by taking an interdisciplinary approach that integrates social exchange perspective into P-O fit theory, both reviewed in Chapter 2. The proposed theoretical model delineates links among the component constructs (i.e., P-O fit, POS, LMX, job satisfaction, organizational commitment, and turnover intention), allowing a more comprehensive description of the P-O fit processes linking to employee outcomes.

\section{Generational Differences in Work Values}

The key insight drawn from generation theory is that a better understanding of unique socio-economic characteristics linked to each generation during their formative years may provide the theoretical underpinning for explaining value shift across 
Figure 3-1.

Proposed Full Research Model (Moderated Mediation Model)

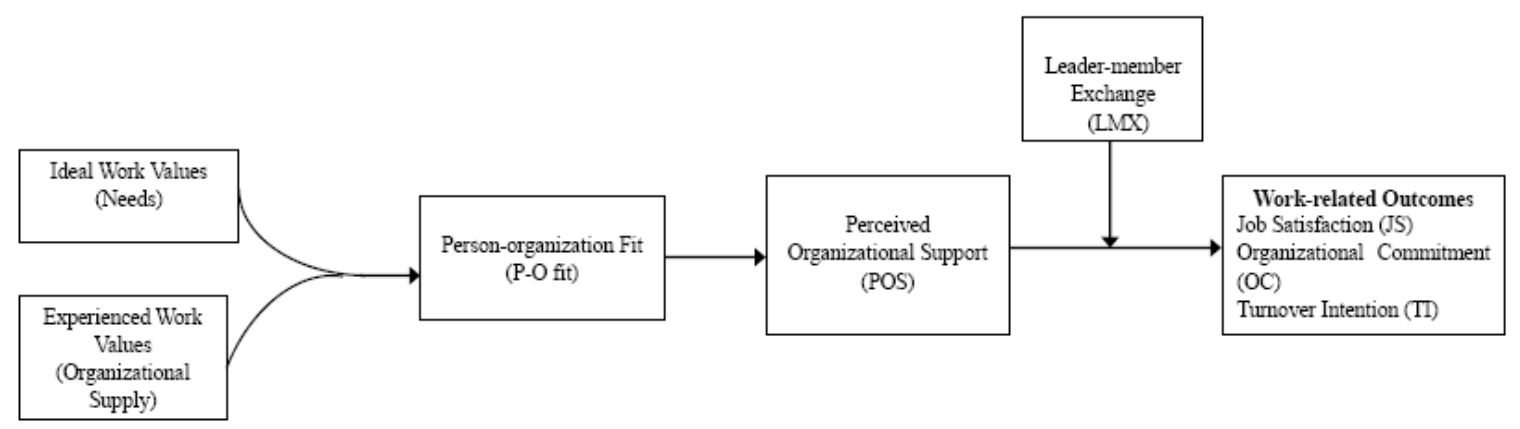

generations. Therefore, I will set the stage for the following hypotheses development by overviewing the two younger Chinese generations in the workplace and characteristics related to the socioeconomic environment during their respective adolescence years.

Despite the controversy surrounding the exact demarcation of generational cohorts based on birth years (Costanza, Badger, Fraser, Severt \& Grade, 2012), I adopted a generational classification scheme (see Table 3-2) based on the great socioeconomic and historical events that define each generational cohort in China. The three dominant generations in the Chinese workforce are labeled Cultural-Revolution Generation (born before 1966), Social-Reform Generation (born 1967-1981), and Millennial Generation (born after 1982). Similar age-group clusters were also used by management scholars in previous research on generational differences in work values in China (Roongrerngsuke \& Liefooghe, 2012; Yi, Ribbens \& Morgan, 2010). More importantly, this age-grouping scheme is consistent with generational-cohort theory that emphasizes the importance of the socioeconomic environment experienced by each generation in conditioning and shaping its value orientation. In addition, such a classification scheme will facilitate 
subsequent hypothesis development as well as data analysis and interpretation related to research question 1 and 2 of this dissertation.

Table 3-2*.

Summary of the Three Generations in China and Their Characteristics

\begin{tabular}{|c|c|c|c|}
\hline Generation & Years of Birth & Age Range & Generational Characteristics \\
\hline $\begin{array}{c}\text { Cultural } \\
\text { Revolution }\end{array}$ & Before 1966 & $>48$ years & $\begin{array}{l}\text { Experienced extreme poverty, } \\
\text { hardship, material scarcity, } \\
\text { cultural revolution, political } \\
\text { conflicts; more collective and } \\
\text { traditional }\end{array}$ \\
\hline Social Reform & 1967-1981 & 33-48 years & $\begin{array}{l}\text { Open-door Policy initiated; } \\
\text { experienced initial stage of } \\
\text { economic reform; better educated } \\
\text { and more exposed to } \\
\text { industrialization and } \\
\text { modernization than Cultural } \\
\text { Revolution generation }\end{array}$ \\
\hline Millennials & After 1982 & $<33$ years & $\begin{array}{l}\text { Deepening of economic reform; } \\
\text { fast two-digit economic growth; } \\
\text { the "One-Child Policy" } \\
\text { generation; the "Little Emperor" } \\
\text { generation; well-looked after and } \\
\text { spoiled by their families; never } \\
\text { experienced hardship; most } \\
\text { individualistic and self-centered }\end{array}$ \\
\hline
\end{tabular}

*Adapted from Yi, Ribbens \& Morgan (2010)

The Cultural-Revolution cohort (born before 1966) grew up in a time of hardship, terrible hunger, and extreme poverty due to natural disasters, as well as political and 
social conflicts in China during Mao’s time (Yang, 2003; Yi et al., 2010). Members from this generation were the "delayed generation" (danwu de yidai) that suffered the most misfortune from the Cultural Revolution; their experiences deprived them of opportunities for education and forced them to work in the countryside during their adolescence (Chen, 1999, p. 228). During their teenage years, members of the SocialRevolution generation (born during 1967-1981) experienced first-hand China’s move towards a market economy under Deng Xiaoping's reforms. Compared with the Cultural Revolution generation, the Social-Revolution cohort received better education, which created more employment opportunities for them upon graduation. When it comes to the Millennial generation (born after 1982), their formative years have witnessed fast economic development in China. In addition, this cohort—called "little emperors or little empresses"- grew up under the One-Child Policy, with all family attention channeled to this single child. That made parents and grandparents more responsive to their needs, which fostered their sense of security and self-assurance (Cameron, Erkal, Gangadharan \& Meng, 2013).

The two cornerstone principles underlying generation-cohort theory are quintessentially linked to Maslow’s (1943; 1954) human need-gratification theory, which posits that higher-order needs (e.g., self-actualization and self-expression) will be more likely to get activated and rise in salience if lower-order needs such as basic, material needs are fulfilled. As predicted by the theoretical models identified above, prior research has found evidence to suggest that better socio-economic conditions experienced by individuals affect the shift of their value orientation towards entertaining higher-order 
needs (e.g., Huang \& Van De Vliert, 2003; Inglehart \& Welzel, 2005; Johnson \& Mortimer, 2015). In the context of China, marketing researchers (Dou, Wang \& Zhou, 2006) on consumer behavior provided empirical support to such a connection by showing the significant generational variations in the pattern of media-program consumption, with the younger Chinese cohort preferring entertainment-related programs relative to information-laden news. In another study, the younger Chinese managers showed higher preference for certain personal values (e.g., openness to change) measured by Schwartz Values Survey (SVS), while scoring lower on other SVS traditional values (e.g., conservation) than their counterparts from the preceding generation cohorts (Egri \& Ralston, 2004). More specifically to work values, the same rationale may explain the recent findings, which indicate that younger workers in the Western context tend to attach more importance to higher-order work needs (e.g., work-life balance and leisure) (Cennamo et al., 2008; Twenge, 2010), and that, by contrast, older cohorts of workers value more work centrality (e.g., Gursoy et al., 2013).

Given the controversy surrounding the exact demarcation of generational cohorts based on birth years and the research focus on the young workers, the discussion thus far leads me to propose the following hypotheses with respect to extrinsic-intrinsic work values in comparing the two young Chinese generations:

Hypothesis 1a: Compared with Social-Reform generation, employees from the Millennials generation will display the lower preference for extrinsic work values. Hypothesis 1b: Compared with Social-Reform generation, employees from the Millennials generation will display the higher preference for intrinsic work values. 


\section{P-O fit and Work Outcomes}

According to Chatman (1989), the core of P-O fit lies in the congruence of values between employees and their employing organizations. From an integrated perspective of needs-supplies fulfillment and work values, such congruence can be further framed as the extent to which employees’ desired work needs get fulfilled by supplies offered by their employers (Kristof, 1996; Edwards \& Shipp, 2007).

A substantial research has provided evidence to support the direct and positive influence of P-O fit on such desirable work attitude as job satisfaction (e.g., Cranny, Smith \& Stone, 1992; Kristof, 1996; Liu et al., 2010; Verquer et al., 2003). These results are in line with Locke's (1969) job satisfaction theory, which asserts that an employee's favorable perception based on comparison between desired expectations and true experience on the job will bring about positive emotion like job satisfaction. Further, considerable research has suggested that employees with a high degree of P-O fit derived from met expectations in regard to needs-supplies fulfillment tend to express greater organizational commitment (Edwards \& Shipp, 2007; Saks \& Ashforth, 1997; Kim, et al., 2013). Many studies have also reported that P-O fit is negatively related to turnover propensity among employees, making them less likely to quit (Edwards \& Shipp, 2007; Kristof-Brown et al., 2005; Moynihan \& Pandey, 2007; Verquer et al., 2003;).

Taken together, according to the previous research findings reviewed above, it is expected that there is a significant positive relationship between employees' P-O fit and desirable work outcomes. Specifically, I posit the following hypotheses:

Hypothesis 2a: P-O fit is positively related to job satisfaction.

Hypothesis $2 b$ : P-O fit is positively related to organizational commitment. 
Hypothesis 2c: P-O fit is negatively related to turnover intention.

\section{Mediating Role of POS in P-O Fit-Work Outcome Relationships}

As noted earlier, the congruence in terms of needs-supplies fulfillment may foster employees’ deep sense of belonging and attachment to their organizations (Edwards \& Shipp, 2007) and lead to their favorable perceptions of the intentions of the organization (e.g., perceived organizational support) in the exchange relationship (Cable \& DeRue, 2002). Based on theory of perceived organizational support (POS), employees with higher POS tend to perceive their employers as valuing their contribution and being highly committed to their well-being (Eisenberger et al., 1986; Shore \& Tetrick, 1991). Such high-quality exchanges, reflected in the employees’ perceptions of the organization's commitment to them, have been found to be motivational in nature driving employees to act in good faith towards their employer and reciprocate with desirable work attitudes and behaviors (e.g., Eisenberger et al., 1986; Farh, Hackett \& Liang, 2007; Mossholder, et al., 2005). For example, drawing on social exchange theory, the recent empirical study by Kim et al. (2013) has demonstrated that the indirect effect of P-O fit on both job satisfaction and affective organizational commitment is mediated by the perceived POS quality. As for the third central work outcome, turnover intention, to the best of my knowledge, no study has ever integrated POS into the P-O fit process in the context of employee turnover intention. However, according to Loi, Hang-Yue, and Foley (2006), recent empirical evidence has provided strong support for the significant beneficial effects of POS in reducing employee intention to leave; more importantly, the authors found the mediating role of POS on the relationships between such psychological 
constructs as distributive and procedural justice — quite similar to the focal construct of P$\mathrm{O}$ fit—and employee turnover intention.

The discussion, so far, seems to suggest that P-O fit and POS are both linked to the work outcomes and that high P-O fit is positively related to POS. In combination, it can be expected that POS plays a mediating role in linking P-O fit and the work-related outcomes of interest in the present study. In another word, the effects of P-O fit on the employee outcomes are transmitted through POS. Hence, I propose the following series of mediation hypotheses:

Hypothesis 3a: There is a mediation effect between $\mathrm{P}-\mathrm{O}$ fit and POS in predicting job satisfaction. That is, the relationship between $\mathrm{P}-\mathrm{O}$ fit and job satisfaction is expected to be mediated by perceived organizational support.

Hypothesis $3 b$ : There is a mediation effect between P-O fit and POS in predicting organizational commitment. That is, the relationship between $\mathrm{P}-\mathrm{O}$ fit and organizational commitment is expected to be mediated by perceived organizational support.

Hypothesis 3c: There is a mediation effect between P-O fit and POS in predicting turnover intention. That is, the relationship between $\mathrm{P}-\mathrm{O}$ fit and turnover intention is expected to be mediated by perceived organizational support.

\section{Moderating Role of LMX in POS-Work Outcome Relationships}

Leader-member exchange (LMX) theory is regarded as a relationship-based approach to leadership and focuses on the exchange quality between employees and their leaders/supervisors. Similar to POS, LMX theory can also trace its theoretical foundation to social exchange theory (Erdogan \& Enders, 2007), that is firmly rooted in the idea of reciprocity (Blau, 1964). Trust and mutual obligation are the hallmark of high-quality LMX relationships. According to LMX theory, supervisors develop exchange 
relationships — that vary in quality—with different subordinates. As a result, the variation in quality of exchanges with their supervisor can substantially influence employee outcomes (e.g., Aryee \& Chen, 2006; Masterson, Lewis, Goldman \& Taylor, 2000; Wayne et al., 1997).

Only recently, scholars have begun to devote increased attention to investigating the interrelationships between POS and LMX (Eisenberger, Shoss, Karagonlar, Gonzalez-Morales, Wickham \& Buffardi, 2014; Kim et al., 2013). As discussed above, employees with high POS are more likely to view organizational policies and practices favorably because they have the assurance that their organization would act with their interest in mind. Consequently, they will also feel more obliged to reciprocate the received assistance and support with positive work outcomes (e.g., Eisenberger et al., 1986; Settoon, et al., 1996). Although both organization and supervisor represent important exchange parties in the social exchange processes, they differ substantially with respect to psychological and physical proximity to an employee (Chen et al., 2002); that is particularly true in the China context (Hui et al., 2004). As such, I expect that for Chinese employees with high-quality LMX the positive relationship between POS and outcomes will be reinforced. For them, they will be more likely to make positive attributions to the organization regarding its policies and practices and thus develop deeper sense of reciprocication. In contrast, low-quality LMX can be detrimental to negatively impact an employee’s perception towards organization, which will result in less desirable work outcomes. Hence, this conceptual analysis leads to the following hypotheses: 
Hypothesis 4a: There is a positive interaction effect between POS and LMX in predicting job satisfaction, such that the relationship between POS and job satisfaction is stronger when LMX quality is high rather than low.

Hypothesis $4 b$ : There is a positive interaction effect between POS and LMX in predicting organizational commitment, such that the relationship between POS and organizational commitment is stronger when LMX quality is high rather than low.

Hypothesis 4c: There is a negative interaction effect between POS and LMX predicting turnover intention, such that the relationship between POS and turnover intention is stronger when LMX quality is low rather than high.

\section{Relational Chain: A Moderated Mediation Model}

The hypotheses above point to a moderating role played by LMX and predict that LMX moderates the association between POS and employee outcomes. By integrating the moderation effect of LMX into the previously hypothesized mediation model of POS, it affords us with an overall moderated mediation model for the relational chain leading from P-O fit to POS, and then relay onto the three work outcomes. It should be noted that such conceptualization is consistent with the second-stage moderation model (Edwards \& Lambert, 2007; Hayes, 2015), which predicts that the strength of indirect relationships between P-O fit and work outcomes through POS is contingent upon the level of LMX quality. Following the discussion so far, I hypothesize that:

Hypothesis 5a: LMX moderates the indirect effect of POS on job satisfaction. That is, the mediation effect of POS is stronger when LMX quality is high rather than low.

Hypothesis 5b: LMX moderates the indirect effect of POS on organizational commitment. That is, the mediation effect of POS is stronger when LMX quality is high rather than low. 
Hypothesis 5c: LMX moderates the indirect effect of POS on turnover intention. That is, the mediation effect of POS is weaker when LMX quality is high rather than low. 


\section{CHAPTER IV}

\section{RESEARCH METHOD}

This chapter provides a general review of the research methods that were used to address the research questions and test the theoretical model shown in Figure 3-1. The central inquiry of this dissertation research is two-fold. First, the differences or similarities in work values were investigated across generational cohorts in the work environment with a particular focus on the young Chinese workers. Second, the relationships between work-value-based person-organization fit (P-O fit) and the work outcomes of job satisfaction, organizational commitment, and turnover intention. This study also aimed to illuminate the possible mechanisms linking P-O fit to various outcome variables of interest to organizations. More specifically, I mainly focused on the combined mediated moderation influence of leader-member exchange quality (LMX) and perceived organizational support (POS) by integrating these two perspectives. In so doing, I intended to delineate a comprehensive model on how P-O fit can be fostered and ultimately lead to work outcomes.

To address these research questions I chose a research design that blended interviews and two survey-based studies. As I mentioned above in Chapter Two, work values is the focal construct that cuts across all the research questions and acts as a linchpin to tie person-organization fit and work-related outcomes in the proposed conceptual model shown in Figure 3-1. Therefore, in Study 1 I used a three-phase research design (Figure 4-1) that mixed both qualitative and quantitative approaches (Bluhm, Hartman, Lee \& Mitchell, 2011; DeVellis, 2003; Lee, 1999) to develop a scale for measuring an employee's perceived importance of the various work aspects. I then 
used a sample of employees from company A to pre-test the questionnaire that includes the constructed work values scale. Overall, the specific goal of study 1 was to ensure that the developed work values scale and other previously developed and validated measures would be suitable and relevant to the Chinese employee sample. In study 2, survey data were collected from employees in company B, C, and D for testing $\mathrm{H}_{1}$ through $\mathrm{H}_{5}$.

Figure 4-1.

A Flow Chart for Research Design of the Study

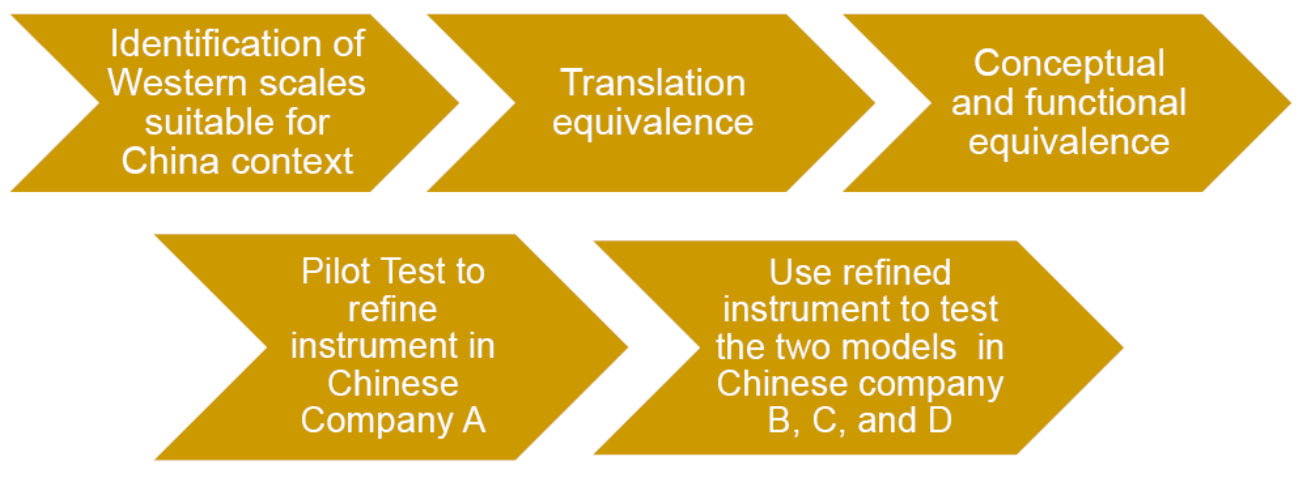

I anchored this study in the Chinese context for the following reasons. First, as discussed in Chapter 2, most research to date on work values was predominantly conducted in Western societies, and in the United States, in particular. Furthermore, there are even fewer studies that have explicitly investigated the generational differences or similarities in work values in a non-Western context. As such, little is known about the cross-cultural applicability of work values theory, as people's perceptions towards importance of work aspects is not culture-free and may be influenced by culture (Schwartz, 1999). A similar argument may apply to the existing research on P-O fit and its correlates, which warrants additional research attention to assessing the universality of 
P-O fit and how it is related to different outcome variables cross-culturally (Lee \& Antonikis, 2014; Oh, Guay, Kim, Harold, Lee, Heo \& Shin, 2014). In all, our knowledge base will be substantially expanded and strengthened by testing Western theories in a cultural context vastly different from the Western societies (Schwartz \& Blisky, 1990). A growing number of scholars have argued that China has presented itself as a fertile non-Western ground for testing the organizational theories developed almost exclusively in the West (Chen, Eberly, Chiang \& Farh, 2014; Peng, Liu, Shenkar \& Wang, 2001; Tsui, 2007; Whetten, 2009).

Second, although the construct of work values has attracted increased attention from both scholars and practitioners alike, there is no clear consensus in regards to its conceptual domain as reflected from a variety of its definitions $(\mathrm{Bu}$ \& McKeen, 2001; Dose, 1997; Wong \& Yuen, 2012). Similarly, despite increasing consensus among researchers that P-O fit is conceptualized as a multifaceted construct, most empirical research has continued to use a single-item measure asking a respondent to rate to what extent he/she feels there is a fit with his/her employer. Such a simplistic and one-dimensional operationalization is lack of sophistication at best and may be especially problematic, as it fails to tap the breadth of the fit concept.

Third, few studies in the past have empirically investigated the processes through which P-O fit may drive employees' responsive attitudes and behaviors (Cable \& DeRue, 2002; Resick, Baltes \& Shantz, 2007; Kim et al., 2013). In the proposed conceptual model (see Figure 3-1), perceived organizational support and 
leader-member exchange, the two crucial boundary conditions are expected to greatly affect the relationships between P-O fit and different outcome variables. More importantly, Chinese employees may exhibit significant while important differences from their Western counterparts in perceiving exchange relationships of POS and LMX within organizations (Settoon et al., 1996). More specifically, Chinese people tend to attach more importance to the development and cultivation of interpersonal ties to individuals or their supervisors than to their organizations due to the heavy Confucian influence (Dong \& Liu, 2010; Hui, Lee \& Rousseau, 2004). Therefore, POS and LMX are likely to play different roles in influencing the underlying processes linking P-O fit and different work outcomes. Such research insights can add evidence-based knowledge to assist organizations in devising more effective HR policies and management practices.

Lastly, China provides a unique non-Western setting in which it continues to undergo dramatic social and economic changes in its pursuit of modernization (Li, Poppo \& Zhou, 2008; Stevens, Xie \& Peng, 2015; Tsui, Schoonhoven, Meyer, Lau \& Milkovich, 2004). Under such conditions of constant influx, both domestic and foreign firms are facing ever-growing HRM challenges exacerbated by China's fast-aging workforce and labor shortage (Li \& Sheldon, 2010; Manpower, 2013). As such, it has become increasingly necessary for organizations to gain evidence-based knowledge on what interventions may be effective in fostering the sense of person-organization fit among employees.

\section{CHAPTER V}


STUDY 1: WORK-VALUE SCALE REFINEMENT AND PILOT TESTING

\section{Overview}

In Study 1, following the best practices and guidelines set forth by Schwab (1980), DeVellis (2003), and Hinkin (1995) I used a three-phase design that blended interviews and a survey-based pilot test to establish valid and reliable measures for the variables in this study. More specifically, the structured multistep process (Chen, Tsui, \& Farh, 2002; Hinkin, 1995) for developing the survey scale of work values can be broken down into three stages: (1) Item generation; (2) Scale evaluation; and (3) Scale refinement and finalization. In addition, a questionnaire containing all measures including the developed work values scale for Study 2 was pre-tested with a sample of employees recruited from Company A over Step 2, the scale-evaluation stage. The primary purpose of Study 1 is twofold: (1) to demonstrate the content validity of all the measures - that is, a scale should contain items that are supposed to represent the construct of interest (DeVellis, 2003; Hinkin, 1995); (2) to ensure that the developed questionnaire is suitable and relevant for the Chinese employee sample in the main hypothesistesting study of Study 2 that will be discussed in detail in the following chapter.

\section{Development and Validation of the Work-value Scale}

\section{Phase 1: Item Generation and Screening}

In scale design, the first stage involves the creation of a pool of items that are generated to reflect a clearly defined construct. The key consideration at this stage is to demonstrate enough content validity of the created measurement (DeVellis, 2003; Hinkin, 1995). 
In general, there are two most prevalently used approaches to generating itemsdeductive and inductive (Hinkin, 1995; 1998). A deductive approach, comparatively the standard method, uses a well-developed theoretical basis to guide item creation (Hinkin, 1998; Schwab, 1980; Street \& Gallupe, 2009). On the other hand, items can be generated through a qualitative approach that can include such flexible and informal methods as direct observation and interviewing. The qualitative approach is generally a preferred way for deriving items when there is little well-founded theoretical grounding on the phenomena under question.

For this study, I mainly used the deductive approach because there are preexisting theoretical grounds and definitions of work values reviewed in Chapter 2. I also used interview, a qualitative research technique, to remain flexible in step of item generation. In addition, I was well aware of the complexity and challenges associated with cross-cultural research (Cavusgil \& Das, 1997)—in particular, researchers are suggested to take extra care in developing a suitable measurement scale that has established cross-cultural validity pertaining to translation, conceptual, and metric equivalence (Cascio, 2012). Such extra effort is particularly warranted for the current study that aims to apply the pool of items of source language in a Chinese context (Farh, Cannella, \& Lee, 2006), as Adler (1997, p. 160, italic added by the author) has aptly pointed out that "human needs [including work values] may well include fundamental or universal aspects, but their importance and the ways in which they express themselves differ across cultures”. Consistent with the 'adaptation approach' to developing a quality measurement scale in China (Farh et al., 2006) I used Super’s (1995) most commonly adopted definition of work values and the dominant approach that classifies work values 
into two constituent elements, extrinsic and intrinsic work values, as the conceptual foundation. Once the conceptual domain of the work-value construct has been clearly articulated, the body of literature on work values was carefully reviewed to identify the candidate scales for their operationalizatoins. I considered Bu and McKeen’s (2001) work-goal scale developed based on Manhardt’s (1972) Work Values Inventory Scale as a viable basis to create the provisional bank of items for later modification and refinement. Another reason for selecting this scale is because it was previously validated cross-culturally among MBA students in both Chinese and Canadian contexts. Moreover, it has been recommended that the large pool of items created should be ‘overinclusive’ (DeVellis, 2003, p. 65) so as to maximumly capture the concept of work values, while allowing some flexibility to remove items if necessary. Thus, to the 24 work-goal-item scale (Bu \& McKeen, 2001) I added back the five items that were included in Manhardt's (1972) original Work Values Inventory Scale but dropped in Bu and McKeen’s (2001) study.

Next, I employed Brislin’s (1970) iterative translation and back-translation method to carefully translate the 29 English work-value items into Chinese. A main objective is to ensure the translation quality by establishing the equivalence between source and target versions of a scale of interest (Brislin, 1970; Cascio, 2012). In the first step of forward translation, the English version of the initial pool of items was translated into Chinese, the target language. In the second step, a staff working at the Human Resource Department of Company B, whose native language is Chinese, was tapped to review the translated items. With her feedback 
on the instrument, I further revised those items and got them ready for back-translation. The third step was back-translation—a more robust process-whereby a close family member of mine, who is a native Chinese and has excellent command of English was kind to offer help with translating the Chinese version of the items back to the original English language. During the final step, I worked with a bi-lingual management professor in a U.S. university to compare side-by-side both the original English version, the backtranslated version, and the Chinese version of all the items. We tried to reconcile the three versions by focusing attention on those items with most discrepancies and reaching consensuses through discussions between us.

At the end of the process, I obtained the provisional pool of 29 items (see Table 51) in Chinese to be considered for eventual inclusion based on the successive screening, where all the items were distributed to experts for review and verification. I next made trips to the four local Chinese companies and conducted multiple short but in-depth interviews with the key managers from all those four Companies A, B, C, and D. During those interviews, I asked the managers to review the item pool in regards to the content validity. In order to solicit candid thoughts as much as possible, all the interviews were arranged individually with each manager and conducted face-to-face at either his/her office or a location suggested by the manager. In addition to key managers from all the four companies, I also contacted two Chinese management professors who are highly knowledgeable in the content area of the employee work values. As suggested by DeVellis (2003), I first provided the definition of work values and described organizational phenomena related to the focal construct in question. I then asked each 
interviewee to freely provide their assessment on how well each item measures the construct of work values as they are purported to.

Throughout this round of interviews, expert reviewers not only provided their 
Table 5-1*.

Original Items ${ }^{a}$, Additional Items ${ }^{b}$, New Items, Final Items for the Work-Value Scale

\begin{tabular}{|c|c|c|c|c|}
\hline Work-Value Items & Original Items $^{a}$ & Additional Items $^{b}$ & New Items ${ }^{c}$ & Final Scale \\
\hline offers perks such as free meal, housing and & & & & \\
\hline transportation allowance & $v$ & & & $v$ \\
\hline permits a balanced lifestyle & 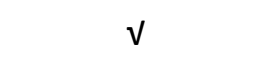 & & & $\mathrm{v}$ \\
\hline permits a regular routine in time and place of work & $\checkmark$ & & & $\checkmark$ \\
\hline permits an accommodation of family responsibilities & 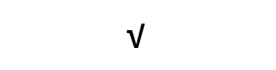 & & & $v$ \\
\hline the company is close to home or conveniently located & & & 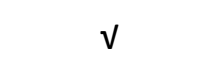 & $\checkmark$ \\
\hline provides ample leisure time off the job & $\checkmark$ & & & $\checkmark$ \\
\hline provides a comfortable work environment & & 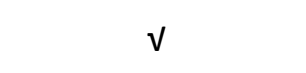 & & 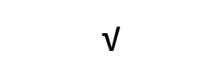 \\
\hline provides job security & $\mathrm{v}$ & & & $\mathrm{v}$ \\
\hline provides the opportunity to earn a high income & $\mathrm{v}$ & & & $\checkmark$ \\
\hline working in a company with a good reputation & & & v & $\checkmark$ \\
\hline respected by others & $\checkmark$ & & & $v$ \\
\hline involves working with congenial associates & $\mathrm{v}$ & & & $\mathrm{v}$ \\
\hline
\end{tabular}


makes a social contribution by the work you do 
requires working on problems of central importance to the organization

requires meeting and speaking with many other people

Encourage continued development of knowledge and skills

Enhance your status in the community $\checkmark$

V

NOTE.

*: adapted from the table in Gilleard, Higgs, Hyde, Wiggins, \& Blane (2005), p. S307

a: original items taken from Bu \& McKeen (2001);

b: original items taken from Manhardt (1972);

c: new items generated based on the interviews with managers

d: final 18 items remaining based on factor analyses and feedback during interviews 
assessment on the appropriateness of each item, but also pointed out additional items that I should consider for eventual inclusion in the final scale. For example, the manager from Company B had the following to say when referring to the finding uncovered from recent exit interviews:

"In order to better understand why some employees decide to leave [our company], an exit interview is usually conducted with the departing employees. In our recent exit interviews, several departing employees voiced their frustration with the long commute to job that adversely affected their personal life." (From the interview with the HR manager from Company B)

The similar observation was also made by the managers from Company A and C. Based on that insight, I generated a new item that describes an ideal job as "the company is close to home or conveniently located" (see Table 5-1).

In the same way, a second new item was also created and incorporated into the item pool, which states an ideal job should involve "working in a company with a good reputation” (see Table 5-1). The addition of this second new item is warranted based on the insights derived from the interview with the key manager from Company D, who expounded on his recent experience with job applicant at a local job fair:

"One critical asset of our company is certainly our good reputation and superior brand name. Let me give you an example here. I went to a local job fair not long ago and was pleased to find that our booth was frequently visited by job applicants, who showed great interest for wanting to work with us by submitting their resumes. Many of them told me that they were attracted to us by our company's positive reputation-they knew that to work for us meant they would be provided with good work environment and taken great care of. In addition, if a person is hired by us, his/her parents or even relatives will 'gain face' (zhang lian) as well as gain bragging rights because we are one of the best firms to work for in the field." (From the Interview with the manager from company D) 
At the end of Phase 1 of item generation, the iterative screening and modification process resulted in a 31-item scale measuring work values (Table 5-1), translated into Chinese and made ready for further scale evaluation in the second stage. As a critical quality-control step right before the following pilot test, I subjected all measures in Chinese to the HR director at Company A, where the pilot test was to be conducted, for her final review and approval.

In the next section, I will describe the pilot test used to evaluate the content and consistency of the developed 31-item scale of work values. In the last section on the final stage of work-value scale construction (Phase 3), I will present the detailed description of how the 31-item scale of work values was examined, refined, and reduced using the first survey sample. In particular, I will also take great care to address potential redundancy and irrelevance issues related to scale design in order to improve factor stability of the work-value items.

\section{Phase 2: Pilot Testing for Evaluation of the Work-value Scale}

In the pilot test, the direct contact person was a staff working in the human resource department of Company A, who was appointed by the company’s HR director to assist me with questionnaire distribution and collection. In this round of pretest, a total of 76 paper-and-pencil questionnaires were sent randomly to employees in Company A. To elicit honest answers from employee respondents, a short letter to explain the nature of the survey and provide complete assurance of subjects’ confidentiality was included in each questionnaire package. With these measures in place, I obtained 64 returned questionnaires representing a $84.2 \%$ response rate. Nonetheless, out of the 64 responses, 16 questionnaires were deemed unusable due to substantial missing answers or obvious 
response bias patterns, which resulted in 48 usable surveys. Most of the employee subjects were male $(69 \%)$, with an average age of 29.67 years $(S D=5.58)$. Regarding received education level, half of the respondents (50\%) had higher education with college associate degree or above and, on average, worked in Company A for 2.77 years of organizational tenure $(S D=2.24)$. Of them, $50 \%$ were first-line employees, 19\% technicians, 17\% low-level managers, 14\% middle-level managers, and none high-level managers. The demographic characteristics of the employee participants for the pilot test are presented in Table 5-2.

Table 5-2.

Demographic Profile of Employee Participants in the Pilot Test $(N=48)$

\begin{tabular}{ccc}
\hline Demographic Characteristics & Frequency (N) & Percentage \\
\hline Gender $^{\mathbf{a}}$ & 33 & $69 \%$ \\
Male & 15 & $31 \%$ \\
Female &
\end{tabular}

\section{Education}

\section{Elementary}

Middle School

High School

Two- or three-year College

University or above
0

11

13

12

12
$0 \%$

$23 \%$

$27 \%$

$25 \%$

$25 \%$ 


\begin{tabular}{ccc} 
Position & & \\
First-Line Employee & 24 & $50 \%$ \\
Technician & 10 & $20 \%$ \\
Low-Level Manager & 8 & $17 \%$ \\
Middle-Level Manager & 6 & $13 \%$ \\
High-Level Manager & 0 & $0 \%$ \\
Age & 29.67 years & \\
Tenure & & \\
& 2.77 years & 2.24 years $(S D)$ \\
\hline
\end{tabular}

For the work-value scale, participants were given the following instructions, "Work is an important part of our lives. Work preferences, goals, and needs may vary among individuals. Listed below are thirty-one factors related to work that might be important to you. Please rate the importance of each factor to you in an ideal job.” Sample items include "working in a company with good reputation" and "permits a balanced life-style”. Responses were made on a scale, ranging from (1) not at all important to me to (5) extremely important to me. Respondents were asked to rate the importance of each work value statement related to an ideal job.

\section{Data Analysis}

As a powerful statistical method, factor analysis is usually used to assist in determining the dimensionality underlying a set of variables; another main application of factor analysis is for the purpose of reducing the number of variables, that is "condensing 
the information so that variation can be accounted for by using a smaller number of variables” (DeVellis, 2003, p. 103).

In general, there are two main types of factor analysis: exploratory and confirmatory. Exploratory factor analysis (EFA) is used for scale development when little certainty exists to allow researchers to specify a priori a certain number of factors (Hayton, Allen \& Scarpello, 2004; Hurley, Scandura, Schriesheim, et al., 1997). On the other hand, confirmatory factor analysis is appropriate when researchers can use theoretical groundings to pre-define the structure that can explain the pattern of the correlations among the set of items (DeVellis, 2003).

Although Bu \& McKeen’s (2001) work-goal scale was developed and validated among full-time MBA students in China, our knowledge is still quite limited about employee work values in the China context. Furthermore, a number of scholars have cautioned against drawing strong conclusions by relying excessively on student samples because students "may not represent any segment of the population of interest” due to their lack of work experience and exposure to the work environment (Bello, Leung, Radebaugh, Tung \& Witteloostuijin, 2009; Gordon, Slade \& Schmitt, 1987, p. 162). As such, it was less clear if the same factor structure previously identified using a Chinese student sample (Bu \& McKeen, 2001) would be equally applicable to the present Chinese employee sample. Therefore, given the exploratory nature of the current study, I conducted 
exploratory factor analysis to investigate the structure of the 31-item work-value scale using the survey sample of 48 Chinese employees recruited from Company A.

I first performed a principal-component factor analysis without imposing any constraints. The main purpose for this initial step is to assess the suitability of performing factor analysis on the 31-item work-value scale based on the results of both the KaiserMeyer-Olkin’s Measure of Sampling Adequacy (Kaiser, 1974) and the Bartlett’s test (Bartlett, 1954).

Next, principal-component analyses with oblique rotation were applied to the data in order to assist in interpretation and ultimately attain a simple structure underlying the set of items, which is regarded as essential to factor analysis (Kline, 2002; DeVellis, 2003). Based on Kaiser’s eigenvalue rule (Nunnally, 1978), only leading factors with eigenvalues more than 1 should be retained. In addition, the following criteria were used to determine whether to keep or eliminate an item from subsequent analysis: (1) only items with factor loadings greater than 0.40 can be considered for eventual inclusion in the work-value scale (Conway \& Hufcutt, 2003; Ford, MacCallium \& Tait, 1986; Hinkin, 1995); (2) those items with substantial cross-loadings greater than 0.35 on more than one component factor are generally identified as prime candidates subject to removal from the scale due to their insufficient discriminant validity (Holt, Armenakis, Field \& Harris, 2007).

Lastly, Cronbach's alpha coefficent, an indicator of the degree of internal consistency, was also calculated to assess the reliability of the work-value scale. As a thumb of rule, a reliability coefficient of 0.7 or above is generally considered to be acceptable (Nunnally, 1978; George \& Mallery, 2005); however, Cronbach’s alpha lower 
than the threshold of 0.7 can be also acceptable for some psychological constructs (Kline, 1999).

Phase 3: Work-value Scale Refinement and Finalization

In the initial factor analysis, two statistical analyses were performed to assess the suitability of the data for factor analysis-Kaiser-Meyer-Olkin (KMO) analysis and Bartlett's test. The value of Kaiser-Meyer-Olkin (KMO) Measure of Sampling Adequacy for the set of 31 work-value items was 0.72, suggesting that it was suitable to conduct factor analysis on the data according to Kaiser’s (1974) appropriateness guideline. The highly significant value of Bartlett's test $\left(\chi^{2}=\right.$ 1135.37, $p=0.000$ ) also met appropriateness criteria for proceeding with factor analysis on the set of items.

Additionally, the exploratory factor analysis without specifying the number of factors indicated that seven factors with eigenvalues greater than 1 were extracted from the data using principal-component analysis with oblique rotation. However, more than half of the 31 work-value items had substantial cross-loadings, making the seven-factor solution less satisfactory. Similar to what $\mathrm{Bu}$ and McKeen (2001) did in their development and validation of their work-goal scale, next I conducted factor analyses by fixing the number of factors to three, four, five, six, and seven. However, none of the above factor extractions provided a clear-cut and satisfactory factor structure because the problem with crossloading items still persisted. Different from the earlier stage in item generation, 
during this step of further scale development and refinement, much attempt should be aimed at developing a short version of the work-value scale by eliminating inappropriate or poorly performing items, as it is advocated that reducing scale length without lowering the internal consistency reliability of the scale would be desirable in the subsequent survey administration on a much larger scale (Hinkin, 1995; DeVellis, 2003).

Subsequently, the same analytical procedure was repeated but in combination with item deletion and retention guided by the criteria set forth beforehand in Phase 2 . Besides relying on statistical techniques, I also used conceptual approaches to aid me in identifying potential items for removal—that is, I also made every attempt to improve the measures' clarity and stability by removing exceptionally lengthy items or those items that may be conceptually ambiguous (Cadogan, Diamantopoulos \& De Mortanges, 1999). In such continued exploration of the data to search for a better alternative, a clear identification of two-factor solution with no cross-loading more than 0.35 was achieved after thirteen items were dropped. It should be noted that several work-value items related to perception towards leaders or organizations were excluded from final inclusion not only because they cross-loaded on both leading factors, but also their content may overlap with other items in the leader-member exchange and perceived organizational support scales included in the final version of the questionnaire. The provisional, subsequently refined, and finalized scales of work values are presented in Table 5-1.

Shown in Table 5-3, the principal-component analysis with a specified number of leading components resulted in an exceptionally clean, interpretable, and parsimonious two-factor structure, with the retained 18 items evenly representing distinctly extrinsic work values (9 items) and intrinsic work values (9 items). Specifically, factor loadings of 
each item on each of the two factors exceeded 0.50 (ranging from 0.51 to 0.83 ), indicating reasonably high correlations between the leading components and their individual items. Overall, the results also suggested that the two-factor model had a good fit with the data, cumulatively explaining $53.6 \%$ of the total variance, which was comparable to previous research (e.g., Bu \& McKeen, 2001). More importantly, the underlying two-factor structure was consistent with the dominant extrinsic-intrinsic dichotomization approach to classifying work values into the two distinct dimensions (e.g., Elizur, 1984; Johnson et al., 2007; Schwartz, 1999; Porter \& Lawler, 1968).

To further evaluate the quality of the18-item scale, three additional statistical analyses were conducted to examine the validity of the work-value instrument. The results of Kaiser-Meyer-Olkin (KMO) test (0.75) and the Bartlett's test $\left(\chi^{2}=539.78, p=0.000\right)$ were both deemed acceptable (Kaiser, 1974; Bartlett, 1954). The Cronbach's alpha coefficients for the two subscales with nine items each (extrinsic work values and intrinsic work values) were 0.89 and 0.88 , respectively, which were also considered acceptable.

Lastly, I performed Pearson correlation analysis of the two leading factors corresponding to the two subscales of the 18-item scale of work values; as anticipated, the Pearson correlation coefficient indicated that extrinsic work values and intrinsic work values were highly correlated $(r=0.49, p<0.01$ for a two-tailed test; $n=48$ ). Thus, as noted by many scholars (Fabrigar, Wegener, MacCallum \& Strahan 1999, cited in Conway \& Huffcutt, 2003; Mertler \& Vannatta, 2005), when there is evidence to indicate strong correlation among 
underlying factors, Oblique rotation should be preferred over the Orthogonal rotation as the rotation method of choice to produce a more reliable and accurate factor structure, as in this study. A summary of all the items in the finalized work-value scale and their factor loadings are presented in Table 5-3.

\section{Pilot Testing of Instrumentation}

In addition to refinement and validation of the work-value scale, in the pilot test I also sought to evaluate the suitability of the other five main scales used to measure the other variables of interest in this study. I used existing literature reviewed in Chapter 2 to guide me in selecting all other scales capturing job satisfaction (JS), organizational commitment (OC), turnover intention (TI), leader-member exchange (LMX), and perceived organizational support (POS) (see Table 2-1). Although these scales are wellestablished and have been validated in the Chinese context with fairly high consistency, it is still strongly recommended that a pilot test should be undertaken to ensure the appropriateness and suitability of those translated scales to the Chinese employee sample (Farh et al., 2006; Chen, Hui \& Sego, 1998).

Similarly, all those scales were translated into Chinese from the source language of English based on Brislin's (1970) translation and back-translation method discussed above; prior to data collection in the pilot test, all those above instruments to measure the other five theoretical constructs were sent to the HR director of Company A to be examined and approved as the final quality-control step. 
The subsequent sections will provide a full and detailed description of each instrument.

Job Satisfaction

For this study, job satisfaction was captured with the 3-item Overall Job Satisfaction Measure developed by Cammann and colleagues (1983) and previously applied in China by Song, Wanberg, Niu and Xie (2006). Sample items were, “All in all, I am satisfied with my job.” and “In general, I don’t like my job.” (reverse-scored). Consistent with previous research, responses to job satisfaction were made on a 
Table 5-3.

Pilot Test (Study 1): Factor Loadings from Principal Component Analysis with Oblimin Rotation

\begin{tabular}{|c|c|c|c|c|}
\hline Chinese Employee Value Items & Mean & S.D. & $\begin{array}{l}\text { Cronbach's } \\
\text { Alpha }\end{array}$ & $\begin{array}{l}\text { Factor } \\
\text { Loading }\end{array}$ \\
\hline Extrinsic Work Values & 3.61 & 0.82 & 0.89 & \\
\hline $\begin{array}{l}\text { 1. offers perks such as free meals, housing and transportation } \\
\text { allowance }\end{array}$ & & & & 0.80 \\
\hline 2. permits a balanced lifestyle & & & & 0.83 \\
\hline 3. permits a regular routine in time and place of work & & & & 0.65 \\
\hline 4. permits an accommodation of family responsibilities & & & & 0.51 \\
\hline 5. the company is close to home or conveniently located & & & & 0.78 \\
\hline 6. provides ample leisure time off the job & & & & 0.76 \\
\hline 7. provides a comfortable work environment & & & & 0.78 \\
\hline 8. provides job security & & & & 0.65 \\
\hline 9. provides the opportunity to earn a high income & & & & 0.60 \\
\hline Intrinsic Work Values & 3.58 & 0.78 & 0.88 & \\
\hline 10. working in a company with a good reputation & & & & 0.72 \\
\hline
\end{tabular}


12. involves working with congenial associates

13. makes a social contribution by the work you do

14. makes use of your specific educational background

15. provides a feeling of accomplishment

16. provides challenging tasks and projects

17. provides change and variety in duties and activities

NOTE.

a: The Pearson correlation coefficient between extrinsic and intrinsic work values for the pilot-test sample is .49 ( $p<.01$, twotailed test, $\mathrm{N}=48$ ) 
7-point scale of agreement, ranging from (1) strongly disagree to (7) strongly agree. Higher scores indicate higher level of overall job satisfaction. The scale's reliability for the pilot-test sample was 0.77 .

\section{Turnover Intention}

An employee's turnover intention was assessed with the same 3 items taken directly from Camman and colleagues (1979). The Chinese version of the same measure was used previously used in the Chinese context, with the reported Cronbach's alpha of 0.60 (Hui, Wong \& Tjosvold, 2007). Higher scores denote greater intention of turnover. The three items were: "I often think about quitting”, "I will probably look for a new job in the next year", and "If I may choose again, I will choose to work for the current organization.” Responses were recorded using a 7-point scale of agreement, ranging from (1) strongly disagree to (7) strongly agree. In the pilot test, the Cronbach's alpha of this scale was 0.89 .

\section{Perceived Organizational Support}

Perceived organizational support (POS) was measured by the eight items from Settoon and colleagues (1996). For the POS scale, half of the eight items were reversescored. One previous study using this scale on Chinese employees reported the Cronbach’s alpha of 0.84 (Farh et al., 2007). Sample items were: “The organization values my contribution to its well-being" and "The organization would ignore any complaint from me” (reverse-scored). Each of the items was measured using a 7-point scale of agreement, ranging from (1) strongly disagree to (7) strongly agree. In the pilot test, the Cronbach's alpha of this scale was 0.86 . 


\section{Leader-member Exchange}

Seven items adapted from Liden, Wayne, and Stilwell (1993) were used to assess the quality of leader-member exchange from the perspective of employees. This scale was previously used on Chinese employees with reported Cronbah's alpha of 0.82 (Aryee \& Chen, 2006). Individuals were asked to rate the level of their agreement on each of the seven statements pertaining to leader-member exchange quality. Responses were made on 7-point scale of agreement, ranging from (1) strongly disagree to (7) strongly agree.

Sample items included: "Regardless of how much formal authority your leader has built into his or her position, he/she is highly likely to use his or her power to help you solve problems in your work." and "I would characterize my working relationship with my leader as good”. In the pilot test, the Cronbach’s alpha of this scale was 0.94 .

All values of Cronbach's alpha for the four translated scales used in the pilot test showed acceptable reliability and consistency, ranging from 0.77 to 0.94 (see Table 5-4). The comparisons with previous studies using the same scales in the China context also indicated that they exhibited comparable or even better internal consistency in the pilot test, as shown in Table 5-4.

In sum, the purpose of Study 1 was two-fold: (1) First, I used interviews and a survey sample to refine and validate the work-value scale for measuring the focal construct in this study; (2) Second, I also used the same survey sample to determine whether the translated English scales will behave properly and used the results to fine-tune the items so as to ensure their suitability and relevance to the Chinese employee sample recruited for Study 2. Overall, these measures 
demonstrated acceptable content validity, translation equivalence, and internal consistency. 
Table 5-4.

Internal Consistency Coefficients (Cronbachs’ Alphas) for All Translated Scales Except the Work-value Scale in Published Study Conducted in China, and Pilot Test and Hypothesis-testing Study of the Dissertation Research

\begin{tabular}{|c|c|c|c|c|}
\hline \multirow[b]{2}{*}{ Name of Scale } & \multirow[b]{2}{*}{ Number of Items } & \multicolumn{3}{|c|}{ Cronbach's Alpha } \\
\hline & & $\begin{array}{l}\text { For Published Study } \\
\text { Conducted in China }\end{array}$ & $\begin{array}{l}\text { For Pilot Test } \\
\text { (Study1) }\end{array}$ & $\begin{array}{c}\text { For Hypothesis- } \\
\text { Testing Study } \\
\text { (Study2) }\end{array}$ \\
\hline 1. Job satisfaction (JS) & 3 & $0.75^{b}$ & 0.77 & $0.94^{\mathrm{a}}$ \\
\hline 2. Turnover intention (TI) & 3 & $0.60^{\mathrm{c}}$ & 0.89 & 0.67 \\
\hline 3. Organizational commitment (OC) & 6 & $0.91^{d}$ & N/A & 0.86 \\
\hline $\begin{array}{l}\text { 4. Perceived organizational support } \\
\text { (POS) }\end{array}$ & 8 & $0.84^{\mathrm{e}}$ & 0.86 & 0.82 \\
\hline 5. Leader-member exchange (LMX) & 7 & $0.82^{f}$ & 0.94 & 0.91 \\
\hline
\end{tabular}

\section{NOTE.}

a: The one reverse-score item in the original job-satisfaction scale was revised for the hypothesis-testing study (Study 2).

b: Song, Wanberg, Niu, \& Xie (2006)

c: Hui, Wong, \& Tjosvold (2007)

d: Francesco \& Chen (2004)

e: Farh, Hackett, \& Liang (2007)

f: Aryee \& Chen (2006) 


\section{CHAPTER VI}

\section{STUDY 2: HYPOTHESES TESTING}

\section{Participants and the Sampling Setting}

The final sample for testing the integrated research model (Figure 3-1) consisted of 179 Chinese employees recruited from three privately-owned small and medium enterprises (SMEs) B, C, and D, located in the Yantze River Delta of China. These hightech companies are within varying industries such as machinery manufacturing, IT service, and polymer and chemical industry. The sample of organizations were selected and invited to participate in this study for the following reasons. First, China’s private sector is said to generate over 70\% of China’s overall GDP (Nee \& Opper, 2012) and it has obtained a dominant position in the labor market, offering almost $80 \%$ of total urban employment according to the recent China Statistical Yearbook (Li, Li, Wu \& Xiong, 2012).

Second, Yantze River Delta has long been recognized as the most economically vibrant and dynamic region in China. Although large numbers of talents with high-caliber abilities and skills usually flock to this region seeking employment and career success (Simon \& Cao, 2009), the gravity of an acute shortage of talent has grown more renowned as firms are seeking after the same talent pool (Cooke, Saini \& Wang, 2014; Hartmann, Feisel \& Schober, 2010; Li \& Sheldon, 2010; Manpower, 2013). The previous interviews with the key managers from the SMEs also revealed that "job-hopping frenzy" (Cooke et al., 2014, p. 233) among the young employees with age ranging early 20s-late 30s years has become the greatest concern for them, attesting to these HR challenges identified in the literature above. Further, these SMEs in this region were selected 
because the workforce employed by them is predominantly composed of young workers of this age group that matches the focus of research priority for this study.

Third, when compared with state-owned enterprises (SOEs), private SMEs in China are relatively less constrained by restrictions imposed by the government for political and social-stability considerations (Ding \& Warner, 1999), and thus have more discretion in adopting best HR practices (Zheng, Morrison, \& O’Neil, 2006). As such, there are most likely to be meaningful and systematic variations—among the SMEs in regards to organizational contexts and thus each individual employee's experience on the job— so that allow us to detect the proposed effects of the organizational interventions on the associations between employee P-O fit and outcomes.

\section{Data Collection Procedures}

The three private small and medium-sized enterprises B, C, and D were among the initial four companies that were contacted through my personal contacts. Upon receiving positive confirmation either through email or text messages in Chinese, I started to schedule appointments with key managers and personnel directors of all the three companies. I then had individual face-to-face meetings with the managers during my first visits to the three companies. The main purpose of the first round of trips is to explain the research objectives and the process of the study with an emphasis on the potential benefits to them. I also used this opportunity to gain a better understanding of the three companies, establish a good interpersonal relationship (guanxi) with them, and pave the way for subsequent research collaborations. As noted by Chen, Hui, and Sego (1998), the presence of researchers is generally recommended to improve the quality of data collected within Chinese organizations and solicit true responses from participants. 
Therefore, the three companies were also invited to provide feedback on the provisional work-value scale in the subsequent face-to-face interviews-a crucial part of the pilot test of Study 1 discussed in Chapter 5.

Based on the results from Study 1 and feedback from the companies revisions were made to finalize the questionnaire following the pilot test. From the feedback, I learned that many employee respondents expressed their preferences for completing a mobile version of the survey, that is, they would be more willing to participate in the survey research if they are allowed to complete the questionnaire on their smart phones via internet. This is understandable given that internet surfing on mobile phone is widely popular with young people who grew up with the internet (Faure \& Fang, 2008; Leung, Bhagat, Buchan, Erez \& Gibson, 2005). In addition, internet-based survey administration has also gained increased legitimacy in organizational research (e.g., Tyler \& Blader, 2005; Weigold, Weigold \& Russell, 2013) for its flexibility and cost-effectiveness in reaching the target population. More importantly, the findings from recent large-scale studies have indicated that data gathered through either paper-pencil or internet methods are generally equivalent in measurement; thus, pooling data obtained using both administration modes is warranted (De Beuckelaer \& Lievens, 2009; Weigold et al., 2013). Therefore, I created a mobile-version of the finalized questionnaire in responding to this suggestion.

During the data collection of Study 2, the three organizations were allowed to choose between an online and a paper-pencil version of the survey to complete based on their preferences. A total of 313 questionnaires were distributed either online or in paperpencil format to respondents with assistance from the three companies' human resource 
staffs. Respondents were asked to anonymously and voluntarily fill out the questionnaire. For encouraging respondents to provide true answers while soliciting their maximum participation I also added a cover page briefly explaining research objectives and assuring the complete confidentiality of their answers. The one hundred completed paper-pencil surveys all came from Company D with about 700 employees. Additionally, 40 and 42 completed online surveys were respectively from the other two companies with about 200 employees each, who preferred to complete the internet-based survey. Following the above suggestion of De Beuckelaer and Lievens (2009), the three data sets obtained from the three organizations were combined, resulting in a combined 182 surveys with a 57.2\% response rate. However, three returned online surveys were deemed unusable due to an obvious response bias in the answers and hence were removed.

As robustness check in justifying the pooling of the three separate samples gathered from three research sites, I performed a Chow test (Chow, 1960) following Tsai (2001). More specifically, I conducted a one-factor (organizations) analysis of variance (ANOVA) test to detect whether there were significant differences across the three groups of employees with regard to their P-O fit score, the single independent variable in the integrative model (Figure 3-1). The results of ANOVA test suggested that there were no statistically significant differences between the three group means of P-O fit—whose operationalization will be explained in detail in the following section—at the $p<0.05$ level $\left(F_{(2,176)}=1.943, p=0.146\right)$. In light of the discussion above, I pooled the remaining 179 questionnaires for subsequent hypothesis testing. 


\section{Measures}

I pretested measures (see Chapter 5) in a pilot sample of 48 employees from various ranks recruited from company A, and modified items on the basis of the pilot test and comments from the key managers. In particular, three major modifications were made to adapt the original pilot survey. These changes or modifications are related to the operationalizations (Table 1-2) of the following key constructs that are also shown in the integrative model (Figure 3-1):

Person-organization fit (P-O fit)

In order to capture the concept of person-organization fit, I added to the final questionnaire another section of the same 18 work-value items right after the work-value scale. Different from the work-value scale used mainly to gauge employees’ perceived importance of the related work aspects, this additional section of items was to survey the respondents in regards to their perception of the true experience on the job using a 5point Likert scale with values ranging from 1 (never had such experience) to 5 (always had such experience) (see Appendix A). Similarly, the 18 items were classified into two work-value dimensions_extrinsic work values and intrinsic work values.

Following Joshi, Kathuria, and Porth (2003), the person-organization fit score was obtained by carrying out the next two steps (see also Table 1-2):

(1) P-O misfit score (as Euclidean Distance) for one given employee was computed using the following formula:

P-O misfit = SQRT [(extrinsic work values (ideal)-extrinsic work values $(\text { experienced) })^{2}+($ intrinsic work values (ideal)-intrinsic work values $($ experienced $\left.))^{2}\right]$ 
(2) P-O fit score for one given employee was calculated using the following formula:

$\mathrm{P}-\mathrm{O}$ fit $=$ (maximum $\mathrm{P}-\mathrm{O}$ misfit from the sample $-\mathrm{P}-\mathrm{O}$ misfit of one given employee) +0.01

Like Joshi and her colleagues (2003), a small constant of 0.01 was added to the equation above so as to avoid zero scores for P-O fit because the Standard Statistical Package for the Social Sciences (SPSS) would treat zero scores as missing values. Moreover, "adding a constant to a variable neither changes the variability in the data nor the regression results” (Joshi et al., 2003, p. 368). As such, the statistical conclusions drawn from the subsequent analyses regarding the underlying pattern of associations among the variables will be unaffected.

Job satisfaction

The one reverse-score item used in the pilot test to measure overall job satisfaction, “In general, I don't like my job.” was reworded to balance the number of the positively- and negatively- worded items based on the comments by the bi-lingual management professor as well as the managers of Company B and D. Such suggestion is particularly meaningful in the China context because too many reverse-score items may increase Chinese subjects' confusion and thus be problematic, likely leading to reduced reliability of the measure of interest due to the dominant cultural emphasis on maintaining social harmony in the Chinese society (Fan, 2000; Taormina, 2013).

With the revised scale, the value of Cronbach's alpha was increased to 0.94 compared to 0.77 for the original job-satisfaction scale used in the pilot test. 


\section{Organizational Commitment}

Based on the HR managers' comments after the pilot test, I learned that low levels of organizational commitment of young employees is another major concern for organizations today, which was not measured by the pilot questionnaire. Furthermore, the affective aspect of organizational commitment was found to be both conceptually and empirically distinct from job satisfaction and turnover intention (Brooke, Russell \& Price, 1989; Tett \& Meyer, 1993), and the mechanisms through which person-organization fit (P-O fit) can impact these three outcome variables may be quite distinct from each other as well. With the above considerations in mind, items to measure organizational commitment were added to the final survey used for the main study (Study 2).

Specifically, a six-item scale, originally developed by Meyer, Allen, and Smith (1993) was employed to measure affective commitment. Respondents were asked to indicate their level of agreement with each of the six statements using 7-point scale with values ranging from (1) strongly disagree to (7) strongly agree. Two of the six items were reverse-scored, similar to the original scale. Sample items were, "I really feel as if this organization’s problems are my own” and “I don’t feel a strong sense of belonging to my organization” (reverse-scored). The same measure was previously translated and used in the China text (Francesco \& Chen, 2004) with a reported scale’s reliability of 0.91.

In all, except for these changes, all other measurement scales included in the final survey were the same with those used in the pilot test (see Appendices for all the instruments included in Study 2). These revisions discussed above were deemed appropriate and necessary to ensure that the final questionnaire was suitable for the sample of Chinese employees described below. 


\section{Control Variables}

At the end of the survey, employees were also asked to provide their demographic information including gender, education, job position, age, and tenure (see Appendix D).

\section{Sample}

The sample for Study 2 was comprised of 179 Chinese workers. Of them, 96 were male (53.6\%) and 83 were female (46.4\%), with males being coded as 1 and females as 2 . Their average tenure with their organizations was 6.6 years $(S D=4.8)$. Participants in my sample were employed in varied job categories, and $4.5 \%$ of the respondents were firstline employees, $21.8 \%$ were technicians, $33.5 \%$ were low-level managers, $31.8 \%$ were middle-level managers, and 7.3\% were high-level managers. Job position was coded as 1 for first-line employee, 2 for technician, 3 for low-level manager, 4 for middle-level manager, and 5 for high-level manager. An overwhelmingly majority of the respondents received university degree or above (92.7\%) and 6.1\% received associate degree. The respondents were also asked to provide their year of birth, from which I computed their age (i.e., 2015 minus year of birth). I then classified them into the two generational cohorts (i.e., 21-33 years as Millennials and 34-48 years as Social-Reform cohort) based on the adapted Yi et al.’s (2010) Chinese generational classification scheme (see Table 32). It should be noted that the eldest employees in the 34-48 years are in their early 40s. 74 respondents (41.3\%) reported their ages in the 21-33 years category and 105 respondents (58.7\%) in the 34-48 years category. The demographic characteristics of the participants in Study 2 are presented in Table 6-1. These five demographic attributes were included as control variables in all subsequent multiple regression analyses because 
they were found to be correlated with job satisfaction (e.g., Brush, Moch \& Pooyan, 2007;

Kuo \& Chen, 2004), organizational commitment (e.g., Billingsley \& Cross, 1992;

Luthans, Baack \& Taylor, 1987; Steers, 1977), and turnover intention (e.g., Arnold \&

Feldman, 1982).

Table 6-1.

Demographic Profile of Employee Participants in Study $2(N=179)$

\begin{tabular}{ccc}
\hline Demographic Characteristics & Frequency (N) & Percentage \\
\hline Gender & \\
Male & & \\
Female & 96 & $53.6 \%$ \\
Education & 83 & $46.4 \%$ \\
Elementary & & \\
Middle School & 0 & $0 \%$ \\
High School & 0 & $0 \%$ \\
College (2-3 years) & 0 & $0 \%$ \\
University or above & 11 & $6.1 \%$ \\
& 166 & $92.7 \%$ \\
Position & & \\
First-Line Employee & 8 & $4.5 \%$ \\
Technician & 39 & $21.8 \%$ \\
Low-Level Manager & 60 & $33.5 \%$ \\
Middle-Level Manager & 57 & $31.8 \%$ \\
High-Level Manager & 13 & $7.3 \%$ \\
Age & & \\
21-33 (Millennials) & 74 & $41.3 \%$ \\
34-48 (Social Reform) & 105 & $58.7 \%$ \\
Tenure & & 4.47 years (SD) \\
\hline
\end{tabular}

Note.

${ }^{\text {a }}$ Males were coded 1 and Females were coded 2.

\section{Analyses}

In this section, the statistical procedures to analyze the data will be discussed in detail. Specifically, I will organize the following discussion around the four research questions and carefully match research questions with appropriate analytical techniques. 
The purpose of this dissertation is to explore two sets of research questions that focus on (1) comparing identified work values across generations; (2) uncovering the mechanisms through which P-O fit can be linked to various employee work outcomes.

\section{Comparisons of Work Values Between Generations}

As noted previously in Chapter 1 , the first research question involved identifying those specific aspects of work that are commonly valued by the Chinese employees from the two young generations. The second research question focused on whether significant generational differences existed with regards to their perceived importance of work values. The following analyses were undertaken to address these two research questions. For the first question of the dissertation research, I ran a principal-component factor analysis with oblique rotation by fixing the number of factors to two based on the factoring results from the previous pilot test. Examination of the factor-loading patterns allowed me to determine if there was a stable two-factor structure underlying the 18 work-value items.

In order for me to address research question two and the first set of hypotheses, mean scores for each of the 18 work-value items were computed. In addition, the two aggregate mean scores for each of the two subscales representing extrinsic and intrinsic work values were also calculated. Next, one-way (generations) multivariate analysis of variance (MANOVA) was conducted to determine if the importance scores (dependent variables) on various work values differed significantly between the two age groups. MANOVA was chosen for the multivariate nature of the second research question that involved testing a set of dependent variables. Further, MANOVA should be the method 
of choice also because of its power to detect differences across groups on a number of dependent variables (i.e., work values) even when there is strong correlation among them (Tabachnick \& Fidell, 2007; Grice \& Iwasaki, 2007). In all, comparisons using one-way MANOVA would allow me to examine the differences between the two generation groups regarding their preferences for the work values.

\section{Exploration of the P-O Fit Processes}

Research questions three and four were related to the second overarching objective of the dissertation: to delineate the mechanisms linking person-organization fit to employee work outcomes, including job satisfaction, organizational commitment, and turnover intention.

Multiple regression analysis is a statistical tool that is widely applied in behavioral and organizational science research to test hypothesized linkages among a set of variables (Cohen, Cohen, West \& Aiken, 2003). In this study I conducted a series of hierarchical regression analyses to test the proposed moderated mediation model (Figure 3-1) while controlling for demographics. More specifically, I examined the processes whereby the social exchange relationships developed with leaders and organizations may influence the relationships between employee P-O fit and work outcomes. Next, I will break down the integrative model and discuss various analytical procedures used for testing each hypothesis.

For the second set of Hypotheses 2a through 2c, the main effects of P-O fit on the work-related outcomes were tested using hierarchical regressions. Independent variables 
were entered into the analysis sequentially in two blocks. That is, the demographics as control variables were entered in the first block and then the single independent variable of P-O fit was entered in the second block. The significance level of the beta weight coefficient was used to determine if P-O fit was a significant predictor of each workrelated outcome after demographics were being controlled for. In addition, the changes in both the population coefficient of determination $\left(\rho^{2}\right)$ and the coefficient of crossvalidation $\left(\rho_{c}^{2}\right)$ (Kromrey \& Hines, 1995; cited in Cascio \& Aguinis, 2011) between these two steps were traced to determine how much variation in each of the three response variables can be attributed to P-O fit. Although both can be used as empirical estimates of shrinkage, there is important but often ignored distinction between these two parameters: "[The $\left.\rho^{2}\right]$ is typically of interest in explanatory research, in which the purpose is to estimate the strength of relationship between a set of regressor variables and a dependent variable... In contrast, $\rho_{c}^{2} \ldots$ is of interest in predictive research, in which the purpose is to estimate the effectiveness of a specific prediction equation when the equation is applied to data other than those in which the equation is derived.” (Kromrey \& Hines, 1995, p. 902 italic added by the author). Such failure to recognize the difference has given rise to confusion and critical misuse of one over the other in the literature-in particular, the $\rho^{2}$, commonly known as the adjusted multiple squared correlation coefficients (adjusted $\mathrm{R}^{2}$ ) was exclusively reported in most management literature irrespective of the preconceived purpose of a corresponding study. Given the dualemphasis nature of the present study—both explanatory and predictive in nature-I calculated and reported the $\rho_{c}{ }^{2}$ (cross-validation $\mathrm{R}^{2}$ ) for prediction optimization using the 
following formula (Browne, 1975; cited in Cascio \& Aguinis, 2011) besides the commonly reported adjusted $\mathrm{R}^{2}$.

$$
\rho_{\mathrm{c}}^{2}=\frac{(\mathrm{N}-\mathrm{k}-3) \rho^{4}+\rho^{2}}{(\mathrm{~N}-2 \mathrm{k}-2) \rho^{2}+\mathrm{k}}
$$

Where $\mathrm{N}$ is the sample size (i.e., the number of employee respondents in my study)

$\mathrm{k}$ is the number of predictor variables available for a regression equation;

$\rho^{2}$ is the population squared multiple correlation coefficient (the adjusted $R^{2}$ ) on $k$ predictors.

The next focus of this study was to empirically examine the hypothesized moderated mediation model. In order to achieve this objective, I followed the same procedures as outlined by Cole, Walter, and Bruch (2008) to test the hypotheses in two sequential processes, Process 1 and Process 2, using an SPSS macro, developed by Preacher and Hayes. The proposed mediation effects of POS were tested in Process 1 (Hypotheses 3a through 3c). In Process 2, I entered LMX as a moderator variable into the mediation model (Hypothesis 4a through 4c) and investigated a set of integrative moderated mediation hypotheses (Hypotheses 5a through 5c). To reduce concerns about multicollinearity (the high correlations among predictor variables including the interaction terms) and to better interpret results, I mean-centered the predictor variables prior to calculating the cross-product terms used in the analyses (Aiken, West \& Reno, 1991; Cole et al., 2008; Zhou, Shin, Brass, Choi, \& Zhang, 2009;). The analytical procedures are described as follows: 


\section{(1) Process 1: Tests of Simple Mediations}

Baron and Kenny’s (1986) multi-step approach is one of the most popular methods among researchers to testing mediation. The simple mediation model is illustrated in Figure 6-2. Essentially, Baron and Kenny’s approach is built on a series of multiple regression analyses and mediation effect is evaluated based on regression coefficients. Despite its popularity, several aspects of this approach have recently received much criticism (e.g., Hayes, 2009; Shrout \& Bolger, 2002). For example, as suggested by Hayes (2009), this approach was found to be “among the lowest in power” to detect mediation effects (or indirect effects) because it involves multiple hypothesis tests along the steps and thus could increase the "possibility of a decision error" (Hayes, 2009, pp. 410-411).

For simplicity and to clarify the confusions, a number of methodologists (Hayes, 2009; Zhao, Lynch \& Chen, 2010) have claimed that the key requirement for establishing mediation is to examine the indirect effect (i.e., $a \times b$, the cross-product of coefficient $a$ and $b$ ) (see the footnote in Figure 6-2); that is, to statistically determine whether it is significantly different from zero or not. In addition, to tackle the shortcomings of Baron and Kenny approach and for easy implementation, the use of SPSS macro has been recommended by many researchers (e.g., Preacher \& Hayes, 2008; Valeri \& VanderWeele, 2013; Zhao et al., 2010). This SPSS macro approach allows a researcher to probe mediation models by bootstrapping confidence intervals (CIs) of the indirect effect itself and thus facilitates easy interpretation of results (Cole et al., 2008; Hayes, 2015). 
Figure 6-2*.

The Total Effect Model and Simple Mediation Model
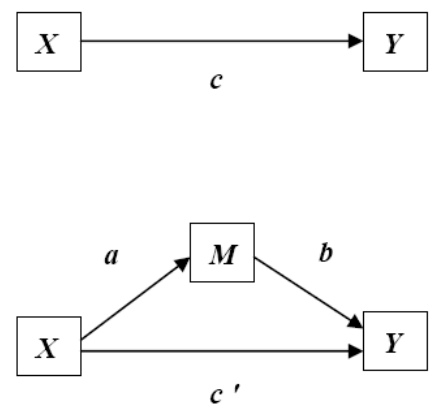

\section{NOTE.}

*: adapted from Hayes, 2009, p. 409.

$\mathrm{X}$ : independent variable.

Y: dependent variable.

M: mediator variable.

a: The coefficient for the regression of $\mathrm{M}$ on $\mathrm{X}$.

$b$ : The coefficient for the regression of $\mathrm{Y}$ on $\mathrm{M}$.

c: The coefficient for the regression of $\mathrm{Y}$ on $\mathrm{X}$ without considering $\mathrm{M}$ (the total effect).

$c$ ': The coefficient for the regression of $\mathrm{Y}$ on $\mathrm{X}$ with $\mathrm{M}$ being controlled for (the direct effect).

$a b$ : The coefficient of the indirect effect (Algebraically, $c=c^{\prime}+a b$ )

(2) Process 2: Tests of Moderated Mediations

As noted by Muller, Judd, and Yzerbyt (2005, p. 854), moderated mediation refers to "a treatment effect is mediated differently as a function of some moderator variable”. It has also been termed conditional indirect effect because the mediation effect is "potentially conditional on the value of one or more moderators" (Preacher, Rucker \& 
Hayes, 2007, p. 215). Regarding moderated mediation hypotheses for this study, I predicted that the strength of the mediation effects changes depending on the level of the moderator, namely, the perceived leader-member exchange quality (LMX) (integrated Hypotheses 5a through 5c). Following Cole and his colleagues (2008), I also employed an SPSS macro for testing the integrated hypotheses in combination with the moderation hypotheses (Hypotheses 4a through 4c). According to Edwards and Lambert (2007) and Hayes (2015) the moderated mediation effects proposed for this study can be conceptualized as the second stage moderation model, as illustrated in Figure 6-3.

Figure 6-3*.

The Conceptual Model for the Second Stage Moderation Model

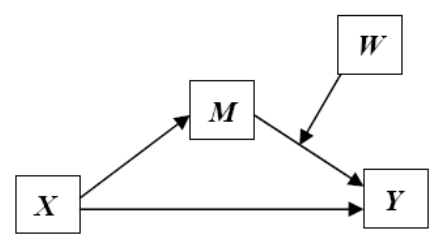

\section{NOTE.}

*: adapted from Edwards \& Lambert, 2007, p. 4 and Hayes, 2015, p. 4

X: independent variable; Y: dependent variable; M: mediator variable; W: second-stage moderator variable.

In sum, this chapter details data gathering, measurement design, and analytical techniques for empirically testing the specific hypotheses proposed in this dissertation. This overview also serves as a guide to presenting the research findings in Chapter 7 and discussion in Chapter 8. 


\section{CHAPTER VII}

\section{RESEARCH FINDINGS}

In this chapter, I will present the findings from the statistical analysis of the gathered data. This chapter is organized as follows. First, I will report the descriptive statistics and correlations among all the variables examined in the main hypothesistesting study. In addition, the results of internal consistency reliability of the studied constructs will also be discussed. Second, the findings from factor analysis of the workvalue scale will be described. Lastly, I will present the rest of the results in light of the four specific research questions raised in Chapter 1.

\section{Descriptive Statistics and Correlation Matrix}

Table 7-1 presents the means, standard deviations, and intercorrelations for all the study variables and control variables included in the present study.

Prior to further analyses, the relationships among the study variables were assessed using Pearson’s correlation. Specifically, as expected, age was positively related to job position $(r=0.24, p<0.01)$ and tenure $(r=0.65, p<0.01)$, education level was positively related to job position $(r=0.16, p<0.05)$, and gender $($ Male $=1$, Female $=2)$ was negatively related to job position $(r=-0.17, p<0.05)$. Regarding the correlations between demographics (control variables) and the key variables of interest, age was positively related to P-O fit $(r=0.16, \mathrm{p}<0.05)$, LMX $(r=0.19, p<0.05)$, job satisfaction $(r=0.25, p<0.01)$, and organizational commitment $(r=0.20, p<0.01)$; position was positively related to LMX ( $r=0.22, p<0.01)$, POS $(r=0.30, p<0.01)$, job satisfaction ( $r=0.27, p<0.01)$, and organizational commitment $(r=0.26, p<0.01)$; in addition, tenure was positively related to both job satisfaction $(r=0.16, p<0.05)$ and 
organizational commitment $(r=0.22, p<0.01)$. These correlations appeared to match what have been posited.

Next, I also conducted an initial assessment of the correlations among the key variables pertaining to the hypotheses. As expected, all of them were significantly correlated with each other in the posited directions $(p<0.05)$. For example, personorganization fit was positively related to LMX $(r=0.18, p<0.05)$ job satisfaction $(r=$ $0.38, p<0.01)$ and organizational commitment $(r=0.25, p<0.01)$, and negatively related to turnover intention $(r=-0.23, p<0.01)$. Overall, all the correlations were consistent with the predicted P-O fit-work outcome relationship.

Finally, as shown in table 7-1, the instruments to measure the main variables showed an adequate degree of internal consistency of reliability, well exceeding the commonly accepted threshold of 0.7 — with the only slight exception of turnover intention at 0.67. Moreover, a comparison with previously reported values of Cronbach's alpha in the China context also suggested that the measures in the present study yielded comparable or even better scores of internal consistency (see Table 5-4).

\section{Factor Analysis of Work-value Scale}

The principal-component analysis with a specified number of leading components resulted in an interpretable and parsimonious two-factor structure, with the 18 work values evenly representing distinctly extrinsic work values (9 items) and intrinsic work values (9 items). Specifically, factor loadings of each item on each of the two factors exceeded 0.50 (ranging from 0.50 to 0.85 ), indicating reasonably high correlations between the two leading factors and their individual items. I also performed additional analyses to assess the quality of the work-value scale. Kaiser-Meyer-Olkin 
Table 7-1.

Descriptive Statistics: Mean, Standard Deviation, Reliability, and Correlations for All Studied variables ${ }^{a}$

\begin{tabular}{|c|c|c|c|c|c|c|c|c|c|c|c|c|c|}
\hline Variables & Mean & S.D. & 1 & 2 & 3 & 4 & 5 & 6 & 7 & 8 & 9 & 10 & 11 \\
\hline 1. Gender ${ }^{\mathrm{b}}$ & 1.46 & 0.50 & - & & & & & & & & & & \\
\hline 2. Age & 32.75 & 5.38 & -0.14 & - & & & & & & & & & \\
\hline 3. Education & 4.94 & 0.24 & -0.04 & -0.03 & - & & & & & & & & \\
\hline 4. Position & 3.16 & 0.10 & $-0.17^{*}$ & $0.24 * *$ & $0.16^{*}$ & - & & & & & & & \\
\hline 5. Tenure & 6.61 & 4.77 & -0.12 & $0.65^{* *}$ & -0.01 & 0.10 & - & & & & & & \\
\hline 6. P-O fit & 3.82 & 0.78 & 0.01 & $0.16^{*}$ & 0.02 & 0.03 & 0.07 & - & & & & & \\
\hline 7. Leader-member exchange & 4.67 & 1.13 & -0.12 & $0.19^{*}$ & -0.13 & $0.22 * *$ & 0.13 & $0.18 *$ & $(0.91)$ & & & & \\
\hline 9. Job Satisfaction & 4.25 & 1.34 & -0.08 & $0.25 * *$ & 0.01 & $0.27 * *$ & $0.16^{*}$ & $0.38 * *$ & $0.46^{* *}$ & $0.53 * *$ & $(0.94)$ & & \\
\hline 10. Organizational commitment & 4.38 & 1.18 & -0.09 & $0.20 * *$ & -0.07 & $0.26 * *$ & $0.22 * *$ & $0.25 * *$ & $0.53 * *$ & $0.60 * *$ & $0.69 * *$ & $(0.86)$ & \\
\hline 11. Turnover intention & 3.59 & 1.24 & 0.10 & -0.10 & -0.002 & -0.24 & -0.13 & $-0.23 * *$ & $-0.43^{* *}$ & $-0.52 * *$ & $-0.70^{* *}$ & $-0.64 * *$ & $(0.67)$ \\
\hline
\end{tabular}

NOTE.

${ }^{a}$ Cronbach’s alpha values as reliability estimates are in parentheses. Statistical Significance: ${ }^{*} p<0.05$, ${ }^{* *} p<0.01$, two-tailed tests with pairwise deletion.

${ }^{\mathrm{b}}$ Males were coded 1 and Females were coded 2. 
(KMO) test $(0.85)$ and the Bartlett's test $\left(\chi^{2}=1438.45, p=0.000\right)$ were both considered acceptable (Kaiser, 1974; Bartlett, 1954). The two subscales of work values showed adequate internal consistency for extrinsic work values (Cronbach’s alpha $=0.88$ ) and intrinsic work values (Cronbach’s alpha $=0.82$ ). Furthermore, the results also suggested that the two-factor model cumulatively explained $47.2 \%$ of the total variance. In addition, these results were consistent with the findings of the pilot study and displayed acceptable measurement properties. The output of factor analysis are presented in Table 7-2.

\section{Results Organized Around Research Questions}

Research Question 1 and 2

The first two research questions asked in this study were: 1) What are the work values that are important to Chinese employees of the two younger generations? 2) Do those identified work values differ significantly between the two younger generations in China?

In the Chinese employee sample, there is no member from the most senior generation at work (born before 1966, Cultural-Revolution generation). Such age structure of the workforce is consistent with the depiction by the key managers in the four companies—quick shift to the dominance of younger workers from the Social-Reform generation and the Millennials generation in Chinese SMEs.

To compare the workers from the two generational cohorts with respect to work values, a one-way (generation cohort) MANOVA was performed between the 18 work values as well as the aggregated extrinsic and intrinsic work values as dependent variables. The complete results of MANOVA are summarized and given in Table 7-3. All 
Table 7-2.

Factor Loadings From Principal Component Analysis with Oblimin Rotation (Study 2)

\begin{tabular}{|c|c|c|c|c|}
\hline Chinese Employee Value Items & Mean & S.D. & $\begin{array}{l}\text { Cronbach's } \\
\text { Alpha }\end{array}$ & $\begin{array}{l}\text { Factor } \\
\text { Loading }\end{array}$ \\
\hline Extrinsic Work Values & 3.54 & 0.73 & 0.88 & \\
\hline $\begin{array}{l}\text { 1. offers perks such as free meals, housing and } \\
\text { transportation allowance }\end{array}$ & & & & 0.50 \\
\hline 2. permits a balanced lifestyle & & & & 0.72 \\
\hline 3. permits a regular routine in time and place of work & & & & 0.71 \\
\hline $\begin{array}{l}\text { 4. permits an accommodation of family } \\
\text { responsibilities }\end{array}$ & & & & 0.74 \\
\hline $\begin{array}{l}\text { 5. the company is close to home or conveniently } \\
\text { located }\end{array}$ & & & & 0.78 \\
\hline 6. provides ample leisure time off the job & & & & 0.85 \\
\hline 7. provides a comfortable work environment & & & & 0.65 \\
\hline 8. provides job security & & & & 0.78 \\
\hline 9. provides the opportunity to earn a high income & & & & 0.63 \\
\hline
\end{tabular}




\section{Intrinsic Work Values}

10. working in a company with a good reputation

11. respected by others

12. involves working with congenial associates

13. makes a social contribution by the work you do

14. makes use of your specific educational background

15. provides a feeling of accomplishment

16. provides challenging tasks and projects

0.72

17. provides change and variety in duties and activities 
Table 7-3.

Mean Scores and Significant Differences on Work Values $(N=179)$

\begin{tabular}{|c|c|c|c|c|c|c|}
\hline & & & & & \multirow{2}{*}{$\begin{array}{c}\begin{array}{c}\text { Mean } \\
\text { Scores }^{\text {a }}\end{array} \\
\text { F-Value }\end{array}$} & \multirow{2}{*}{$\begin{array}{c}\begin{array}{c}\text { Significant } \\
\text { erences }\end{array} \\
\text { SR-M }\end{array}$} \\
\hline & $\mathrm{SR}^{\mathrm{b}}$ & SD & $\mathrm{M}^{\mathrm{b}}$ & SD & & \\
\hline & $\mathrm{N}=74$ & & $\mathrm{~N}=105$ & & & \\
\hline Extrinsic Work Values & 3.59 & 0.82 & 3.50 & 0.66 & 0.57 & NS \\
\hline 1. offers perks such free meal, housing and transportation allowance & 3.39 & 1.30 & 3.12 & 1.04 & 2.33 & NS \\
\hline 2. permits a balanced lifestyle & 3.93 & 0.98 & 4.00 & 0.84 & 0.24 & NS \\
\hline 3. permits a regular routine in time and place of work & 3.28 & 1.17 & 3.31 & 1.16 & 0.03 & NS \\
\hline 4. permits an accommodation of family responsibilities & 3.95 & 0.95 & 4.06 & 0.77 & 0.75 & NS \\
\hline 5. the company is close to home or conveniently located & 3.14 & 1.11 & 2.96 & 0.98 & 1.21 & NS \\
\hline 6. provides ample leisure time off the job & 3.36 & 1.08 & 3.38 & 1.08 & 0.01 & NS \\
\hline 7. provides a comfortable work environment & 3.38 & 1.08 & 3.15 & 1.02 & 2.03 & NS \\
\hline 8. provides job security & 3.78 & 1.09 & 3.70 & 0.89 & 0.29 & NS \\
\hline 9. provides the opportunity to earn a high income & 4.07 & 0.94 & 3.84 & 0.82 & 3.00 & NS \\
\hline Intrinsic Work Values & 3.51 & 0.67 & 3.57 & 0.63 & 0.31 & NS \\
\hline
\end{tabular}


10. working in a company with a good reputation

$\begin{array}{llllll}3.59 & 1.03 & 3.79 & 0.93 & 1.76 & \text { NS } \\ 4.09 & 0.85 & 4.16 & 0.81 & 0.29 & \text { NS } \\ 3.96 & 0.97 & 3.86 & 1.01 & 0.46 & \text { NS } \\ 3.23 & 1.18 & 3.43 & 1.03 & 1.44 & \text { NS } \\ 3.16 & 1.14 & 3.35 & 1.19 & 1.15 & \text { NS } \\ 4.08 & 0.93 & 4.10 & 0.80 & 0.01 & \text { NS } \\ 3.09 & 1.04 & 3.07 & 1.05 & 0.03 & \text { NS } \\ 3.12 & 0.99 & 3.03 & 1.06 & 0.35 & \text { NS } \\ 3.28 & 0.97 & 3.33 & 1.04 & 0.29 & \text { NS }\end{array}$

11. respected by others

12. involves working with congenial associates

13. makes a social contribution by the work you do

14. makes use of your specific educational background

15. provides a feeling of accomplishment

16. provides challenging tasks and projects

17. provides change and variety in duties and activities

18. requires originality and creativeness

3.28

\section{NOTE.}

a 5= Extremely important to me; 1= Not at all important to me.

${ }^{\mathrm{b}} \mathrm{M}=$ Generation of Millennials; SR = Generation of Social Reform

${ }^{\mathrm{c}} \mathrm{NS}=$ No significant difference. 
the importance scores for the aggregated work values range from 3.50 to 3.59 . For specific work values, it should be noted that both generations were found to rate as significantly important such work values as "respected by others”, “provides an opportunity to earn high income”, and “provides a feeling of accomplishment”. Given that all responses were made on a five-point Likert scale, the results indicated that most work-value items retained in the final instrument were rated as close to "significantly important” by all respondents. In all, the mean scores suggested that these work values were indeed deemed important to the Chinese workers from both generational cohorts.

To answer the second research question, work-value differences between the Social-Reform generation and Millennial generation were examined. The generationaldifference hypotheses predict that compared with the Social-Reform generation the Millennial generation will exhibit higher preference towards intrinsic work values that are closely tied to the work itself while scoring lower on the importance of rewards external to work. A one-way multivariate analysis of variance (MANOVA) revealed no significant difference between the two generations when all these work values were considered jointly (Wilk's $\left.\lambda=0.91, F_{(18,160)}, p=0.638\right)$. Following the MANOVA, a series of univariate F-tests were performed. The mean scores and standard deviations on each of the 18 work-value items are presented in Table 7-3. Based on the comparison of the specific work values and the two aggregate scores of extrinsic and intrinsic work values there were no statistically significant differences found between the two generations (see Table 7-3). Thus, the hypotheses that predicted significant differences between the two generations in respect to extrinsic and intrinsic work values were not empirically supported. 


\section{Research Question 3 and 4}

The second set of research questions were asked to guide my subsequent exploration of mechanisms for deciphering the work-value-based P-O fit processes, through which work values are linked to employee work attitudes and behaviors. Specifically, the two research questions were: 3) What is the relationship between P-O fit and work-related outcomes (i.e., job satisfaction, organizational commitment, and turnover intention) that are of interest to organizations in Chinese organizations? 4) What are the roles played by POS and LMX in influencing the linkages between P-O fit and work-related outcomes of interest to organizations?

For research question three and four, a series of hypotheses were tested using hierarchical regression analyses with the five demographics variables being controlled for. Table 7-4 presents a summary of the results for Hypotheses 2a, 2b, and 2c.

As Table 7-4 reveals, $\mathrm{P}-\mathrm{O}$ fit was a significant predictor for job satisfaction $(\beta=$ $0.35, p<0.001$ ), organizational commitment $(\beta=0.22, p<0.01$ ), and turnover intention $(\beta=-0.23, p<0.01)$. These results provided empirical support for the predicted main effects of P-O fit on the employee work outcomes after the demographic variables were controlled for. In addition, with the inclusion of the variable of P-O fit, the explained variance in job satisfaction, organizational commitment, and turnover intention rose by $12 \%, 5 \%$, and $5 \%$ respectively. These increases in $R^{2}$ were found to be all statistically significant, $\Delta F(1,170)=25.42, p<0.00001$ (Job Satisfaction), $\Delta F(1,169)=9.56, p<$ 0.01(organizational commitment), and $\Delta F(1,170)=10.18, p<0.01$ (turnover intention). Thus, support was found for the main effects of P-O fit (H2a, H2b, and H2c). 
Table 7-4.

Results of Hierarchical Regression Analysis with Job Satisfaction, Organizational Commitment, and Turnover Intention as Outcome Measures ${ }^{a}$

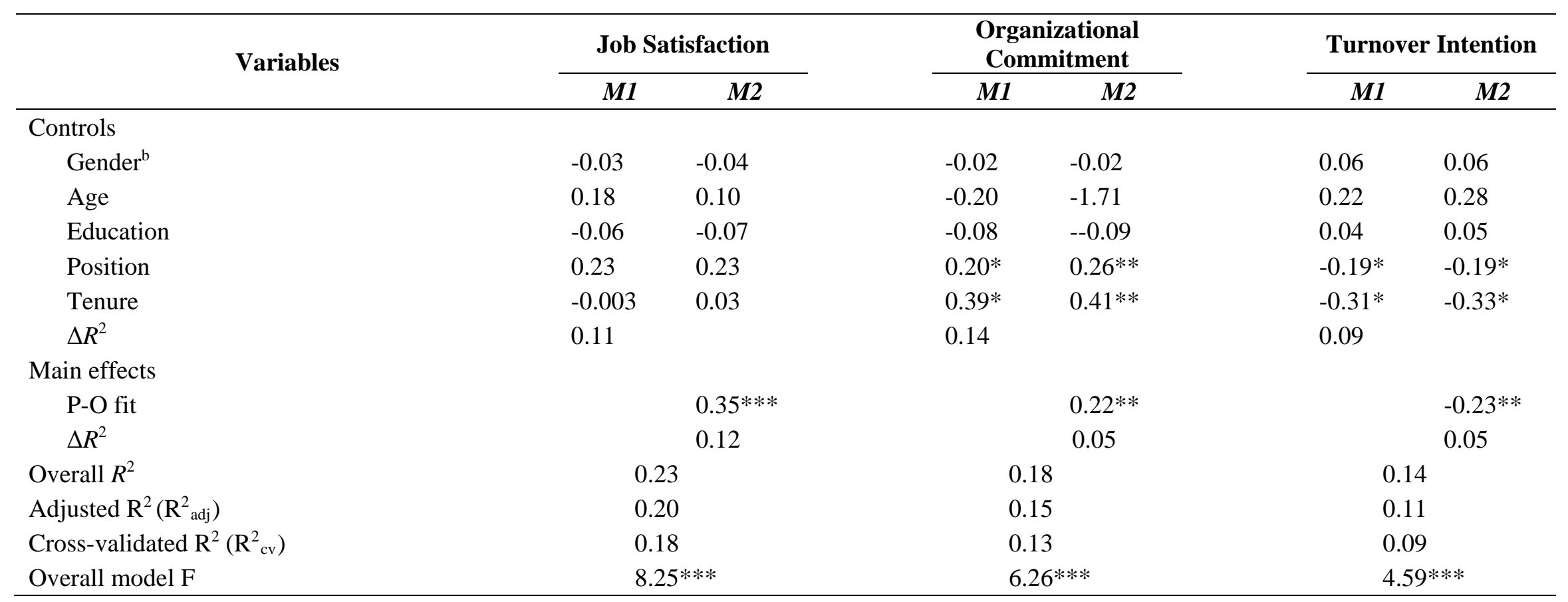

NOTE.

a Statistical Significance: $* p<0.05, * * p<0.01,{ }^{* * *} p<0.001$, two-tailed tests with pairwise deletion.

${ }^{\mathrm{b}}$ Males were coded 1 and Females were coded 2. 
For testing the proposed mediation effects, a series of regression analyses were performed using an SPSS macro created by Preacher and Hayes, while controlling for the five demographics variables. Figure 7-5 displays the complete estimates of the indirect effects of P-O fit on work outcomes through POS as the hypothesized mediator (Hypotheses 3a, 3b, and 3c). The SPSS macro output indicated that P-O fit was a significant predictor of POS $(B=0.39, t=4.62, p<0.001)$, and that POS was a significant predictor of job satisfaction $(B=0.64, t=6.58, p<0.001)$, organizational commitment $(B=0.93, t=9.04, p<0.001)$, and turnover intention $(B=-0.64, t=-6.72, p$ $<0.001)$. In addition, P-O fit's unstandardized regression weight coefficient on job satisfaction decreased after controlling for POS, although still remained statistically significant $(B=0.35, p<0.001)$, suggesting that the direct effect of P-O fit on job satisfaction was only partially transferred through POS—-that is, partial mediation according to Baron and Kenny (1986). In the similar vein, P-O fit was no longer a significant predictor for organizational commitment ( $B=0.05$, n.s.) and turnover intention $(B=-0.12$, n.s. $)$ after controlling for POS, suggesting full mediation in the sense that POS completely mediated the effects of P-O fit on both organizational commitment and turnover intention (Baron \& Kenny, 1986; Holmbeck, 1997). The results above provided support for the proposed mediation hypotheses. Finally, the indirect effects in the mediation models were further tested using a Bootstrap estimation approach with 5000 samples. The Bootstrap results also confirmed that the mediated effects of POS were statistically significant and had the predicted signs, job satisfaction path $(B=0.25$, $S E=0.07,95 \% \mathrm{CI}=0.11,0.37)$, organizational commitment path $(B=0.28, S E=0.07$, $95 \% \mathrm{CI}=0.13,0.40)$, and turnover intention path $(B=-0.25, S E=0.07,95 \% \mathrm{CI}=-0.38$, 
-0.11), which all did not include zero. Therefore, the three mediation Hypotheses 3a, 3b, and 3c were supported based on the results discussed above.

The complete results from testing the proposed interaction hypotheses are displayed in Table 7-6-1, 7-6-2, and 7-6-3. As for Hypotheses 4a, 4b, and 4c, I speculated that there is a positive interaction effect between POS and LMX on work-related outcomes, such that the relationship between POS and job satisfaction and organizational commitment is stronger when LMX quality is high rather than low, while the interaction effect is negative and significant for turnover intention. The statistical findings demonstrated that the interaction term between POS and LMX, represented by the product POS $\times$ LMX, was positive and statistically significant for both job satisfaction path $(B=0.19, t=2.91, p<0.01)$ and organizational commitment path, $B=0.16, t=3.01$, $p<0.01)$. However, the interaction term was not statistically significant for turnover intention path ( $B=-0.06, t=-0.98, n . s$.), although showing the predicted negative sign. Thus, Hypotheses 4a and 4b were supported but not Hypothesis 4c.

The findings obtained in testing the three proposed moderated mediation models are also summarized in Table 7-6-1, 7-6-2, and 7-6-3. As originally predicted, the mediation effects of POS on the connections of P-O fit, job satisfaction, and organizational commitment were conditional upon the level of LMX at one standard deviation above the mean, at the mean, and at one standard deviation below the mean. Specifically, for the job satisfaction path, the bootstrapped indirect effects varied from $0.21,0.14$, to 0.07 at the different levels of LMX mentioned above. Additionally, the bootstrapped index of conditional indirect effects also corroborated the expectation ( $B=$ $0.06, S E=0.03,95 \% \mathrm{CI}=0.02,0.13$ ), because zero didn't fall into the $95 \%$ confidence 
Figure 7-5.

The Indirect Effects of P-O Fit on Work Outcomes through POS
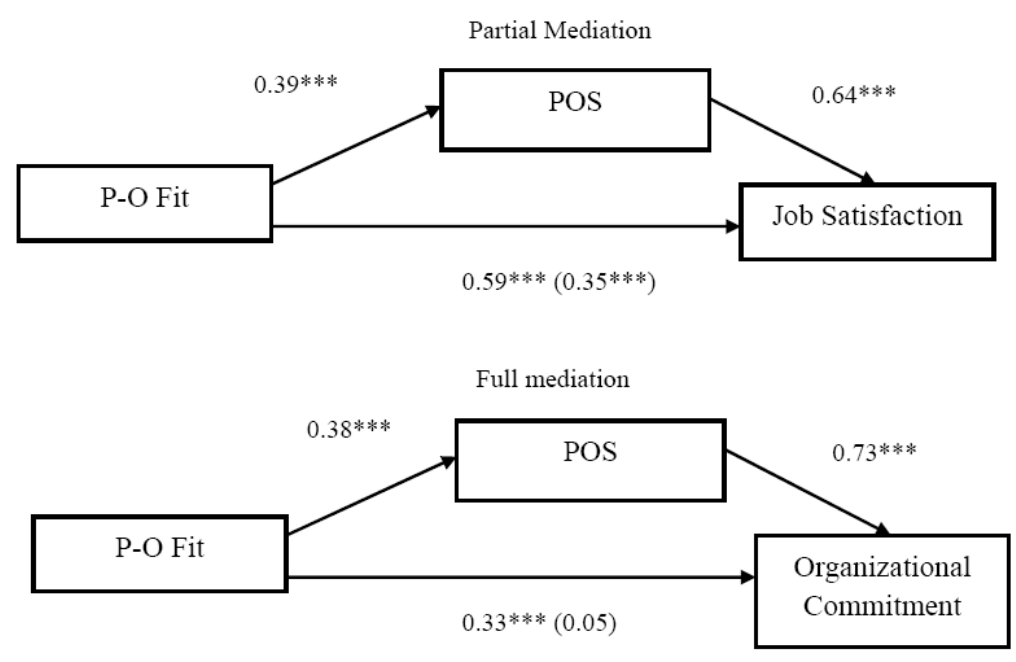

Full Mediation

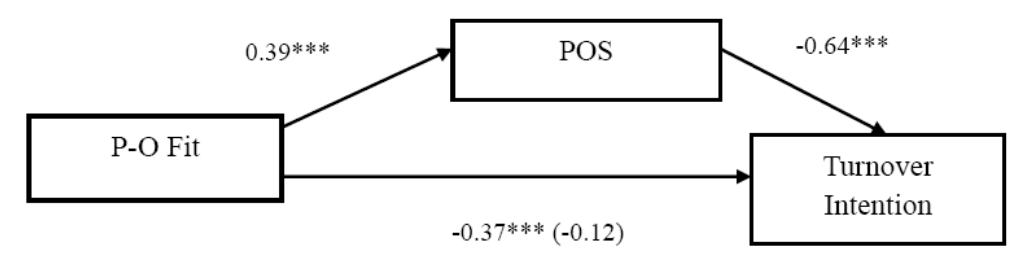

Note. ${ }^{*} p<.05,{ }^{* *} p<.01,{ }^{* * *} p<.001$; unstandardized regression weight coefficients from the output of an SPSS macro were shown; gender, age, education, job position, and tenure all have been controlled for in all mediation models above. 
Table 7-6-1.

Regression Results for Conditional Indirect Effect (Job Satisfaction as the Dependent Variable)

\begin{tabular}{|c|c|c|c|c|}
\hline Predictor & $B$ & SE & $t$ & $p$ \\
\hline & \multicolumn{4}{|l|}{ Job Satisfaction (JS) } \\
\hline Constant & 0.85 & 1.71 & 0.49 & 0.62 \\
\hline Person-organization fit (P-O fit) & 0.36 & 0.11 & 3.14 & 0.002 \\
\hline Perceived organizational support (POS) & 0.42 & 0.11 & 3.73 & 0.000 \\
\hline Leader-member exchange (LMX) & 0.31 & 0.09 & 3.37 & 0.000 \\
\hline \multirow[t]{2}{*}{ POS $\times$ LMX } & 0.19 & 0.06 & 2.91 & 0.004 \\
\hline & \multicolumn{4}{|c|}{ Perceived organizational support (POS) } \\
\hline Constant & 0.08 & 1.35 & 0.06 & 0.95 \\
\hline Person-organization fit (P-O fit) & 0.33 & 0.09 & 3.76 & 0.000 \\
\hline \multirow[t]{2}{*}{ Leader-member exchange (LMX) } & Boot indirect effect & Boot SE & Boot LL 95\%CI & Boot UL (95\%) CI \\
\hline & \multicolumn{4}{|c|}{ Conditional indirect effect at LMX $=M \pm 1 S D$} \\
\hline$-1 S D$ & 0.07 & 0.05 & -0.01 & 0.20 \\
\hline M & 0.14 & 0.05 & 0.06 & 0.27 \\
\hline $1 S D$ & 0.21 & 0.07 & 0.10 & 0.36 \\
\hline \multirow[t]{2}{*}{ Overall Index of Moderated Mediation } & Index & Boot SE & Boot LL 95\% CI & Boot UL 95\% CI \\
\hline & 0.06 & 0.03 & 0.02 & 0.13 \\
\hline
\end{tabular}

NOTE.

Unstandardized regression weight coefficients with all the five demographics being controlled for were reported. Bootstrap size $=$ 5000. LL = lower limit; UL = upper limit; CI = confidence interval. 
Table 7-6-2.

Regression Results for Conditional Indirect Effect (Organizational Commitment as the Dependent Variable)

\begin{tabular}{|c|c|c|c|c|}
\hline Predictor & $B$ & $S E$ & $t$ & $p$ \\
\hline & \multicolumn{4}{|c|}{ Organizational Commitment } \\
\hline Constant & 4.04 & 1.40 & 2.88 & 0.004 \\
\hline Person-organization fit (P-O fit) & 0.07 & 0.09 & 0.80 & 0.425 \\
\hline Perceived organizational support (POS) & 0.54 & 0.09 & 5.86 & 0.000 \\
\hline Leader-member exchange (LMX) & 0.28 & 0.08 & 3.65 & 0.000 \\
\hline \multirow[t]{2}{*}{ POS $\times$ LMX } & 0.16 & 0.05 & 3.01 & 0.003 \\
\hline & \multicolumn{4}{|c|}{ Perceived organizational support (POS) } \\
\hline Constant & 0.27 & 1.35 & 0.20 & 0.84 \\
\hline Person-organization fit (P-O fit) & 0.33 & 0.09 & 3.69 & 0.000 \\
\hline \multirow[t]{2}{*}{ Leader-member exchange (LMX) } & Boot indirect effect & Boot SE & Boot LL 95\% CI & Boot UL 95\% CI \\
\hline & \multicolumn{4}{|c|}{ Conditional indirect effect at $\mathrm{LMX}=M \pm 1 S D$} \\
\hline$-1 S D$ & 0.12 & 0.06 & 0.03 & 0.28 \\
\hline M & 0.18 & 0.06 & 0.08 & 0.30 \\
\hline $1 S D$ & 0.24 & 0.06 & 0.11 & 0.37 \\
\hline \multirow[t]{2}{*}{ Overall Index of Moderated Mediation } & Index & Boot SE & Boot LL 95\% CI & Boot UL 95\% CI \\
\hline & 0.05 & 0.02 & 0.01 & 0.11 \\
\hline
\end{tabular}

NOTE.

Unstandardized regression weight coefficients with all the five demographics being controlled for were reported. Bootstrap size $=$ 5000. LL = lower limit; UL = upper limit; CI = confidence interval. 
Table 7-6-3.

Regression Results for Conditional Indirect Effect (Turnover Intention as the Dependent Variable)

\begin{tabular}{|c|c|c|c|c|}
\hline Predictor & $B$ & $S E$ & $t$ & $p$ \\
\hline & \multicolumn{4}{|l|}{ Turnover Intention } \\
\hline Constant & 4.27 & 1.70 & 2.51 & 0.013 \\
\hline Person-organization fit (P-O fit) & -0.19 & 0.11 & -1.65 & 0.101 \\
\hline Perceived organizational support (POS) & -0.52 & 0.11 & -4.59 & 0.000 \\
\hline Leader-member exchange (LMX) & -0.21 & 0.09 & -2.28 & 0.024 \\
\hline POS $\times$ LMX & -0.06 & 0.06 & -0.98 & 0.326 \\
\hline \multicolumn{5}{|c|}{ Perceived organizational support (POS) } \\
\hline Constant & 0.08 & 1.35 & 0.06 & 0.95 \\
\hline Person-organization fit (P-O fit) & 0.33 & 0.09 & 3.76 & 0.000 \\
\hline \multirow[t]{2}{*}{ Leader-member exchange (LMX) } & Boot indirect effect & Boot SE & Boot LL 95\% CI & Boot UL 95\% CI \\
\hline & \multicolumn{4}{|c|}{ Conditional indirect effect at $\mathrm{LMX}=M \pm 1 S D$} \\
\hline$-1 S D$ & -0.15 & 0.07 & -0.33 & -0.04 \\
\hline$M$ & -0.17 & 0.06 & -0.32 & -0.07 \\
\hline $1 S D$ & -0.20 & 0.06 & -0.34 & -0.09 \\
\hline \multirow[t]{2}{*}{ Overall Index of Moderated Mediation } & Index & Boot SE & Boot LL 95\% CI & Boot UL 95\% CI \\
\hline & -0.02 & 0.03 & -0.07 & 0.03 \\
\hline
\end{tabular}

NOTE.

Unstandardized regression weight coefficients with all the five demographics being controlled for were reported. Bootstrap size $=$ 5000. LL = lower limit; UL = upper limit; CI = confidence interval. 
interval. Likewise, for the organizational commitment path, the bootstrapped indirect effect varied from $0.24,0.18$ to 0.24 at the three levels of LMX; the bootrapped index of conditional indirect effect was also significantly different from zero $(B=0.05, S E=0.02$, $95 \% \mathrm{CI}=0.01,0.11)$. However, the conditional indirect effect for the turnover intention path was not supported by the empirical evidence because the bootstrapped index of conditional indirect effect was not significantly different from zero, $B=-0.02, S E=0.03$, $95 \%$ CI $=-0.07,0.03$, which included zero. These Bootstrap results above, thus, further corroborated the expectations on conditional indirect effects. Collectively, Hypothesis 5a was supported such that the indirect effect of POS on the relationship between P-O fit and job satisfaction changed in strength depended on the different levels of LMX quality that employees tended to develop with their supervisors. Similarly, the moderated mediation model of organizational commitment (H5b) was also supported but no supportive evidence from the results was found for Hypothesis 5c of the moderated mediation model of turnover intention.

In summary, the research findings empirically established the mediating role of POS in the relationships between P-O fit and such work attitudes as job satisfaction and organizational commitment. Equally interesting, however, was the discovery that the mediation effects of POS varied across the level of LMX and that the overall moderated mediation was found to be statistically significant only for job satisfaction and organizational commitment but not for turnover intention. 


\section{CHAPTER VIII}

\section{DISCUSSION AND CONCLUSION}

With increased representation of young workers in the workforce, we are facing many challenges in managing the growing population of young workers. Recent literature has pointed out that new issues and problems spawned by age diversity in the workplace are likely to emerge and become increasingly important to tackle in the foreseeable future. Therefore, there is an urgent need for companies to gain a better grasp of work valuesmanifested as employees' expectations of various work needs—especially those of young workers (Loughlin \& Barling, 2001; Twenge et al, 2010). Moreover, understanding the mechanisms whereby work values are linked to employee work-related outcomes is of crucial importance to business firms and other organizations that are in the forefront of coping with new HR challenges related to the unfolding population trend while striving to build a fully engaged and highly motivated workforce.

The purpose of this dissertation was to achieve two main objectives: 1) explore the work values of young Chinese workers with a balanced focus on both generational differences and similarities; 2) investigate how person-organization fit (P-O fit)—largely hinged upon the needs-supply related to work—-might be related to perceived organizational support (POS), leader-member exchange (LMX), and important employee work-related outcomes. In this chapter, the research findings of the current study will be put into perspective of previous research so as to offer theoretical and practical insight into the work-value profile of young workers and the work-value-based P-O fit processes. The subsequent discussion of the results is organized around the four key research questions to highlight the implications of these findings. At the end of the chapter, I will 
conclude with the limitations of the present study and propose potentially fruitful venues for future research.

\section{Work-value Profile of the Two Young Generation Cohorts}

Drawing on research on theory of generations and work values, the present study was intended to directly compare the two younger generation cohorts (i.e., Social-Reform Generation, and Millennial Generation) in the Chinese workforce with regard to the magnitude of importance each generation attaches to various work priorities. The comparison in the study, overall, did not show statistically significant generational differences in work values among the young Chinese employees. Furthermore, when it comes to the rating of each work value item under the two work-value dimensions (i.e., intrinsic work values and extrinsic work values), there were considerable generational similarities in all the 18 specific work values tested in the study.

The generation cohort theory contends that employees from different generation cohorts would vary in their perception of the importance of various work aspects because unique social forces each generation has been exposed to during impressionable years can significantly shape their values. As such, it was expected that, when compared with their older counterparts from the Social-Reform generation, the younger Millennial employees would exhibit stronger preferences for those needs intrinsic to the work itself while attaching lesser importance to those rewards external to work. Contradictory to my predictions, the sampled Social-Reform and Millennial employees scored similarly on valuing both intrinsic work values (e.g., achievement and accomplishment, challenging and meaningful work) and extrinsic work values (e.g., pay and working conditions). 
These results are in direct contrast to those found in similar studies in Western societies, where research findings were contradictory at best. For instance, Lyons, Duxbury, and Higgins (2007) found that the two most recent generations in Canada—Generation Xers (born 1965-1979) and Generation Y (born after 1980)—did show large and meaningful differences in both openness to change and self-enhancement; more specifically, Canadian GenYers scored lower on openness to change and higher on conservation values than their GenXer counterparts. In another comparative study, based on their analysis of work values of US employees in the hospitality industry, Chen and Choi (2008) showed that Gen Xers reported significantly higher scores on security and independence than Gen Yers.

These unexpected findings of the current study could be subject to three possible interpretations. First, the results on extrinsic work values could be a reflection of deeprooted cultural influence, which can be traced to traditional Confucian teachings. One dominating and fundamental Confucian ideal is related to filial piety (xiao) that bounds children to respect for, obey, and care for their parents and elderly family members. Within the Chinese society, filial piety primarily defines adult children's obligation to reciprocate the receipt of care and welfare provided by their parents and elders when they were young. Hence, members from the two Chinese younger generation cohorts are facing enormous social and economic pressures while striving to fulfill filial responsibility, and, as a result, similarly valued material rewards associated with work.

Second, another possible explanation for the generational commonalities on both extrinsic and intrinsic work values could be linked to the life-stage perspective. According to Erikson (1982) and Levinson (1978), when individuals pass through various 
developmental stages in their entire life including, but not limited to, entry into a fulltime employment, marriage, and parenthood, they tend to face with different challenges and thus may experience orderly changes in their behavior, value orientation, and individual needs over time. Accordingly, as people get old they become less aggressive and more nurturing, and aim at self-transcendence and commitment to helping others for promoting societal welfare. Thus, the observed generational similarities in work needs could be attributed to the same life-cycle stage that the two generation cohorts were going through at the time of the study. This may be particularly true with reference to the collected demographic information from the employee respondents. For example, the average age difference between the two generation cohorts was about 8 years in the sample, suggesting their closeness in age. In addition, the participants in the study were predominantly well-educated; the majority of the sample (93\%) held university and above degrees.

Third, these generational commonalities might be a result of the overarching economic transformation in China that members from the two generation cohorts have all been exposed to. Regarding each work-value factor, the younger Chinese employees showed important similarities. Notably, job security in the present study was consistently rated as highly important by both generations. Of particular relevance to HRM in China is the diffusion of such institutionalized HRM practices as labor contracts and performance-related rewards systems in the early1980s, which gradually replaced the “iron rice-bowl” (tie fan wan) (Cooke, 2009; Ding, Goodall \& Warner, 2000)—that means, under this system workers were provided with almost guaranteed job tenure. To reform and smash the "iron-rice bowl”, these above-mentioned Western-style HRM practices 
were put in place in the hope to foster competition and promote efficiency within Chinese business organizations. As a result, when “iron rice-bowl” employment system finally phased out, so did the sense of guaranteed employment security that was associated with it. Therefore, it would be equally desirable for employees-irrespective of generational membership—when an employer can offer employment stability and job security.

In summary, the comparisons between the two young generations in the Chinese workplace overall didn’t provide evidence to support the generational difference hypotheses among young workers. This finding highlights the necessity that the reader use caution to avoid stereotypical thinking towards age-based generation cohorts, which is in line with a recent meta-analytic review study showing that many commonly held generalizations on age stereotypes may not be sustained (Ng \& Feldman, 2012). More importantly, instead of fueling the negative age bias in the workforce, I suggest to further develop appreciation of the underlying reasons for those observed generational differences or similarities, which can be the first step in bridging generational gap in the workplace.

\section{Mechanisms Liking P-O Fit to Employee Work Outcomes}

Both researchers and practitioners alike have long recognized the importance of the employee's perceived P-O fit for its impact on employee attitudes and behaviors. However, scholars have yet to develop a theoretically sound and parsimonious way of capturing or operationalizing the seminal conception of P-O fit-hinged upon value congruence. Additionally, much recent research has increasingly placed emphasis on deciphering the complex P-O fit processes by turning attention to identifying the 
boundary conditions under which the P-O fit theory may or may not hold. In the present study, I integrated the needs-supplies fulfillment approach of P-O fit and the fit concept in the strategy literature to develop a coherent, theory-driven measure of P-O fit. Furthermore, to unpack the underlying P-O fit processes, I then drew on social exchange theory to offer a more comprehensive view of the pathways leading from the work-valuebased P-O fit to the three central work outcomes.

Consistent with previous research, there is robust evidence in the present study for supporting the main effect hypotheses 2a through 2c. Specifically, as predicted, I found that P-O fit was positively related to both employee job satisfaction and affective organizational commitment, while being negatively related to employee intention to leave. In addition, the results of my study also provided strong support for the mediating role of POS in the relationships between P-O fit and important work outcomes. Furthermore, in line with my predictions, LMX was found to moderate the relationships between POS and its two work outcomes (i.e., job satisfaction and organizational commitment). These findings overall suggested that LMX mitigates or buffers the negative consequences of low-quality exchange relationships between employees and their employers. Another important finding of the study is that the indirect effect of POS leading from P-O fit onto the two outcomes (i.e., job satisfaction and affective organizational commitment) varied significantly as a function of LMX levels, suggesting overall moderated mediation. However, the lack of statistical support for either the LMX moderation or the moderated mediation pathways for turnover intention is quite intriguing and puzzling. Although unexpected, my non-finding of the hypothesized pathways may not necessarily prove their non-existence, but may be attributed to the lack of wide variance in perceived LMX 
quality (mean $=4.67, S D=1.13$ ) — which is understandable given the homogeneous sample of employees with respect to their demographic characteristics. Another explanation may be related to the complexity of turnover intention as a convoluted psychological and emotional process — heavily influenced by vital cues that employees receive through social interaction at work. In this case, such socially constructed cues may not be fully reflected by LMX, or employees’ exchange relationships with their leaders.

\section{Significance of the Study}

\section{Theoretical Contributions}

The research findings from this study have made several contributions to theory development and research in the realm of generation management within organizational settings. First, in responding to the call for adding generation and culture as two additional research domains to resuscitate the stream of research on work values (Leuty \& Hansen, 2011), the study extends our current knowledge of employee work values and generational differences/similarities manifested in the workplace. Second, by paying particular attention to potential sub-cultural variations associated with generational cohorts within a country, this study overcomes the questionable assumption of cultural homogeneity, which is common in cross-cultural management research. Most notably, this study represents an important initial step to shift away from the focus on primarily demonstrating differences across cultures_prevailing in the existing cross-cultural research—by devoting equal attention to theoretical considerations that can help explain those differences or similarities (Au, 1999; Malpass, 1977). 
The present study also offers major contributions to the theories of P-O fit and social exchange relationships in three ways. First, the findings highlight the importance of P-O fit that is hinged upon the alignment of employee work values. Second, the results add credence to the accumulating evidence suggesting the wider cross-cultural generalizability of P-O fit and its effects (Kim et al., 2013; Oh, et al., 2014). Third, taking a social exchange theory perspective, the current research also identifies the boundary conditions and incorporates them into the $\mathrm{P}-\mathrm{O}$ fit theory to present a more comprehensive and complete view of P-O fit processes. The study results from examining the proposed mechanisms involved in P-O fit processes shed more light to illuminate how fit perception is formed and then exerts influence on work attitudes and behaviors desirable to organizations in conjunction with the two crucial psychological experiences at work, POS and LMX.

Second, whereas there have been some research to examine the agerelated generational differences in work values and find important differences, research findings were contradictory at best (Lyons \& Kuron, 2013). One possible explanation for the lack of consistency across studies may stem from the variations in operationalizations of the key construct of work values because it is most likely that "generations may not always see eye-to-eye due to different interpretations of item content.” (Meriac, Woehr \& Banister, 2010, p. 322). The above critique, while insightful and valuable, falls short of providing practical guidance for addressing the measurement equivalence issue. Such measurement concern is of particular relevance to the present study conducted in China, where 
sub-national variations can be extreme (e.g., Redfern \& Crawford, 2010; Tung \& Verbeke, 2010), such as those among generations within organizational settings (Cox, et al., 2014; Li \& Nimon, 2008). By using multiple-step scale development and validation, I was able to tackle, from the outset, the specific concern towards studying work values across different age groups and thus to add confidence in drawing strong conclusions from the present work.

Third, a careful literature review suggested that the most commonly adopted P-O fit measure involves asking respondents to rate the level of congruence they perceive with their employers (Kristof, 1996). Although the application of this subjective model has received mounting criticism for its lack of sophistication and one-dimensionality without fully tapping the breadth of fit concept (Cable \& DeRue, 2002; Venkatraman, 1989), to date, there is little systematic effort devoted to optimizing the P-O fit measure. My dissertation represents a comprehensive effort aiming at developing a more coherent framework for measuring P-O fit by integrating the fit operationalization drawn from previous literature (Joshi, Kathuria, \& Porth, 2003; Venkatraman, 1984) with the seminal conceptualization of value-based P-O fit (Chatman, 1989; Kristof, 1996). In so doing, I have proposed a new approach to study P-O fit, offering a potentially useful way to achieve greater integration of the P-O fit literature that has been criticized for being highly fragmented and lacking coherence in the past (Edwards, 2008; Edwards \& Cable, 2009; Yu, 2014).

\section{Managerial Implications}

From a practical perspective, this study also adds incremental value in informing HR practices in organizations with evidence-based information. That is, it intends to 
bring to light the ways how members from the different cohorts may value work aspects differently or similarly. Although no significant differences in work values between the two young generations were detected, I caution the reader not to make extreme interpretations from this non-finding; instead, it might be still warranted for organizations not to completely ignore the potentially crucial differences across generations while aiming at better understanding the underlying causes for the observed generational differences or similarities.

In addition, in order to devise effective as well as flexible HR practices conducive to an employee's individual work needs, it is important for organizations to constantly monitor what employees may value the most. Managers may also need to learn new ways to leverage such knowledge, given their continued focus on effectively attracting and retaining talented employees in the increasingly intensified war for talent worldwide, and in China, in particular. For example, managers may have much to gain by paying attention to both extrinsic and intrinsic aspects related to work so as to more effectively redesign job and manage work flow and thus to increase their motivational potential. It should also be noted that not all work-value factors may carry equal weight, with regards to motivational properties, in influencing work outcomes. Hence, some caution appears appropriate that organizations may need to evaluate the benefits against the potential costs related to implementing customized HR strategies to target specific work needs of employees so as to increase the relevance and effectiveness of such investment. 
From the current study, I have also attempted to derive relevant practical implications by shedding more fresh light on the P-O fit processes whose understanding understanding may have the potential to assist managers in designing effective organizational interventions that will likely induce the desired work outcomes of employees. As amply demonstrated both in this research and elsewhere in most previous studies, P-O fit is found to be positively related to job satisfaction and organizational commitment while being negatively associated with turnover intention. These findings highlight the importance for organizations to take employee work values into consideration when crafting HR strategies. In practice, the specific work values uncovered as highly valued by the employees may serve as a good starting point for managers wishing to search for useful ways of enhancing employees' feelings of fit and sense of affiliation with their employer and thus keeping them actively engaged in their jobs. Indeed, organizations may benefit from undertaking tactics that serve to fulfill employee's work needs and ensure high employee value congruence.

The empirical evidence has further pointed to the critical, while functionally distinct, roles played by LMX and POS in influencing the P-O fit processes. In that regard, business firms and other organizations are encouraged to concentrate efforts in promoting the development of a focal employee's quality relations with both the leader and the organization. To achieve those objectives, organizations may consider offering training and development programs to equip managers with the necessary skills for effectively forming positive and supportive LMX with subordinates. Building on the knowledge of employee work values organization leaders may also consider using a variety of ways to recognize and appreciate their subordinates by helping them set 
realistic goals, providing timely feedback on performance as well as ongoing guidance when needed. Another way for organizations to enhance employee sense of POS is to build a thriving value-based organizational culture that promotes employee well-being and personal growth, and in turn fosters employee bonding with the organization.

\section{Limitations of the Study and Implications for Future Research}

In spite of the aforementioned contributions of the present study, there are several limitations that still merit further discussion and future investigation. First, this study found no empirical support to generational theory when explaining the differences in work values across the generations suggests that unique socio-cultural and historical events may not fully capture the complexity of the concept of generation. The failure to obtain statistical evidence for the hypothesized work-value differences between the two Chinese younger generations does not necessarily negate the generation theory. As I have mentioned above, the complex interaction between employees and their immediate environment settings such as family and workplace, is likely to exert substantial influences in shaping their work value orientation while being socialized into the world of work (Loughlin \& Barling, 2001). As such, in future studies, researchers need to incorporate other most influential contextual factors into the conceptualization of generation and explore the role played by those environmental characteristics (Joshi et al., 2010; Lyons and Kuron, 2013) to further enhance our understanding of the multifaceted generational phenomena. Furthermore, despite the research focus on young workers, the lack of representation of participants from the old, Cultural-Revolution generation in the 
sample may limit the study's generalizability. Therefore, future research should aim at expanding sampling scope to obtain a larger sample representative of the Chinese employees from all the three dominant generation cohorts in the work environment. In order to do so, I suggest that future researchers may need to shift research setting from SMEs in the present study to SOEs that still hire a considerably large population of old workers.

The second limitation lies in the methodology that is used to study generational differences in work values. Because the age-based generational effects are inevitably intertwined with age-based life-cycle effects, the cross-sectional research design implemented in this study will not be able to allow us to disentangle these effects. As suggested by many other scholars (Au, 1999; Cogin, 2012; Parry \& Urwin, 2011; Twenge et al., 2010), longitudinal study with comprehensive data collection effort, as well as more sophisticated research method should be utilized in the future research endeavor to shed more light on this topic. Moreover, in addition to age-based generation cohorts, research on other individual characteristics, such as gender, personality, and birthplace is needed. It would also be interesting to explore how they may interact with generation membership and ultimately link to individual work values. More research should also be extended to consider other countries beyond China if we are to better grasp the within-country generational phenomena. For example, one research question that might arise is whether the same value patterns across generations hold for the other three BRIC emerging-market countries, as significant sub-national differences have been found for Brazil (Lenartowicz \& Roth, 2001), Russia (Atsmon, Kertesz \& Vital, 2011), and India (Atsmon et al., 2011) 
Last but not least, the present study demonstrated the usefulness of integrating work values and social exchange perspectives to uncover important insight into the P-O fit processes. Notably, however, only two key aspects of social exchange within the organization were examined (i.e., POS and LMX). Future researchers should incorporate into the P-O fit model other exchange relationships and explore their effects on the relation between P-O fit and work outcomes. For example, P-O fit is likely to affect coworker exchanges (CWX), the exchange relationships formed by the focal employee with his/her coworkers (Sherony \& Green, 2002), and trust in organization and supervisor (Aryee et al., 2002), which might ultimately influence employee work attitudes and behaviors.

\section{Conclusion}

The increasing representation of young workers in today's workplace and the rising complexity of managing an age-diverse workforce that comes along with it necessitate organizations to re-evaluate their human resource policies and practices so as to address imminent HR challenges pertaining to staffing, motivation, and training and development. One such primary focus related to generational phenomena in the work context involves gaining a better and fundamental grasp of employees’ work values.

With the current study I hope to "cast a brick to attract a jade” (pao zhuan yin yu), encouraging more research efforts to cast a wider net to capture more in-depth mechanisms behind the change in work values across generations as well as to gain a deeper understanding of the value-based person-organization fit processes. After all, organizations and policy makers, well equipped with these insights, may arguably be 
better positioned to craft flexible HR policies that may help more effectively manage employee work needs. In so doing, organization leaders may also help promote and nurture the type of supportive work environment, where all employees irrespective of their generational membership can work effectively together and continue to thrive and prosper. 


\section{LIST OF REFERENCES}

Aadland, E. (2010). Values in professional practice: Towards a critical reflective methodology. Journal of Business Ethics, 97(3), 461-472.

Adler, N. (1997). International dimensions of organizational behavior. Cincinnati, OH: ITP

Aiken, L. S., West, S. G., \& Reno, R. R. (1991). Multiple regression: Testing and interpreting interactions. Newburry Park, CA: Sage.

Allen, N. J., \& Meyer, J. P. (1996). Affective, continuance, and normative commitment to the organization: An examination of construct validity. Journal of Vocational Behavior, 49(3), 252-276.

Arnold, H. J., \& Feldman, D. C. (1982). A multivariate analysis of the determinants of job turnover. Journal of Applied Psychology, 67(3), 350-360.

Aryee, S., Budhwar, P. S., \& Chen, Z. X. (2002). Trust as a mediator of the relationship between organizational justice and work outcomes: Test of a social exchange model. Journal of organizational Behavior, 23(3), 267-285.

Aryee, S., \& Chen, Z. X. (2006). Leader-member exchange in a Chinese context: Antecedents, the mediating role of psychological empowerment and outcomes. Journal of Business Research, 59(7), 793-801.

Atsmon, Y., Kertesz, A., \& Vital, I. (2011). Is your emerging-market strategy local enough?. McKinsey Quarterly. April, 1-13.

Au, K. Y. (1999). Intra-cultural variation: Evidence and implications for International Business. Journal of International Business Studies, 30(4), 799-812.

Barnes-Farrell, J. L., \& Matthews, R. (2007). Age and work attitudes. In K. S. Shultz \& G. A. Adams (Eds.), Aging and work in the 21st century: 139-162. New York: Psychology Press.

Barney, J. (1991). Firm resources and sustained competitive advantage. Journal of Management, 17(1), 99-120.

Baron, R. M., \& Kenny, D. A. (1986). The moderator-mediator variable distinction in social psychological research: Conceptual, strategic, and statistical considerations. Journal of Personality and Social Psychology, 51(6), 1173-1182. 
Bartlett, M. S. (1954). A note on the multiplying factors for various $\chi^{2}$ approximations. Journal of the Royal Statistical Society. Series B (Methodological), 296-298.

Bartunek, J. M. (2007). Academic-practitioner collaboration need not require joint or relevant research: Toward a relational scholarship of integration. Academy of Management Journal, 50(6), 1323-1333.

Bello, D., Leung, K., Radebaugh, L., Tung, R. L., \& Witteloostuijn, A. V. (2009). From the editors: Student samples in international business research. Journal of International Business Studies, 40(3), 361-364.

Billingsley, B. S., \& Cross, L. H. (1992). Predictors of commitment, job satisfaction, and intent to stay in teaching: A comparison of general and special educators. The Journal of Special Education, 25(4), 453-471.

Blau, P. M. (1964). Exchange and power in social life. New York: John Wiley \& Sons.

Bluhm, D. J., Harman, W., Lee, T. W., \& Mitchell, T. R. (2011). Qualitative research in management: A decade of progress. Journal of Management Studies, 48(8), 18661891.

Borg, I., Groenen, P. F., Jehn, K. A., Bilsky, W., \& Schwartz, S. H. (2011). Embedding the organizational culture profile into Schwartz's theory of universals in values. Journal of Personnel Psychology, 10(1), 1-12.

Brislin, R. W. (1970). Back-translation for cross-cultural research. Journal of crosscultural psychology, 1(3), 185-216.

Brooks, C., \& Manza, J. (1994). Do changing values explain the new politics? A critical assessment of the postmaterialist thesis. The Sociological Quarterly, 35(4), 541570 .

Brooke, P. P., Russell, D. W., \& Price, J. L. (1988). Discriminant validation of measures of job satisfaction, job involvement, and organizational commitment. Journal of applied psychology, 73(2), 139-145.

Browne, M. W. (1975). Predictive validity of a linear regression equation. British Journal of Mathematical and Statistical Psychology, 28(1), 79-87.

Brush, D. H., Moch, M. K., \& Pooyan, A. (1987). Individual demographic differences and job satisfaction. Journal of Organizational Behavior, 8(2), 139-155.

Bryant, F. B., \&Yarnold, P. R. (1995). Principal-components analysis and exploratory and confirmatory factor analysis. In L.G. Grimm \& P.R. Yarnold, (Eds), Reading 
and understanding multivariate statistics. , (pp. 99-136). Washington, DC: American Psychological Association.

Bu, N., \& McKeen, C. A. (2001). Work goals among male and female business students in Canada and China: the effects of culture and gender. The International Journal of Human Resource Management, 12(2), 166-183.

Burke, M. (2004). Generational Differences: Survey Report. Alexandria, VA: Society for Human Resource Management.

Cable, D. M., \& DeRue, D. S. (2002). The convergent and discriminant validity of subjective fit perceptions. Journal of Applied Psychology, 87(5), 875-884.

Cable, D. M., \& Edwards, J. R. (2004). Complementary and supplementary fit: a theoretical and empirical integration. Journal of Applied Psychology, 89(5), 822834.

Cable, D. M., \& Judge, T. A. (1996). Person-organization fit, job choice decisions, and organizational entry. Organizational Behavior and Human Decision Processes, 67(3), 294-311.

Cadogan, J. W., Diamantopoulos, A., \& De Mortanges, C. P. (1999). A measure of export market orientation: scale development and cross-cultural validation. Journal of International Business Studies, 30(4), 689-707.

Cameron, L., Erkal, N., Gangadharan, L., \& Meng, X. (2013). Little emperors: Behavioral impacts of China's one-child policy. Science, 339(6122), 953-957.

Cammann, C., Fichman, M., Jenkins, D., \& Klesh, J. (1979). The Michigan Assessment Questionnaire. Ann Arbor, MI: University of Michigan.

Cammann, C., Fichman, M., Jenkins, G. D., \& Klesh, J. (1983). Michigan organizational assessment questionnaire. In S. E. Seashore, E. E. Lawler, P. H. Mirvis \& C. Cammann (Eds.), Assessing organizational change: A guide to methods, measures, and practices (pp. 71-138). New York: Wiley.

Cascio, W. F. (2012). Methodological issues in international HR management research. The International Journal of Human Resource Management, 23(12), 2532-2545.

Cascio, W. F. (2015). Strategic HRM: Too Important for an Insular Approach. Human Resource Management, 54(3), 423-426.

Cascio, W.F. \& Aguinis, H. (2011). Applied psychology in human resource management (7th ed.). Upper Saddle River, NJ: Pearson Prentice Hall. 
Cavusgil, S. T., \& Das, A. (1997). Methodological issues in empirical cross-cultural research: A survey of the management literature and a framework. MIR: Management International Review, 37(1), 71-96.

Cennamo, L., \& Gardner, D. (2008). Generational differences in work values, outcomes and person-organization values fit. Journal of Managerial Psychology, 23(8), 891-906.

Chatman, J. A. (1989). Improving interactional organizational research: A model of person-organization fit. Academy of Management Review, 14(3), 333-349.

Chatman, J. A. (1991). Matching People and Organizations: Selection and Socialization in Public Accounting Firms. Administrative Science Quarterly, 36(3) 459-484.

Chaudhuri, S., \& Ghosh, R. (2012). Reverse mentoring: A social exchange tool for keeping the boomers engaged and millennials committed. Human Resource Development Review, 11(1), 55-76.

Chen, P. J., \& Choi, Y. (2008). Generational differences in work values: a study of hospitality management. International Journal of Contemporary Hospitality Management, 20(6), 595-615.

Chen, X. P., Eberly, M. B., Chiang, T. J., Farh, J. L., \& Cheng, B. S. (2014). Affective Trust in Chinese Leaders Linking Paternalistic Leadership to Employee Performance. Journal of Management, 40(3), 796-819.

Chen, X. P., Hui, C., \& Sego, D. J. (1998). The role of organizational citizenship behavior in turnover: Conceptualization and preliminary tests of key hypotheses. Journal of Applied Psychology, 83(6), 922-931.

Chen, W., \& Hoskin, J. (2007). Multinational corporations in China: Finding and keeping talent. SHRM: October: 1-4.

Chen, Y. (1999). Lost in revolution and reform: The socioeconomic pains of China's red guards generation, 1966-1996. Journal of Contemporary China, 8(21), 219-239.

Chen, Z. X., Tsui, A. S., \& Farh, J. L. (2002). Loyalty to supervisor vs. organizational commitment: Relationships to employee performance in China. Journal of Occupational and Organizational Psychology, 75(3), 339-356.

Chow, G. C. (1960). Tests of equality between sets of coefficients in two linear regressions. Econometrica: Journal of the Econometric Society, 28(3), 591-605. 
Chu, K. (2013, December 13). Chinese firms vie to woo coveted workers, upping the ante on Western rivals. Wall Street Journal - Eastern Edition, p.B4.

Cogin, J. (2012). Are generational differences in work values fact or fiction? Multicountry evidence and implications. The International Journal of Human Resource Management, 23(11), 2268-2294.

Cohen, J., Cohen, P., West, S.G., \& Aiken, L. S. (2003). Applied multiple regression/correlation analysis for the behavioral sciences (3rd ed.). Hillsdale, NJ: Erlbaum.

Cole, M. S., Walter, F., \& Bruch, H. (2008). Affective mechanisms linking dysfunctional behavior to performance in work teams: a moderated mediation study. Journal of Applied Psychology, 93(5), 945-957.

Conway, J. M., \& Huffcutt, A. I. (2003). A review and evaluation of exploratory factor analysis practices in organizational research. Organizational Research Methods, 6(2), 147-168.

Cooke, F. L. (2009). A decade of transformation of HRM in China: A review of literature and suggestions for future studies. Asia Pacific Journal of Human Resources, 47(1), 6-40.

Cooke, F. L. (2012). Human resource management in China: New trends and practices, London: Routledge.

Cooke, F. L., Saini, D. S., \& Wang, J. (2014). Talent management in China and India: A comparison of management perceptions and human resource practices. Journal of World Business, 49(2), 225-235.

Costanza, D. P., Badger, J. M., Fraser, R. L., Severt, J. B., \& Gade, P. A. (2012). Generational differences in work-related attitudes: A meta-analysis. Journal of Business and Psychology, 27(4), 375-394.

Cox, A., Hannif, Z., \& Rowley, C. (2014). Leadership styles and generational effects: Examples of US companies in Vietnam. The International Journal of Human Resource Management, 25(1), 1-22.

Cranny, C. J., Smith, P. C., \& Stone, E. F. (1992). Job satisfaction: How people feel about their jobs, and how it affects their performance. New York: Lexington.

Cropanzano, R., \& Mitchell, M. S. (2005). Social exchange theory: An interdisciplinary review. Journal of Management, 31(6), 874-900. 
De Beuckelaer, A., \& Lievens, F. (2009). Measurement Equivalence of Paper -and- Pencil and Interne

Examination in 16 Countries. Applied Psychology: An International Review, 58(2), 336-361.

DeVellis, R. F. (2003). Scale development: Theory and applications (2nd ed.). Thousand Oaks, CA: Sage.

Diener, E. (2000). Subjective well-being: The science of happiness and a proposal for a national index. American Psychologist, 55(1), 34-43.

Ding, D. Z., Goodall, K., \& Warner, M. (2000). The end of the'iron rice-bowl': whither Chinese human resource management?. International Journal of Human Resource Management, 11(2), 217-236.

Ding, D. Z., \& Warner, M. (1999). 'Re-inventing’ China’s Industrial Relations at Enterprise Hhdaustricah Empirical FieldRelations Journal, 30(3), 243-260.

Dong, K., \& Liu, Y. (2010). Cross-cultural management in China. Cross Cultural Management: An International Journal, 17(3), 223-243.

Dose, J. J. (1997). Work values: An integrative framework and illustrative application to organizational socialization. Journal of Occupational and Organizational Psychology, 70(3), 219-240.

Dou, W., Wang, G., \& Zhou, N. (2006). Generational and regional differences in media consumption patterns of Chinese generation X consumers. Journal of Advertising, 35(2), 101-110.

Drazin, R., \& Van de Ven, A. H. (1985). Alternative forms of fit in contingency theory. Administrative Science Quarterly, 30(4), 514-539.

Dziuban, C. D., \& Shirkey, E. C. (1974). When is a correlation matrix appropriate for factor analysis? Some decision rules. Psychological Bulletin, 81(6), 358-361.

Eccles, J. S., \& Wigfield, A. (2002). Motivational beliefs, values, and goals. Annual Review of Psychology, 53(1), 109-132.

Edwards, J. R. (1996). An examination of competing versions of the person-environment fit approach to stress. Academy of Management Journal, 39(2), 292-339.

Edwards, J. R. (2008). Person-Environment Fit in Organizations: An Assessment of Theoretical Progress. Academy of Management Annals, 2(1), 167-230. 
Edwards, J. R., \& Cable, D. M. (2009). The value of value congruence. Journal of Applied Psychology, 94(3), 654-677.

Edwards, J. R., \& Cooper, C. L. (1990). The person

Recurring problems and some suggested solutions. Journal of Organizational Behavior, 11(4), 293-307.

Edwards, J. R., \& Lambert, L. S. (2007). Methods for integrating moderation and mediation: a general analytical framework using moderated path analysis. Psychological Methods, 12(1), 1-22.

Edwards, J. R. \& Shipp, A. J. (2007). The relationship between person-environment fit and outcomes: An integrative theoretical framework. In C. Ostroff \& T. A. Judge (Eds.), Perspectives on organizational fit (pp. 209-258). San Francisco: JosseyBass, 2007.

Egri, C. P., \& Ralston, D. A. (2004). Generation cohorts and personal values: A comparison of China and the United States. Organization Science, 15(2), 210-220.

Eisenberger, R., Armeli, S., Rexwinkel, B., Lynch, P. D., \& Rhoades, L. (2001). Reciprocation of perceived organizational support. Journal of Applied Psychology, 86(1), 42-51.

Eisenberger, R., Huntington, R., Hutchison, S., \& Sowa, D. (1986). Perceived organizational support. Journal of Applied Psychology, 71(3), 500-507.

Eisenberger, R., Shoss, M. K., Karagonlar, G., Gonzalez-Morales, M. G., Wickham, R. E., \& Buffardi, L. C. (2014). The supervisor POS-LMX-subordinate POS chain: Moderation by reciprocation wariness and supervisor's organizational embodiment. Journal of Organizational Behavior, 35(5), 635-656.

Elizur, D. (1984). Facets of work values: A structural analysis of work outcomes. Journal of Applied Psychology, 69(3), 379-389.

Elizur, D., Borg, I., Hunt, R., \& Becker, I. (1991). The structure of work values: A cross cultural comparison. Journal of Organizational Behavior, 12(1), 21-38

Erdogan, B., \& Enders, J. (2007). Support from the top: supervisors’ perceived organizational support as a moderator of leader-member exchange to satisfaction and performance relationships. Journal of Applied Psychology, 92(2), 321-330. 
Erdogan, B., Kraimer, M. L., \& Liden, R. C. (2004). Work value congruence and intrinsic career success: the compensatory roles of leader perceived organizational support. Personnel Psychology, 57(2), 305-332.

Erikson, E. H. (1982). The life cycle completed: A review. New York: Norton.

Fabrigar, L. R., Wegener, D. T., MacCallum, R. C., \& Strahan, E. J. (1999). Evaluating the use of exploratory factor analysis in psychological research. Psychological Methods, 4(3), 272-299.

Fan, Y. (2000). A classification of Chinese culture. Cross Cultural Management: An International Journal, 7(2), 3-10.

Farh, J. L., Cannella, A. A., \& Lee, C. (2006). Approaches to scale development in Chinese management research. Management and Organization Review, 2(3), 301318.

Farh, J. L., Hackett, R. D., \& Liang, J. (2007). Individual-level cultural values as moderators of perceived organizational support-employee outcome relationships in China: Comparing the effects of power distance and traditionality. Academy of Management Journal, 50(3), 715-729.

Faure, G. O., \& Fang, T. (2008). Changing Chinese values: Keeping up with paradoxes. International Business Review, 17(2), 194-207.

Ford, J. K., MacCallum, R. C., \& Tait, M. (1986). The application of exploratory factor analysis in applied psychology: A critical review and analysis. Personnel Psychology, 39(2), 291-314.

Francesco, A. M., \& Chen, Z. X. (2004). Collectivism in Action Its Moderating Effects on the Relationship between Organizational Commitment and Employee Performance in China. Group \& Organization Management, 29(4), 425-441.

French, J. R., Caplan, R. D., \& Van Harrison, R. (1982). The mechanisms of job stress and strain. New York: J. Wiley.

George, M., \& Mallery, P. (2005). SPSS for windows step by step: a simple guide and reference 12.0 update (5th ed.). Boston: Allyn and Bacon.

Gilleard, C., Higgs, P., Hyde, M., Wiggins, R., \& Blane, D. (2005). Class, cohort, and consumption: The British experience of the third age. The Journals of Gerontology Series B: Psychological Sciences and Social Sciences, 60(6), S305S310. 
Glass, A. (2007). Understanding generational differences for competitive success. Industrial and Commercial Training, 39(2), 98-103.

Gordon, M. E., Slade, L. A., \& Schmitt, N. (1987). Student guinea pigs: Porcine predictors and particularistic phenomena. Academy of Management Review, 12(1), 160-163.

Gouldner, A. W. (1960). The norm of reciprocity: A preliminary statement. American Sociological Review, 25(2), 161-178.

Graen, G. B., \& Scandura, T. A. (1987). Toward a psychology of dyadic organizing. In L.L. Cummings \& B.M. Staw (Eds.), Research in Organizational Behavior (Vol. 9, pp. 175-208). Greenwich, CT: JAI.

Grice, J. W., \& Iwasaki, M. (2007). A truly multivariate approach to MANOVA. Applied Multivariate Research, 12(3), 199-226.

Gupta, A. K., \& Wang, H. (2009). Getting China and India right: Strategies for leveraging the world's fastest growing economies for global advantage. John Wiley \& Sons.

Gursoy, D., Chi, C. G.-Q., \& Karadag, E. (2013). Generational differences in work values and attitudes among frontline and service contact employees. International Journal of Hospitality Management, 32(1), 40-48.

Gursoy, D., Maier, T. A., \& Chi, C. G. (2008). Generational differences: An examination of work values and generational gaps in the hospitality workforce. International Journal of Hospitality Management, 27(3), 448-458.

Hartmann, E., Feisel, E., \& Schober, H. (2010). Talent management of western MNCs in China: Balancing global integration and local responsiveness. Journal of World Business, 45(2), 169-178.

Harpaz, I. (1990). The importance of work goals: An international perspective. Journal of International Business Studies, 21(1), 75-93.

Hayes, A. F. (2009). Beyond Baron and Kenny: Statistical mediation analysis in the new millennium. Communication Monographs, 76(4), 408-420.

Hayes, A. F. (2015). An index and test of linear moderated mediation. Multivariate Behavioral Research, 50(1), 1-22. 
Hayton, J. C., Allen, D. G., \& Scarpello, V. (2004). Factor retention decisions in exploratory factor analysis: A tutorial on parallel analysis. Organizational Research Methods, 7(2), 191-205.

Hinkin, T. R. (1995). A review of scale development practices in the study of organizations. Journal of Management, 21(5), 967-988.

Hinkin, T. R. (1998). A brief tutorial on the development of measures for use in survey questionnaires. Organizational Research Methods, 1(1), 104-121.

Holt, D. T., Armenakis, A. A., Feild, H. S., \& Harris, S. G. (2007). Readiness for organizational change the systematic development of a scale. The Journal of Applied Behavioral Science, 43(2), 232-255.

Hofstede, G. (2001). Culture's consequences (2nd ed.). Thousand Oaks, CA: Sage.

Hom, P. W., Tsui, A. S., Wu, J. B., Lee, T. W., Zhang, A. Y., Fu, P. P., \& Li, L. (2009). Explaining employment relationships with social exchange and job embeddedness. Journal of Applied Psychology, 94(2), 277-297.

Holmbeck, G. N. (1997). Towards terminological, conceptual, and statistical clarity in the study of mediators and moderators: Examples from the child-clinical and prediatric psychology literatures. Journal of Consulting and Clinical Psychology, 65(4), 599-610.

House, R. J., Hanges, P. J., Javidan, M., Dorfman, P. W., \& Gupta, V. (2004). Culture, Leadership, and Organizations: The GLOBE Study of 62 Societies. Thousand Oaks, CA: Sage.

Huang, X., \& Van De Vliert, E. (2003). Where intrinsic job satisfaction fails to work: National moderators of intrinsic motivation. Journal of Organizational Behavior, 24(2), 159-179.

Hui, C., Lee, C., \& Rousseau, D. M. (2004). Employment relationships in China: do workers relate to the organization or to people?. Organization Science, 15(2), 232-240.

Hui, C., Wong, A., \& Tjosvold, D. (2007). Turnover intention and performance in China: The role of positive affectivity, Chinese values, perceived organizational support and constructive controversy. Journal of Occupational and Organizational Psychology, 80(4), 735-751. 
Hurley, A. E., Scandura, T. A., Schriesheim, C. A., Brannick, M. T., Seers, A., Vandenberg, R. J., \& Williams, L. J. (1997). Exploratory and confirmatory factor analysis: Guidelines, issues, and alternatives. Journal of Organizational Behavior, 18(6), 667-683.

Inglehart, R. F. (1977). The Silent Revolution: Changing Values and Political Styles among Western Publics. Princeton, NJ: Princeton University Press.

Inglehart, R. F. (1990). Culture Shift in Advanced Industrial Society. Princeton, NJ: Princeton University Press.

Inglehart, R., \& Welzel, C. (2005). Modernization, Cultural Change, and Democracy: The human development sequence. Cambridge, UK: Cambridge University Press.

Inglehart, R. F. (2008). Changing values among Western publics from 1970 to 2006. West European Politics, 31(1-2), 130-146.

John, C. H. S., \& Roth, P. L. (1999). The impact of cross-validation adjustments on estimates of effect size in business policy and strategy research. Organizational Research Methods, 2(2), 157-174.

Johnson, M. K., \& Mortimer, J. T. (2015). Reinforcement or compensation? The effects of parents' work and financial conditions on adolescents' work values during the Great Recession. Journal of Vocational Behavior, 87, 89-100.

Johnson, M. K., Mortimer, J. T., Lee, J. C., \& Stern, M. J. (2007). Judgments about work: Dimensionality revisited. Work and Occupations, 34(3), 290-317.

Johnson, M. K., Sage, R. A., \& Mortimer, J. T. (2012). Work values, early career difficulties, and the US economic recession. Social Psychology Quarterly, 75(3), 242-267.

Joshi, A., Dencker, J. C., \& Franz, G. (2011). Generations in organizations. Research in Organizational Behavior, 31, 177-205.

Joshi, A., Dencker, J. C., Franz, G., \& Martocchio, J. J. (2010). Unpacking Generational Identities in Organizations. Academy of Management Review, 35(3): 392-414.

Joshi, M. P., Kathuria, R., \& Porth, S. J. (2003). Alignment of strategic priorities and performance: an integration of operations and strategic management perspectives. Journal of Operations Management, 21(3), 353-369. 
Judge, T. A. (1994). Person-organization fit and the theory of work adjustment: Implications for satisfaction, tenure, and career success. Journal of Vocational Behavior, 44(1), 32-54.

Kaiser, H. F. (1974). An index of factorial simplicity. Psychometrika, 39(1), 31-36.

Kanchier, C., \& Unruh, W. R. (1989). Work values: How do managers who change jobs differ from those who do not?. Journal of Employment Counseling, 26(3), 107116.

Kanfer, R., \& Ackerman, P. L. (2004). Aging, adult development, and work motivation. Academy of Management Review, 29(3), 440-458.

Kim, T. Y., Aryee, S., Loi, R., \& Kim, S. P. (2013). Person-organization fit and employee outcomes: test of a social exchange model. The International Journal of Human Resource Management, 24(19), 3719-3737.

Kline, P. (1999). The handbook of psychological testing (2nd ed.). London: Routeledge.

Kline, P. (2002). An easy guide to factor analysis. London: Routledge.

Kristof, A. L. (1996). Person-organization fit: an integrative review of its conceptualizations, measurement, and implications. Personnel psychology, 49(1), $1-49$.

Kristof-Brown, A. L., \& Guay, R. P. (2010). Person-Environment Fit. In S. Zedeck (Ed.), APA Handbook of Industrial and Organizational Psychology (Vol. 3): American Psychological Association.

Kristof-Brown, A. L., Zimmerman, R. D., \& Johnson, E. C. (2005). Consequences of individuals' fit at work: a meta-analysis of person-job, person-organization, and person-supervisor fit. Personnel psychology, 58(2), 281-342.

Kromrey, J. D., \& Hines, C. V. (1995). Use of empirical estimates of shrinkage in multiple regression: a caution. Educational and Psychological Measurement, 55(6), 901-925.

Kulik, C. T., Ryan, S., Harper, S., \& George, G. (2014). Aging populations and management. Academy of Management Journal, 57(4), 929-935.

Kumar, V., Mudambi, R., \& Gray, S. (2013). Internationalization, innovation and institutions: the 3 I's underpinning the competitiveness of emerging market firms. Journal of International Management, 19(3), 203-206. 
Kuncel, N. R., \& Borneman, M. J. (2007). Toward a new method of detecting deliberately faked personality tests: The use of idiosyncratic item responses. International Journal of Selection and Assessment, 15(2), 220-231.

Kuo, Y. \& Chen, L. (2004). Individual demographic differences and job satisfaction among information technology personnel: an empirical study in Taiwan. International Journal of Management, 21(2), 221-231.

Kupperschmidt, B. R. (2000). Multigeneration employees: strategies for effective management. The health care manager,19(1), 65-76.

Lancaster, L. C., \& Stillman, D. (2002). When generations collide: Who they are. Why they clash. How to solve the generational puzzle at work. New York City: HarperCollins Publishers.

Lee, T. W. (1999). Using qualitative methods in organizational research. Thousand Oaks, CA: Sage.

Lee, Y. T., \& Antonakis, J. (2014). When Preference Is Not Satisfied but the Individual Is How Power Distance Moderates Person-Job Fit. Journal of Management, 40(3), 641-675.

Leung, K., Bhagat, R. S., Buchan, N. R., Erez, M., \& Gibson, C. B. (2005). Culture and international business: Recent advances and their implications for future research. Journal of International Business Studies, 36(4), 357-378.

Leuty, M. E., \& Hansen, J.-I. C. (2011). Evidence of construct validity for work values. Journal of Vocational Behavior, 79(2), 379-390.

Levinson, D. (1978). The Seasons of a Man's Life. New York: Alfred A. Knopf.

Li, H., Li, L., Wu, B., \& Xiong, Y. (2012). The end of cheap Chinese labor. The Journal of Economic Perspectives, 26(4), 57-74

Li, J., \& Nimon, K. (2008). The importance of recognizing generational differences in HRD policy and practices: A study of workers in Qinhuangdao, China. Human Resource Development International, 11(2), 167-182.

Li, J. J., Poppo, L., \& Zhou, K. Z. (2008). Do managerial ties in China always produce value?. Competition, uncertainty, and domestic vs. foreign firms. Strategic Management Journal, 29(4), 383-400. 
Li, Y., \& Sheldon, P. (2010). HRM lives inside and outside the firm: employers, skill shortages and the local labour market in China. The International Journal of Human Resource Management, 21(12), 2173-2193.

Liden, R. C., Wayne, S. J., \& Stilwell, D. (1993). A longitudinal study on the early development of leader-member exchanges. Journal of Applied Psychology, 78(4), 662-674.

Liu, B., Liu, J., \& Hu, J. (2010). Person-organization fit, job satisfaction, and turnover intention: An empirical study in the Chinese public sector. Social Behavior and Personality: An International Journal, 38(5), 615-625.

Locke, E. A. (1969). What is job satisfaction?. Organizational Behavior \& Human Decision Processes, 4, 309-336.

Locke, E. A. (1976). The nature and causes of job satisfaction. In M. D. Dunnette (Ed.), Handbook of industrial and organizational psychology, (pp. 1297-1350). Chicago: Rand McNally.

Loi, R., Hang-Yue, N., \& Foley, S. (2006). Linking employees' justice perceptions to organizational commitment and intention to leave: The mediating role of perceived organizational support. Journal of Occupational and Organizational Psychology, 79(1), 101-120.

Loughlin, C., \& Barling, J. (2001). Young workers' work values, attitudes, and behaviours. Journal of Occupational and Organizational Psychology, 74(4), 543558.

Luthans, F., Baack, D., \& Taylor, L. (1987). Organizational commitment: Analysis of antecedents. Human Relations, 40(4), 219-235.

Lyons, S. T., Duxbury, L., \& Higgins, C. (2007). An empirical assessment of generational differences in basic human values. Psychological Reports, 101(2), 339-352.

Lyons, S. T., Higgins, C. A., \& Duxbury, L. (2010). Work values: Development of a new three-dimensional structure based on confirmatory smallest space analysis. Journal of Organizational Behavior, 31(7), 969-1002.

Lyons, S., \& Kuron, L. (2013). Generational differences in the workplace: A review of the evidence and directions for future research. Journal of Organizational Behavior, 35(S1): S139-S157. 
Ma, S., \& Trigo, V. (2008). Winning the war for managerial talent in China: An empirical study. Chinese Economy, 41(3), 34-57.

Macky, K., Gardner, D., \& Forsyth, S. (2008). Generational differences at work: Introduction and overview. Journal of Managerial Psychology, 23(8), 857-861.

Malpass, R. S. (1977). Theory and method in cross-cultural psychology. American Psychologist, 32(12), 1069-1079.

Manhardt, P. J. (1972). Job orientation of male and female college graduates in business. Personnel Psychology, 25(2), 361-368.

Mannheim, K. (1952). The problem of generations. In D. Kecskemeti (Ed.), Essays on the Sociology of Knowledge, pp. 276-322. London: Routledge \& Kegan Paul (Original work was published in 1928).

Manpower. (2013). 2013 Talent shortage survey results. Available at http://www.manpowergroup.us/campaigns/talent-shortage2013/pdf/2013_Talent_Shortage_Survey_Results_US_lo_0510.pdf. (Accessed 28 October , 2014).

Maslow, A. H. (1943). A theory of human motivation. Psychological review, 50(4), 370396.

Maslow, A. H. (1954). Motivation and personality. New York: Harper

Materson, S. S., Lewis, K., Goldman, B. M., \& Taylor, M. S. (2000). Integrating justice and social exchange: The differing effects of fair procedures and treatment on work relationships. Academy of Management Journal, 43(4), 738-748.

Meglino, B. M., Ravlin, E. C., \& Adkins, C. L. (1989). A work values approach to corporate culture: A field test of the value congruence process and its relationship to individual outcomes. Journal of Applied Psychology, 74(3), 424-432.

Meriac, J. P., Woehr, D. J., \& Banister, C. (2010). Generational differences in work ethic: An examination of measurement equivalence across three cohorts. Journal of Business and Psychology, 25(2), 315-324.

Mertler, C. A., \& Vannatta, R. A. (2005). Advanced and multivariate statistical methods. (3rd ed.). Glendale, CA: Pyrczak publishing.

Meyer, J. P., Allen, N. J., \& Smith, C. A. (1993). Commitment to organizations and occupations: Extension and test of a three-component conceptualization. Journal of Applied Psychology, 78(4), 538-551. 
McSweeney, B. (2009). Dynamic diversity: Variety and variation within countries. Organization Studies, 30(9), 933-957.

Morris, M. W. (2014). Values as the essence of culture: Foundation or fallacy?. Journal of Cross-Cultural Psychology, 45(1), 14-24.

Mossholder, K. W., Settoon, R. P., \& Henagan, S. C. (2005). A relational perspective on turnover: Examining structural, attitudinal, and behavioral predictors. Academy of Management Journal, 48(4), 607-618.

Moynihan, D. P., \& Pandey, S. K. (2008). The ties that bind: Social networks, personorganization value fit, and turnover intention. Journal of Public Administration Research and Theory, 18(2), 205-227.

Muchinsky, P. M. (2003). Psychology applied to work: An introduction to industrial and organizational psychology ( $7^{\text {th }}$ ed.). Thousand Oaks, CA: Sage.

Muller, D., Judd, C. M., \& Yzerbyt, V. Y. (2005). When moderation is mediated and mediation is moderated. Journal of Personality and Social Psychology, 89(6), 852-863.

Nee, V., \& Opper, S. (2012). Capitalism from below: Markets and institutional change in China. Harvard University Press.

Ng, T. W., \& Feldman, D. C. (2012). Evaluating six common stereotypes about older workers with meta-analytical data. Personnel Psychology, 65(4), 821-858.

Nunnally, J. C. (1978). Psychometric theory (2nd ed.). New York: McGraw-Hill.

Oh, I. S., Guay, R. P., Kim, K., Harold, C. M., Lee, J. H., Heo, C. G., \& Shin, K. H. (2014). Fit Happens Globally: A Meta-Analytic Comparison of the Relationships of Person-Environment Fit Dimensions with Work Attitudes and Performance Across East Asia, Europe, and North America. Personnel Psychology, 67(1), 99152.

O'Reilly, C. A., Chatman, J., \& Caldwell, D. F. (1991). People and organizational culture: A profile comparison approach to assessing person-organization fit. Academy of Management Journal, 34(3), 487-516.

Parry, E., \& Urwin, P. (2011). Generational Differences in Work Values: A Review of Theory and Evidence. International Journal of Management Reviews, 13(1): 7996. 
PBS. 2014. Aging in America. http://nbr.com/category/aging-in-america/ (Accessed on August, 12th, 2014).

Peng, M. W., Lu, Y., Shenkar, O., \& Wang, D. Y. (2001). Treasures in the China house: A review of management and organizational research on Greater China. Journal of Business Research, 52(2), 95-110.

Pfeffer, J. (1995). Producing sustainable competitive advantage through the effective management of people. Academy of Management Executive, 9(1), 55-69.

Porter, L. W., \& Lawler, E. E. (1968). Managerial attitudes and performance. Homewood, Illinois: Irwin.

Preacher, K. J., \& Hayes, A. F. (2008). Asymptotic and resampling strategies for assessing and comparing indirect effects in multiple mediator models. Behavior Research Methods, 40(3), 879-891.

Preacher, K. J., Rucker, D. D., \& Hayes, A. F. (2007). Addressing moderated mediation hypotheses: Theory, methods, and prescriptions. Multivariate Behavioral Research, 42(1), 185-227.

Pryor, R. (1982). Values, preferences, needs, work ethics, and orientations to work: Toward a conceptual and empirical integration. Journal of Vocational Behavior, 20(1), 40-52.

Redfern, K., \& Crawford, J. (2010). Regional differences in business ethics in the People's Republic of China: A multi-dimensional approach to the effects of modernisation. Asia Pacific Journal of Management, 27(2), 215-235.

Resick, C. J., Baltes, B. B., \& Shantz, C. W. (2007). Person-organization fit and workrelated attitudes and decisions: examining interactive effects with job fit and conscientiousness. Journal of Applied Psychology, 92(5), 1446-1455.

Riordan, C. M., \& Vandenberg, R. J. (1994). A central question in cross-cultural research: Do employees of different cultures interpret work-related measures in an equivalent manner?. Journal of Management, 20(3), 643-671.

Roongrerngsuke, S., \& Liefooghe, A. (2013). Attracting gold-collar workers: comparing organizational attractiveness and work-related values across generations in China, India and Thailand. Asia Pacific Business Review, 19(3), 337-355.

Ros, M., Schwartz, S. H., \& Surkiss, S. (1999). Basic individual values, work values, and the meaning of work. Applied Psychology, 48(1), 49-71. 
Rousseau, D. M., Sitkin, S. B., Burt, R. S., \& Camerer, C. (1998). Not so different after all: A cross-discipline view of trust. Academy of Management Review, 23(3), 393404.

Ryder, N. B. (1965). The cohort as a concept in the study of social change. American Sociological Review, 30(6), 843-861.

Rynes, S. L. (2007). Editor's Afterword Let's Create A Tipping Point: What Academics and Practitioners can do, Alone and Together. Academy of Management Journal, 50(5), 1046-1054.

Sasaki, I., \& Yoshikawa, K. (2014). Going beyond national cultures - Dynamic interaction between intra-national, regional, and organizational realities. Journal of World Business, 49(3), 455-464.

Sagie, A., Elizur, D., \& Koslowsky, M. (1996). Work values: A theoretical overview and a model of their effects. Journal of Organizational Behavior, 7(S1), 503-514.

Saks, A. M., \& Ashforth, B. E. (1997). Organizational socialization: Making sense of the past and present as a prologue for the future. Journal of Vocational Behavior, 51(2), 234-279.

Schwab, D. P. (1980). Construct validity in organizational behavior. In L. L. Cummings \& B. M. Staw (Eds.), Research in Organizational Behavior (Vol. 2): 3-43. Greenwich, CT: JAI Press.

Schwartz, S. H. (1994). Are There Universal Aspects in the Structure and Contents of Human Values? Journal of Social Issues, 50(4): 19-45.

Schwartz, S. H. (1999). A theory of cultural values and some implications for work. Applied Psychology: An International Review, 48(1), 23-47.

Schwartz, S. H., \& Bilsky, W. (1990). Toward a theory of the universal content and structure of values: Extensions and cross-cultural replications. Journal of Personality and Social Psychology, 58(5), 878-891.

Settoon, R. P., Bennett, N., \& Liden, R. C. (1996). Social exchange in organizations: Perceived organizational support, leader-member exchange, and employee reciprocity. Journal of Applied Psychology, 81(3), 219-227.

Sherony, K. M., \& Green, S. G. (2002). Coworker exchange: relationships between coworkers, leader-member exchange, and work attitudes. Journal of Applied Psychology, 87(3), 542-548. 
Shore, L. M., \& Tetrick, L. E. (1991). A construct validity study of the Survey of Perceived Organizational Support. Journal of applied psychology, 76(5), 637-643.

Shrout, P. E., \& Bolger, N. (2002). Mediation in experimental and nonexperimental studies: new procedures and recommendations. Psychological Methods, 7(4), 422-445.

Smola, K. W., \& Sutton, C. D. 2002. Generational differences: revisiting generational work values for the new millennium. Journal of Organizational Behavior, 23(4): 363-382.

Simon, D. F., \& Cao, C. (2009). China's emerging technological edge: assessing the role of high-end talent. Cambridge University Press.

Song, L. J., Tsui, A. S., \& Law, K. S. (2009). Unpacking employee responses to organizational exchange mechanisms: The role of social and economic exchange perceptions. Journal of Management, 35(1), 56-93.

Song, Z., Wanberg, C., Niu, X., \& Xie, Y. (2006). Action-state orientation and the theory of planned behavior: A study of job search in China. Journal of Vocational Behavior, 68(3), 490-503.

Steers, R. M. (1977). Antecedents and outcomes of organizational commitment. Administrative Science Quarterly, 22(1), 46-56.

Stevens, C. E., Xie, E., \& Peng, M. W. (2015). Toward a legitimacy-based view of political risk: The case of Google and Yahoo in China. Strategic Management Journal (in press).

Street, C. T., \& Gallupe, R. B. (2009). A proposal for operationalizing the pace and scope of organizational change in management studies. Organizational Research Methods, 12(4), 720-737.

Sujansky, J. G., \& Ferri-Reed, J. (2009). Keeping The Millenials: Why Companies are Losing Billions in Turnover to this Generation and What to Do About It. Hoboken, NJ: John Wiley \& Sons, Inc.

Super, D. E. (1970). Work values inventory: Manual. Boston: Houghton-Mifflin.

Super, D. E. (1995). Values: Their nature, assessment, and practical Use. In D. E. Super and B. Sverko (Eds.), Life Roles, Values, and Careers: International Findings of the Work Importance Study. The Jossey-Bass Social and Behavioral Science Series. San Francisco, CA: Jossey-Bass. 
Tabachnick, B. G., \& Fidell, L. S. (2007). Using multivariate statistics (5th ed.). Boston: Allyn and Bacon.

Taormina, R.J. (2013). Measuring trust in China: Resolving eastern and western differences in concepts of trust. Paper presented at the 3rd Asian Conference on Psychology \& the Behavioral Science, March, 2013, Osaka, Japan.

Taras, V., Steel, P., \& Kirkman, B. L. (2012). Improving national cultural indices using a longitudinal meta-analysis of Hofstede's dimensions. Journal of World Business, 47(3), 329-341.

Tett, R. P., \& Meyer, J. P. (1993). Job satisfaction, organizational commitment, turnover intention, and turnover: path analyses based on meta-analytic findings. Personnel Psychology, 46(2), 259-293.

Thomas W. Lee. (1999). Using qualitative methods in organizational research. Sage.

Tsai, W. (2001). Knowledge transfer in intraorganizational networks: Effects of network position and absorptive capacity on business unit innovation and performance. Academy of Management Journal, 44(5), 996-1004.

Tsui, A. (2004). Contributing to Global Management Knowledge: A Case for High Quality Indigenous Research. Asia Pacific Journal of Management, 21(4), 491513.

Tsui, A. S. (2007). From homogenization to pluralism: International management research in the academy and beyond. Academy of Management Journal, 50(6), 1353-1364.

Tsui, A. S., Schoonhoven, C. B., Meyer, M. W., Lau, C. M., \& Milkovich, G. T. (2004). Organization and management in the midst of societal transformation: The People's Republic of China. Organization Science, 15(2), 133-144.

Tung, R. L., \& Verbeke, A. (2010). Beyond Hofstede and GLOBE: Improving the quality of cross-cultural research. Journal of International Business Studies, 41(8), 12591274.

Turban, D. B., Lau, C. M., Ngo, H. Y., Chow, I. H., \& Si, S. X. (2001). Organizational attractiveness of firms in the People's Republic of China: A person-organization fit perspective. Journal of Applied Psychology, 86(2), 194-206. 
Twenge, J. M. (2001). Changes in women's assertiveness in response to status and roles: A cross-temporal meta-analysis, 1931-1993. Journal of Personality and Social Psychology, 81(1), 133-145.

Twenge, J. M. (2010). A review of the empirical evidence on generational differences in work attitudes. Journal of Business and Psychology, 25(2), 201-210.

Twenge, J. M., \& Campbell, S. M. (2008). Generational differences in psychological traits and their impact on the workplace. Journal of Managerial Psychology, 23(8), 862-877.

Twenge, J. M., Campbell, S. M., Hoffman, B. J., \& Lance, C. E. (2010). Generational differences in work values: Leisure and extrinsic values increasing, social and intrinsic values decreasing. Journal of Management, 36(5), 1117-1142.

Tyler, T. R., \& Blader, S. L. (2005). Can businesses effectively regulate employee conduct? The antecedents of rule following in work settings. Academy of Management Journal, 48(6), 1143-1158.

Valeri, L., \& VanderWeele, T. J. (2013). Mediation analysis allowing for exposuremediator interactions and causal interpretation: Theoretical assumptions and implementation with SAS and SPSS macros. Psychological Methods, 18(2), 137150.

Van de Ven, A. H., \& Drazin, R. (1985). The concept of fit in contingency theory. In L. L. Cummings \& B. M. Staw (Eds.), Research in organizational behavior (Vol. 7, pp. 333-365). Greenwhich, CT: JAI Press.

Vansteenkiste, M., Neyrinck, B., Niemiec, C. P., Soenens, B., De Witte, H., \& Van den Broeck, A. (2007). On the relations among work value orientations, psychological need satisfaction and job outcomes: A self-determination theory approach. Journal of Occupational and Organizational Psychology, 80(2), 251-277.

Venkatraman, N. (1989). The concept of fit in strategy research: Toward verbal and statistical correspondence. Academy of Management Review, 14(3), 423-444.

Venkatraman, N., \& Camillus, J. C. (1984). Exploring the concept of "fit” in strategic management. Academy of Management Review, 9(3), 513-525.

Verquer, M. L., Beehr, T. A., \& Wagner, S. H. (2003). A meta-analysis of relations between person-organization fit and work attitudes. Journal of Vocational Behavior, 63(3), 473-489. 
Wanous, J. P., \& Lawler, E. E. (1972). Measurement and meaning of job satisfaction. Journal of Applied Psychology, 56(2), 95-105.

Wayne, S. J., Shore, L. M., \& Liden, R. C. (1997). Perceived organizational support and leader-member exchange: A social exchange perspective. Academy of Management Journal, 40(1), 82-111.

Weigold, A., Weigold, I. K., \& Russell, E. J. (2013). Examination of the equivalence of self-report survey-based paper-and-pencil and internet data collection methods. Psychological Methods, 18(1), 53-70.

Werbel, J. D., \& Gilliland, S. W. (1999). Person-environment fit in the selection process. In G.R. Ferris (Ed.), Research in personnel and human resources management (Vol. 17, pp. 209-243). Stamford, CT: JAI Press.

Whetten, D. A. (2009). An examination of the interface between context and theory applied to the study of Chinese organizations. Management and Organization Review, 5(1), 29-55.

Winter, R. P., \& Jackson, B. A. (2014). Expanding the younger worker employment relationship: Insights from values-based organizations. Human Resource Management, 53(2), 311-328

Wong, S. W., \& Yuen, M. (2012). Work Values of University Students in Chinese Mainland, Taiwan, and Hong Kong. International Journal for the Advancement of Counselling, 34(4), 269-285.

Wong, Y. T. (2012). Job security and justice: predicting employees' trust in Chinese international joint ventures. The International Journal of Human Resource Management, 23(19), 4129-4144.

Wu, M., \& Wang, J. (2012). Developing a charismatic leadership model for Chinese organizations: the mediating role of loyalty to supervisors. The International Journal of Human Resource Management, 23(19), 4069-4084.

Yang, G. (2003). China's Zhiqing Generation Nostalgia, Identity, and Cultural Resistance in the 1990s. Modern China, 29(3), 267-296.

Yi, X., Ribbens, B., \& Morgan, C. N. (2010). Generational differences in China: Career implications. Career Development International, 15(6), 601-620. 
Yu, K. Y. T. (2014). Person-organization fit effects on organizational attraction: A test of an expectations-based model. Organizational Behavior and Human Decision Processes, 124(1), 75-94.

Zemke, R., Raines, C., \& Filipczak, B. (2000). Generations at work: Managing the clash of Veterans, Boomers, Xers, and Nexters in your workplace. New York: Amacom.

Zhao, X., Lynch, J. G., \& Chen, Q. (2010). Reconsidering Baron and Kenny: Myths and truths about mediation analysis. Journal of Consumer Research, 37(2), 197-206.

Zheng, C., Morrison, M., \& O'Neill, G. (2006). An empirical study of high performance HRM practices in Chinese SMEs. The International Journal of Human Resource Management, 17(10), 1772-1803.

Zhou, J., Shin, S. J., Brass, D. J., Choi, J., \& Zhang, Z. X. (2009). Social networks, personal values, and creativity: evidence for curvilinear and interaction effects. Journal of Applied Psychology, 94(6), 1544-1552.

Zhu, C. J., Cooper, B., De Cieri, H., \& Dowling, P. J. (2005). A problematic transition to a strategic role: Human resource management in industrial enterprises in China. The International Journal of Human Resource Management, 16(4), 513-531. 


\section{APPENDICES}

Appendix A: Employee Work Value Survey

\section{Employee Work Values Survey}

Section 1

Please make only one selection to rate the importance of each statement related to an ideal job.

\begin{tabular}{|c|c|c|c|c|c|}
\hline & $\begin{array}{l}\text { Not at all } \\
\text { important }\end{array}$ & $\begin{array}{c}\text { Somewhat } \\
\text { not } \\
\text { important }\end{array}$ & Neutral & $\begin{array}{l}\text { Somewhat } \\
\text { important }\end{array}$ & $\begin{array}{l}\text { Extremely } \\
\text { important }\end{array}$ \\
\hline $\begin{array}{l}\text { (1) working in a company with a good } \\
\text { reputation }\end{array}$ & & & & & \\
\hline (2) respected by others & & & & & \\
\hline $\begin{array}{l}\text { (3) involves working with congenial } \\
\text { associates }\end{array}$ & & & & & \\
\hline $\begin{array}{l}\text { (4) makes a social contribution by the work } \\
\text { you do }\end{array}$ & & & & & \\
\hline $\begin{array}{l}\text { (5) makes use of your specific educational } \\
\text { background }\end{array}$ & & & & & \\
\hline $\begin{array}{l}\text { (6) offers perks such as free meals, housing } \\
\text { and transportation allowance }\end{array}$ & & & & & \\
\hline ( 7 ) provides a feeling of accomplishment & & & & & \\
\hline ( 8 ) permits a balanced lifestyle & & & & & \\
\hline $\begin{array}{l}\text { (9) permits a regular routine in time and } \\
\text { place of work }\end{array}$ & & & & & \\
\hline $\begin{array}{l}\text { ( } 10) \text { permits an accommodation of family } \\
\text { responsibilities }\end{array}$ & & & & & \\
\hline $\begin{array}{l}\text { (11) the company is close to home or } \\
\text { conveniently located }\end{array}$ & & & & & \\
\hline (12) provides ample leisure time off the job & & & & & \\
\hline (13) provides challenging tasks and projects & & & & & \\
\hline $\begin{array}{l}\text { (14) provides change and variety in duties } \\
\text { and activities }\end{array}$ & & & & & \\
\hline $\begin{array}{l}\text { ( } 15) \text { provides a comfortable work } \\
\text { environment }\end{array}$ & & & & & \\
\hline (16) provides job security & & & & & \\
\hline $\begin{array}{l}\text { ( } 17 \text { ) provides the opportunity to earn a high } \\
\text { income }\end{array}$ & & & & & \\
\hline (18) requires originality and creativeness & & & & & \\
\hline
\end{tabular}


Please make only one selection to rate the level of your agreement on each statement related to your true experience on the job.

\begin{tabular}{|c|c|c|c|c|c|}
\hline & $\begin{array}{l}\text { Never had } \\
\text { such } \\
\text { experience }\end{array}$ & $\begin{array}{c}\text { Rarely } \\
\text { had such } \\
\text { experience }\end{array}$ & Neutral & $\begin{array}{c}\text { Usually } \\
\text { had such } \\
\text { experience }\end{array}$ & $\begin{array}{l}\text { Always had } \\
\text { such } \\
\text { experience }\end{array}$ \\
\hline $\begin{array}{l}\text { (1) working in a company with a good } \\
\text { reputation }\end{array}$ & & & & & \\
\hline (2) respected by others & & & & & \\
\hline (3) involves working with congenial associates & & & & & \\
\hline $\begin{array}{l}\text { (4) makes a social contribution by the work you } \\
\text { do }\end{array}$ & & & & & \\
\hline $\begin{array}{l}\text { (5) makes use of your specific educational } \\
\text { background }\end{array}$ & & & & & \\
\hline $\begin{array}{l}\text { ( } 6 \text { ) offers perks such as free meals, housing and } \\
\text { transportation allowance }\end{array}$ & & & & & \\
\hline ( 7 ) provides a feeling of accomplishment & & & & & \\
\hline (8) permits a balanced lifestyle & & & & & \\
\hline $\begin{array}{l}\text { ( } 9 \text { ) permits a regular routine in time and place of } \\
\text { work }\end{array}$ & & & & & \\
\hline $\begin{array}{l}\text { ( } 10) \text { permits an accommodation of family } \\
\text { responsibilities }\end{array}$ & & & & & \\
\hline $\begin{array}{l}\text { (11) the company is close to home or } \\
\text { conveniently located }\end{array}$ & & & & & \\
\hline (12) provides ample leisure time off the job & & & & & \\
\hline (13) provides challenging tasks and projects & & & & & \\
\hline $\begin{array}{l}\text { ( } 14 \text { ) provides change and variety in duties and } \\
\text { activities }\end{array}$ & & & & & \\
\hline (15) provides a comfortable work environment & & & & & \\
\hline (16) provides job security & & & & & \\
\hline $\begin{array}{l}\text { ( } 17 \text { ) provides the opportunity to earn a high } \\
\text { income }\end{array}$ & & & & & \\
\hline (18) requires originality and creativeness & & & & & \\
\hline
\end{tabular}


Appendix B: Combined Survey of Job-satisfaction Scale (Cammann, Fichman, Jenkins, \& Klesh, 1983), Organizational-commitment Scale (Meyer, Allen, \& Smith, 1993; Allen \& Meyer, 1996), and Turnover-intention Scale (Cammann, Fichman, Jenkins, \& Klesh, 1979)

\section{Section 2}

Please make only one selection to indicate your level of agreement on each statement.

\begin{tabular}{|c|c|c|c|c|c|c|c|}
\hline & 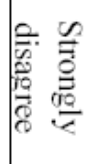 & $\begin{array}{l}\text { అ. } \\
\frac{0}{4} \\
\frac{0}{00} \\
\frac{0}{8} \\
8\end{array}$ & 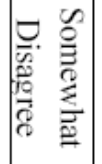 & $\begin{array}{l}\frac{5}{8} \\
\frac{2}{8} \\
\frac{2}{2} \\
\frac{2}{2}\end{array}$ & 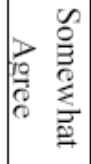 & $\underset{80}{8}$ & 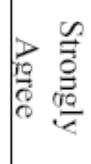 \\
\hline 1. All in all, I am satisfied with my job. & & & & & & & \\
\hline 2. In general, I like my job. & & & & & & & \\
\hline 3. In general, I like working here. & & & & & & & \\
\hline 4. I often think about quitting. & & & & & & & \\
\hline 5. I will probably look for a new job in the next year. & & & & & & & \\
\hline $\begin{array}{l}\text { 6. If I may choose again, I will choose to work for the current } \\
\text { organization. }\end{array}$ & & & & & & & \\
\hline 7. I really feel as if this organization's problems are my own. & & & & & & & \\
\hline $\begin{array}{l}\text { 8. I would be very happy to spend the rest of my career with this } \\
\text { organization. }\end{array}$ & & & & & & & \\
\hline 9. This organization has a great deal of personal meaning to me. & & & & & & & \\
\hline 10. I feel like part of the family at my organization. & & & & & & & \\
\hline 11. I do not feel a strong sense of belonging to my organization. & & & & & & & \\
\hline 12. I do not emotionally attached to this organization. & & & & & & & \\
\hline
\end{tabular}


Appendix C: Combined Survey of Perceived Organizational Support (POS) Scale (Settoon, Bennett, \& Liden, 1996) and Leader-Member Exchange (LMX) Scale (Liden, Wayne \& Stilwell, 1993)

\section{Section 3}

Please make only one selection to indicate your level of agreement on each statement.

\begin{tabular}{|c|c|c|c|c|c|c|c|}
\hline & 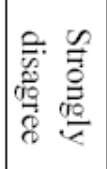 & 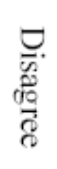 & 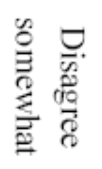 & $\begin{array}{l}\frac{c}{\frac{2}{2}} \\
\frac{0}{2} \\
\frac{0}{2}\end{array}$ & 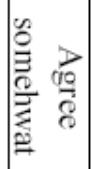 & $\frac{\sqrt{10}}{8}$ & $\frac{n}{0}$ \\
\hline (1) The organization values my contribution to its well-bein & & & & & & & \\
\hline $\begin{array}{l}\text { ( } 2 \text { ) The organization fails to appreciate any extra effort from } \\
\text { me. }\end{array}$ & & & & & & & \\
\hline ( 3 ) The organization would ignore any complaint from me. & & & & & & & \\
\hline (4) The organization really cares about my well-being. & & & & & & & \\
\hline $\begin{array}{l}\text { ( } 5 \text { )Even I did the best job possible, the organization would fa } \\
\text { to notice. }\end{array}$ & & & & & & & \\
\hline $\begin{array}{l}\text { (6) The organization cares about my general satisfaction at } \\
\text { work. }\end{array}$ & & & & & & & \\
\hline ( 7 ) The organization shows very little concern for me. & & & & & & & \\
\hline ( 8 ) The organization takes pride in my accomplishment. & & & & & & & \\
\hline $\begin{array}{l}\text { (9) You know where you stand with your leader, or you } \\
\text { usually know how satisfied your leader with what you do. }\end{array}$ & & & & & & & \\
\hline ( 10 ) Your leader understands your job problems and needs. & & & & & & & \\
\hline ( 11 ) Your leader recognizes your potential. & & & & & & & \\
\hline $\begin{array}{l}\text { ( } 12 \text { ) Regardless of how much formal authority your leader ha } \\
\text { built into his or her position, he/she is highly likely to use his o } \\
\text { her power to help you solve problems in your work. }\end{array}$ & & & & & & & \\
\hline $\begin{array}{l}\text { ( } 13 \text { ) Regardless of the amount of formal authority your lead } \\
\text { has, he/she is highly likely to "bail you out" at his or her } \\
\text { expense. }\end{array}$ & & & & & & & \\
\hline $\begin{array}{l}\text { ( } 14 \text { ) I have enough confidence in my leader that I would } \\
\text { defend and justify his or her decision if he or she were not } \\
\text { present to do so. }\end{array}$ & & & & & & & \\
\hline $\begin{array}{l}\text { ( } 15 \text { ) I would characterize my working relationship with my } \\
\text { leader as good. }\end{array}$ & & & & & & & \\
\hline
\end{tabular}




\section{Appendix D: Demographic Information}

\section{Section 4}

Please provide your demographic information. All information will be kept confidential.

1. Your gender: (1) Male

(2) Female

2、Your year of birth: 19

3. Your place of birth: Province City

4. What is the highest level of education you have completed: (1) Elementary school or below

(2) Junior high school (3) High school or Secondary vocational school (4) Associate degree

(5) Bachelor degree or above

5. Your job position: (1) Worker (2) Technician (3) First-line Manager (4) Middle-level manager (5) Executive Manager

6. How many years in total have you been working? years

7. How long have you been employed at this organization? years

8. Your monthly salary: (1) $Y 2500$ or below (3) $Y 3501-4500$
(2) $Y 2501-3500$

(5) $Y 5500$ or above

9、Your average monthly performance-based bonus pay in the past 6 months: (1) Lower than your peer at the organization (2) About the same as your peer at the organization (3) Higher than your peer at the organization

10. What is your marital status? (1) Married with kid(s) (2) Married without kid(s) (3) Single parent (4) Never been married

This is the end of the survey. Thank you so much for your participation and support! 
VITA

JUN YANG

1997-2001

B.Eng., Applied Chemistry

South-Central University for Nationalities

Hubei, China (P.R.C)

2001-2004

M. Eng., Material Science

Chonbuk National University

Chonbuk, South Korea

2004-2007

M.Sc., Chemistry

Michigan State University

East Lansing, Michigan

2008-2010

M.Sc., International Business

University of Colorado Denver

Denver, Colorado

2010-2015

Doctor of Business Administration (DBA) Candidate

Florida International University

Miami, Florida

\section{PUBLICATIONS AND PRESENTATIONS}

Yang J., Yu, C. S. A Generational Subculture Approach to Work Values: Winning the Race for Talents in China. Paper presented at Academy of Management Annual Meeting, 2015, Vancouver, Canada.

Yang J. A Sub-national Comparison of Chinese Young Workers' Expectations for HR Practices: Convergence, Divergence, or Crossvergence?. Paper presented at The First HR Division (AOM) International Conference, 2014, Beijing, China.

Xia, W. D., Von Glinow, M. A., Li, Y. X., Thams, Y., Yang, J., Liu, Y. China’s Value Stream Approach to the Internationalization Process: Early Stages, Attempts to Go Global, and Returnees Localizing a 'Third Way'. Paper presented at Academy of International Business Annual Meeting, 2013, Istanbul, Turkey. 